\title{
A Diagnostic Model for The Large-Scale Tropical Circulation Based on Moist Static Energy Balance
}

Chen-Shuo Fan ( $\square$ chen-shuo.fan@monash.edu )

Monash University Faculty of Science https://orcid.org/0000-0002-2925-9441

Dietmar Dommenget

Monash University Faculty of Science

\section{Research Article}

Keywords: Tropical circulation, Moist static energy, Gross moist stability, Diagnostic model

Posted Date: March 24th, 2021

DOI: https://doi.org/10.21203/rs.3.rs-330749/v1

License: (9) This work is licensed under a Creative Commons Attribution 4.0 International License. Read Full License

Version of Record: A version of this preprint was published at Climate Dynamics on July 7th, 2021. See the published version at https://doi.org/10.1007/s00382-021-05861-2. 


\title{
1 A diagnostic model for the large-scale tropical 2 circulation based on moist static energy balance
}

by Chen-Shuo Fan* and Dietmar Dommenget

5

6 *: corresponding author; chen-shuo.fan@monash.edu

ARC Centre of Excellence for Climate Extremes, School of Earth Atmosphere and Environment, Monash

8 University, Clayton, Victoria 3800, Australia

Submitted to Climate Dynamics, 14 November 2020

12

\begin{abstract}
In this study we present a diagnostic model for the large-scale tropical circulation (vertical motion) based on the moist static energy equation for first baroclinic mode anomalies (MSEB model). The aim of this model is to provide a basis for conceptual understanding of the drivers of the large-scale tropical circulation changes or variations as they are observed or simulated in Coupled Model Inter-comparison Project Phase (CMIP) models. The MSEB model is based on previous studies relating vertical motion in the tropics to the driving forces of the tropospheric column heating rate, advection of moisture and heat, and the moist stability of the air columns scaled by the first baroclinic mode. We apply and evaluate the skill of this model on the basis of observations (reanalysis) and CMIP model simulations of the large-scale tropical vertical motion. The model is capable of diagnosing the large-scale pattern of vertical motion of the mean state, annual cycle, interannual variability, model-to-model variations and in warmer climates of climate change scenarios with correlations of $0.6-0.8$ and nearly unbiased amplitudes for the whole tropics $\left(30^{\circ} \mathrm{S}-30^{\circ} \mathrm{N}\right)$. The skills are generally better over oceans at large scales and worse over land regions. The model also tends to have an upward motion bias at higher latitudes, but still has good correlations in variations even at the higher latitudes. It is further illustrated how the MSEB model can be used to diagnose the sensitivity of the tropical vertical motion to the forcing terms of the models for the mean state, seasonal cycle and interannual variability such as El Nino. The model clearly illustrates how the seasonal cycle in the circulation is driven by the incoming solar radiation and how the El Nino shift in the Walker circulation results mainly from the sea-surface temperature changes. Overall, the model provides a very good diagnostic tool to understand tropical circulation change on larger and longer (>month) time scales.
\end{abstract}

\section{Keywords}

Tropical circulation / Moist static energy / Gross moist stability / Diagnostic model 
The large-scale tropical circulation is a key element in the climate system. The large-scale patterns of upward and downward motion control the large-scale distribution of precipitation and droughts (Lau and Yang 2003; Satoh 2013; Nguyen et al. 2013). Conceptual understanding of what forces these large-scale structures, how they change under global warming and why model simulations have biases in them are some of the most important issues in climate research. This study aims to contribute to the understanding of the drivers of large-scale tropical pattern of vertical motion, by introducing a simple diagnostic model of vertical motion in the tropics based on moist static energy equation for the first baroclinic mode (MSEB).

Future climate change scenario simulation with the Coupled Model Inter-comparison Project (CMIP) models project negative trends (a weakening) in the Walker circulation's intensity (Vecchi and Soden 2007; Power and Kociuba 2011; Bayr et al. 2014). According to Tokinaga et al. (2012), the weakening circulation is mainly driven by the sea-surface temperature (SST) warming pattern. However, some other studies indicate a large spread within the models and also show strong mismatches with recently observed trends, which undermines the confidence we can have in these projections (Bayr et al. 2014; England et al. 2014; Plesca et al. 2018; Lian et al. 2018; Luo et al. 2018). The Hadley circulation, in turn, shows a meridional widening in the past few decades based on multiple independent datasets (Hu et al. 2018), but no consistent results are found for a trend in the strength of the circulation (Mitas et al. 2006). Ma et al. (2018) found that theoretical predictions agree that the tropics should expand poleward during global warming, but also mention there is uncertainty in the rate of the Hadley circulation expansion through observations and model diagnostics.

The general tropical circulation is weakening in CMIP climate change scenario simulations (Held and Soden 2006; Vecchi and Soden 2007), affecting the rate by which tropical and global mean precipitation is changing. The globally-averaged precipitation is roughly equal to the product of column-integrated water vapor and convective mass flux, which is related to the strength of tropical circulation. The globally-averaged precipitation increase is $\sim 2 \%$ per degree global warming, more slowly than column-integrated water vapor increases $\sim 7 \%$ per degree global warming, indicating that convective mass flux is slowing down. Increased atmospheric stability is a key factor in this weakening of the tropical circulation (Chou et al. 2009; Chou and Chen 2010; Kjellsson 2015; Wills et al. 2017; Vallis 2017; Ma et al. 2018).

Tropical circulation changes affect precipitation changes not only by the general weakening of the circulation, but also by the shifting of the main circulation patterns (Davis and Rosenlof 2012; Chadwick et al. 2013; Wills et al. 2016; Davis and Birner 2017; Staten et al. 2018; Stassen et al. 2019). These changes in the mean circulation patterns dominate precipitation changes in many regions, and it is therefore essential for the understanding of precipitation changes to understand how the large-scale circulation changes in the tropics come about.

In addition to the importance of understanding tropical circulation changes in climate change scenarios, it is important to understand why CMIP simulations create mean tropical circulation patterns that are significantly different from the observed (Lian et al. 2018; Stassen et al. 2019; Chemke and Polvani 2019). A prominent example is the double (Intertropical Convergence Zone) ITCZ problem in model simulations ( $\mathrm{Li}$ and Xie 2014; Adam et al. 2016; Samanta et al. 2019; Fiedler et al. 2020). Another example of limitations in tropical atmospheric circulations is how CMIP models simulate the El Niño-Southern Oscillation (ENSO), the dominant mode of interannual climate variability. Several studies have pointed out that the models simulate too strong cold tongue SSTs in the tropical Pacific and a too weak response of the equatorial zonal wind stress to the SST anomalies of El Nino (Bellenger et al. 2014; Vijayeta and Dommenget 2018; Bayr et al. 2019). Both of these biases are related to biases in the atmospheric circulation patterns. A conceptual understanding of the drivers of these biases in CMIP model simulations is important for improving these models.

For all the examples mentioned above, a theoretical framework is needed to conceptually understand what drives these changes (i.e. strength and location of tropical circulations) or variations (i.e. bias of ITCZ and ENSO). The theoretical frameworks that discuss the interaction between tropical convection (vertical motion) and the largescale climate environment are based on moist static energy (MSE) budgets (Neelin and Held 1987; Neelin and Yu 1994; Chou and Neelin 2004; Chou et al. 2009; Raymond et al. 2009; Bischoff and Schneider 2014). The MSE budget diagnoses the vertical motion on the basis of the net radiation, moisture flux, heat flux, horizontal wind field, and the moist static stability profile. Studies of large-scale tropical circulation changes often relate these changes to elements of the MSE budget. For instance, Chou and Chen (2010); Kjellsson (2015); Wills et al. (2017) presented GCM simulations of a Walker circulation. The weakening of the Walker circulation with warming resulted from an increase in gross moist stability, a measure of the tropospheric MSE stratification, which provides effective static stability for tropical circulations. Studies about the Hadley circulation expansion mentioned plausible explanations for Hadley circulation widening in recent literature include increased gross moist stability and increased tropopause height (Held 2001; Lu et al. 2007; Staten et al. 2018).

Earlier studies proposed a model for tropical circulation which is referred to as quasi-equilibrium tropical circulation model (QTCM; Neelin and Zeng 2000; Zeng et al. 2000, Bretherton and Sobel 2002; Peters and 
Bretherton 2005). This intermediate complex model includes a longwave radiation scheme, a cloud prediction method, shortwave radiation schemes, and a land surface model. It follows the convective quasi-equilibrium (QE) assumption and the theoretical framework of the MSE budget. A key element of this model are prognostic equations for the tropical circulation.

The aim of this study is to develop a simple diagnostic model for the tropical $\left(30^{\circ} \mathrm{S}\right.$ to $30^{\circ} \mathrm{N}$ ) circulation (vertical motion only) based on the monthly mean MSE budget, not considering higher-frequency variations in any of the input fields. The model will allow us to diagnose the vertical motion in the tropics by the large-scale climate environment in terms of local heating, transport of heat and moisture and by the overall stability of the troposphere. In the following, we will outline the derivation of this model and apply it to observed and CMIP model simulations. The study will evaluate the skill of this model in diagnosing the annual mean circulation, the seasonal cycle, interannual variability including ENSO, tropical warming and inter-model variations. Further, we will illustrate how the model can be used to estimate sensitivities of the tropical vertical motions to the driving environmental variables.

109

The study is organized as follows: The data and simulations used in this study are shortly introduced in Section 2. This will be followed by the derivation of the MSEB model based on the finding of previous studies in Section 3. We will then apply the model to a number of different datasets and evaluate its skill and limitations in section 4. In section 5 we illustrate how the MSEB model can be used to estimate sensitivities to the climate environment on the basis of the annual mean circulation, the seasonal cycle and El Nino event composites. The study will be concluded with a summary and discussion in section 6.

\section{Data and experiments}

From the data supported by European Center for Medium-Range Weather Forecast (ECMWF), we obtained monthly ERA5 (Hersbach et al. 2020) reanalysis data with a spatial resolution $3.75^{\circ} \times 3.75^{\circ}$. Further, we used model simulations, from the Coupled Model Inter-comparison Project Phase 5 (CMIP5) monthly multi-model dataset from the Historical and RCP8.5 warming scenario (Taylor et al. 2012). We use all available models with the necessary data fields for this study (see Table 1). The variables are extracted as surface and pressure level (14 pressure levels, $1000 \mathrm{hPa}$ to $30 \mathrm{hPa}$ ) data basis. The surface variables include latent heat flux $(E)$, sensible heat flux $(H)$, sea-surface temperature (SST), and radiative fluxes at the surface and top of the atmosphere. The multi-layer variables include vertical wind $(\boldsymbol{\omega})$, horizontal wind $(\mathbf{v})$, specific humidity $(q)$, temperature $(T)$, and geopotential (z).

All calculations for the MSEB model are done on the original data model grids and then interpolated onto a common $3.75^{\circ} \times 3.75^{\circ}$ grid for analysis. Throughout the analysis, we define tropical region as latitudes less than or equal to 30 degree from the equator. For testing MSEB model on different boundary setting, we used land-sea mask which is based on Rand's Global Elevation and Depth Data (Rand Corporation 1980). We also define the period of 1960-1989 as historical climate and 2070-2099 as future warming climate for CMIP5 data period, and 1960-1989 as historical climate for ERA5 data period in this study.

The ERA5 and CMIP5 (Historical scenario) monthly data are utilized to test the MSEB model under historical climate background. The CMIP5 (RCP8.5 scenario) monthly data is utilized to test the MSEB model under future climate background. In order to assess MSEB model under ENSO related case, we further take data from ERA5 during 1990-2018 for including more El Nino events.

\section{A diagnostic model for the tropical vertical air motion based on the moist static energy for first baroclinic mode anomalies (MSEB)}

The diagnostic model for the tropical large-scale circulation formulated in this study is based on the MSE budget formulated in a number of previous publications. In the following we will shortly derive the model equations, give a short description of the physical concepts of the model and give a short discussion on the climate variables that drive this model. All variables and parameters of the MSEB model are listed in Table 2.

\section{a. MSEB model derivation}

The climate variables that drive the large-scale tropical circulation can be evaluated by the MSE budget (Chou and Neelin 2004; Chou et al. 2009; Chou et al. 2013; Levine and Boos 2016; Wills et al. 2017). Chou et al. (2013) formulated the vertically integrated MSE equation at a steady state as

$<\omega \partial_{\mathrm{p}} h>_{P_{\mathrm{T}}} \approx-<\mathbf{v} \cdot \nabla\left(L_{v} q+C_{p} T\right)>_{P_{\mathrm{T}}}+F_{\text {net }}$, 
where the vertical integral \langle\rangle$_{P_{\mathrm{T}}}$ denotes a mass integration from the surface to the tropical mean tropopause height, $P_{\mathrm{T}}$, and $\partial_{\mathrm{p}}$ the gradients along the vertical pressure coordinates. $P_{\mathrm{T}}$ is defined as the lowest level at which the lapse rate $\geq-2^{\circ} \mathrm{C} / \mathrm{km}$ (WMO 1992). The lapse rate is computed based on the tropical-mean temperature profile. Due to the low vertical resolution of pressure levels in the observations and the CGCM datasets, a spline function interpolation is used to determine the tropopause height and the climate variables at this level more precisely. The MSE $(h)$ combines an air parcel's enthalpy $\left(C_{p} T\right)$, potential energy $(g z)$, and latent energy $\left(L_{v} q\right)$. It is defined as

$h=C_{p} T+L_{v} q+g z$

Figure 1 shows an example of the vertical profile of the tropical mean MSE $(h)$ as function of tropical mean surface temperature together with the estimated $P_{\mathrm{T}}$. The latter increases near linearly with increasing tropical mean surface temperature. The changing tropopause heights will affect the MSEB model, as will be discussed further in the following sections. It is therefore estimated for each time step of the dataset analyzed. The net energy flux, $F_{n e t}$ into the atmospheric column is

The net heat flux into the top of the atmosphere is

$F_{\text {top }}=S_{\text {top }}^{\downarrow}-S_{\text {top }}^{\uparrow}-R_{\text {top }}^{\uparrow}$,

and the net heat flux into the surface is

$F_{\text {sur }}=S_{\text {sur }}^{\downarrow}-S_{\text {sur }}^{\uparrow}-R_{\text {sur }}^{\downarrow}-R_{\text {sur }}^{\uparrow}-E-H$.

Following the derivation in Chou et al. (2013) and Wills et al. (2017), using the convective quasi equilibrium (QE) assumption for deep convection (Emanuel et al. 1994; Emanuel 2007; Neelin and Zeng 2000). The continuity equation can be solved for the deep convective vertical structure of $\omega$ from the baroclinic wind (Yu and Neelin 1997; Yu et al. 1998; Wills et al. 2017):

$\omega(\mathrm{p}, \mathrm{x}, \mathrm{y}) \approx-\delta p \Omega(\mathrm{p}) \nabla \cdot \mathrm{v}_{1}(\mathrm{x}, \mathrm{y})$

where $\delta p$ represents tropospheric depth, and $\nabla \cdot \mathbf{v}_{1}$ is the divergence induced by the first baroclinic winds (Neelin and Yu 1994; Yu et al. 1998). $\Omega$ as the shape of vertical velocity profile for deep convection since vertical motion is mainly associated with deep convection in tropics by $\mathrm{QE}$ assumption. The derivation of the vertical wind modes $\Omega$ follows Levine and Boos (2016) and Wills et al. (2017). The result is that $\Omega$ is determined uniquely from the tropical-mean temperature profile (averaged between $30^{\circ} \mathrm{N}$ and $30^{\circ} \mathrm{S}$ latitudes). According to Wills et al. (2017), the QE vertical velocity profiles $\Omega$ (Fig. 1c) is similar to the vertical velocity profiles in the tropical ascent region in idealized GCM simulations.

with

$<\omega \partial_{\mathrm{p}} h>_{P_{\mathrm{T}}} \approx \frac{\delta p}{g} M \nabla \cdot \mathbf{v}_{1}$

where $M$ is defined as the gross moist stability

$M=-g<\Omega \partial_{\mathrm{p}} h>_{P_{\mathrm{T}}}$.

By moving RHS divergence of baroclinic wind of Eq. [8] to LHS and replacing $\omega$ with Eq. [6], the gross moist 208 stability $M$ can be interpreted as the MSE export from a tropospheric column by the mean circulation per unit of 

considered as the depth of deep convection in the calculation of gross moist stability in Eq. [9]. In order to express the vertical motion as function of the driving forcings, $\nabla \cdot \mathbf{v}_{1}$ in Eq. [6] can be expressed by using Eqs. [7]-[9]. This new equation defines the MSEB (moist static energy equation for first baroclinic mode anomalies) model for this study:

$\omega \approx-g \cdot \Omega \cdot \frac{-<\mathbf{v} \cdot \nabla\left(L_{v} q+C_{p} T\right)>_{P_{\mathrm{T}}}+F_{n e t}}{M}$,

where the numerator is the sum of MSE advection and net energy flux, denominator is gross moist stability $M$. In this study, the MSEB model is based on monthly mean data, not considering high-frequency transient terms. We will discuss some of the limitations that result from this in section $4 \mathrm{c}$.

\section{b. A Conceptual description of the MSEB model}

The MSEB model of Eq. [10] is applied to reanalysis of observations and CMIP5 model simulations in Fig. 2 based on climatological values for all variables on the RHS. The resulting mean tropospheric vertical motion at $500 \mathrm{hPa}(\omega)$ on the LHS is similar in pattern and amplitude to the observed values for both observations and model simulations. Details and limitations of this model will be discussed further in the following sections.

Eq. [10] represents a diagnostic model of the vertical air motion $(\omega)$ on the LHS, as a function of a number of terms and factors on the RHS that drive either upward or downward motions. The sketch in Fig. 3 describes the concept of this model. The numerator terms of the MSEB model are the advection of moisture and heat, and the net heating into the air column. If $F_{\text {top }}$ is larger than $F_{\text {sur }}$, then $F_{n e t}$ is positive, which will lead to upward motion in the troposphere (upper left panel in Fig. 3). Similarly, if there is a net advection of moisture and heat into the air column, then there will be upward motion in the troposphere (upper left panel in Fig. 3). In turn, if $F_{n e t}$ is zero and there is no net advection of moisture and heat into the air column, then there will be no vertical motion in the troposphere (upper middle panel in Fig. 3). Downward motion (upper right panel in Fig. 3) is a result of a larger heat flux into the surface $\left(F_{\text {sur }}\right)$ than the incoming radiation at the top of the air column $\left(F_{\text {top }}\right)$ or a net advection of moisture and heating out of the air column.

The denominator of the MSEB model $(M)$ determines how sensitive the air column reacts to the forcing terms. In this diagram, the orange shaded represents unstable air mass (positive vertical MSE gradient) and gray shaded represents stable air mass (negative vertical MSE gradient). The integral of vertical MSE gradient $\left\langle\Omega \partial_{\mathrm{p}} h\right\rangle$ is in general negative and, according to Eq. [9], indicating a positive $M$ and a stable atmospheric air column profile. The more negative vertical MSE gradient, the more stable is the air column, and subsequently the vertical motion is less intense for the same amount of forcing terms (lower panels in Fig. 3).

\section{c. Elements of the MSEB model}

Figure 4 and 1c show the main elements of the MSEB model of Eq. [10]. The sum of the four forcing terms (Fig. 4c-f) scaled by the $M$ denominator (Fig. 4g) and the baroclinic mode (Fig. 1c) lead to the total MSEB estimate of $\omega$ (Fig. 4b). It has to be noted here that each of these elements is a result of a number of climate variables too (e.g. $F_{\text {top }}$ results from Eq. [4], which includes incoming solar radiation, surface albedo, total cloud albedo, thermal radiation of the atmosphere and surface). Further, the different elements shown here may be driven by the same climate elements with similar or opposing relations. Thus, the elements cannot be considered independent of each other. Subsequently, they may be highly interrelated to each other.

$F_{\text {top }}$ is positive throughout the tropics leading to upward motion nearly everywhere (Fig. 4c). It is stronger at low latitudes, due to larger incoming solar radiation, and is enhanced in regions with a moister atmosphere or stronger higher-level cloud cover (e.g. warm pool regions), due to the reduced loss of heat by outgoing thermal radiation. The heat uptake at the surface $\left(F_{\text {sur }}\right)$ is dominated by the SST pattern and is very small over land, due to the small heat capacity of the land surface (Fig. 4d). Regions with relative cold SST in respect to the zonal band lead to downward motion (e.g. coastal and equatorial upwelling regions), while relatively warm SST regions support upward motion (e.g. western subtropical region of the ocean basins).

The advection of heat has little effect on the equatorial regions but is mostly affecting the high latitudes boundaries of the tropics (Fig. 4e). The advection of moisture is far more important in the equatorial and subtropical regions (Fig. 4f). The advection is almost universally negative in the tropical regions, reflecting mean horizontal dry advection from subtropical into the equatorial humid areas. It thus primarily leads to downward motion in the 
subtropical regions (Fig. 4c-f). Finally, the denominator of the MSEB model $(M)$ is scaling the sensitivity of the tropospheric air columns to the forcing terms (Fig. 4g). Here the baroclinic mode $(\Omega)$ in $M$ effectively works as a weighting function for the integration of the vertical MSE $(h)$ at each different pressure level, with highest weights at around $200 \mathrm{hPa}$ to $600 \mathrm{hPa}$ (Fig. 1c). The overall $M$ scaling effect varies roughly by a factor 3 . It is smallest in the warm pool regions, representing less stable tropospheric air columns, and is largest in the higher latitudes, representing a more stable air column.

\section{Performance and limits}

We now evaluate how well the MSEB model can capture $\omega$ in the observations, as well as, for the CMIP model simulations. We will illustrate common biases, regional differences and also consider the CMIP simulations in the RCP8.5 scenario to test the model in a warmer climate.

\section{a. Performance for the climatological mean $\omega$}

Figure 2 compares the observed and the CMIP model ensemble mean simulated $\omega$ (at $500 \mathrm{hPa}$ ) with the corresponding MSEB model estimates. Similarly, the MSEB estimation for the 12 individual CMIP simulations are shown in Fig. S1 (see auxiliary material). Fig. 2 illustrate that the MSEB model captures the pattern and amplitude of $\omega($ at $500 \mathrm{hP})$ fairly well, both on larger and smaller scales. This holds for the observations, the individual CMIP simulations and for the CMIP ensemble mean. Further, it is notable that the structures over land are on much smaller scale, and it is also over land where we see larger mismatches between $\omega$ and the MSEB model estimates (e.g. compare equatorial Africa Fig. 2a and b). The larger scale structures over oceans are fairly well captured, but at higher latitudes there appears to be a tendency for more upward motion in the MSEB model estimates than found in the corresponding dataset. The overall pattern correlation is mostly between 0.6 to 0.8 . The MSEB model estimates $\omega$ for different layers in the troposphere are shown in Fig. 5. The pattern of the MSEB estimate is the same on all levels, as the terms on the RHS of eq. [10] are all vertical integrals, but the magnitude of the $\omega$ pattern is scaled by the baroclinic mode, $\Omega$. This assumes smaller magnitudes at lower levels, largest at about $500 \mathrm{hPa}$, and then somewhat lower magnitudes at higher levels (Fig. 1c and 5). We can see that the best fit with the observed $\omega$ is on the $500 \mathrm{hPa}$ level, both in terms of pattern and magnitudes. The observed $\omega$ is stronger at lower levels, and its pattern is similar on all levels. However, it does have some minor changes with height (baroclinic changes), in particular over land regions (e.g. Australia or South Africa).

We can quantify how well the pattern of MSEB model estimates match the true $\omega$ of the corresponding dataset for both, the pattern correlation and the amplitude, by calculating Taylor diagrams, see Fig 6. Here we included a comparison for the observations, all 12 CMIP models, and the ensemble mean. The pattern correlations for $\omega$ (at $500 \mathrm{hPa}$ ) for the whole tropics are moderate, with most values between 0.5 to 0.7 (black points in Fig. $6 \mathrm{a}$ ). The amplitude (standard deviation of the pattern) is with values between 0.75 to 1.1 . However, there are clear systematic differences in how the MSEB model performs over oceans or land regions. The pattern correlation for ocean points is systematically larger (blue points in Fig. 6a), while over land regions the correlation values are lower (yellow points in Fig. 6a). The amplitude estimates are also different, with the oceans much closer to 1.0, but mostly slightly below 1.0. The Land points have amplitudes that are largely overestimated or underestimated, with the range between 0.5 and 1.6.

The Taylor diagrams on different vertical levels illustrate that the MSEB model fits best at 500hPa level (Fig. 6b). At lower and higher levels the pattern correlations are less and the magnitudes are scaled incorrectly. At the lower levels the magnitudes are strongly underestimated and at higher levels the magnitudes are over estimated. This suggests that the scaling by the baroclinic mode $(\Omega)$ is too strong, and a more uniform scaling would be more accurate.

\section{b. Application to variations on different time scales, inter-model differences and in a warmer climate}

We now like to apply the MSEB model to variations of $\omega$ to illustrate how the model can capture variability. A good starting point for variability over time, is the seasonal cycle, as it marks the most significant temporal variability on larger and longer (>months) time scales. Figure 7 compares the seasonal cycle $\omega$ (at 500hPa) for observed and CMIP model ensemble mean with the MSEB model estimates.

The seasonal cycle in $\omega$ is marked by the expected seasonal shift (Dima and Wallace 2003; Cook 2004), with more upward motion on the summer hemisphere and less in the winter hemisphere. This meridional structure is however altered significantly at different regions (e.g. northwest Pacific), and the patterns vary in different CMIP 
simulations (see auxiliary material Fig. S2). These seasonal variations are well captured by the MSEB model, with a pattern correlation between 0.7 to 0.8 over oceans, and somewhat lesser correlation over land.

In Fig. S1 (see auxiliary material) we illustrated the match between $\omega$ and the MSEB estimates for the climatological annual mean. Here we can notice that each CMIP model has a different mean tropical circulation. The differences of each model from the CMIP ensemble mean are shown in Fig. S3 (see auxiliary material). The differences patterns are fairly complex, different for each model and also different in magnitudes. The differences are of larger scale over oceans and smaller scales over land. The MSEB model can capture some of these structures over ocean, with pattern correlations between 0.3 and 0.7 , but not as well capture over land with correlations below 0.5 . These correlation values are significantly lower than for the climatological annual mean (see auxiliary material Fig. S1) or the seasonal cycle (see auxiliary material Fig. S2). This is partly related to the weaker signal, with magnitudes of the difference pattern being significantly smaller than for the climatological annual mean or the seasonal cycle, but may also reflect the more complex structure of these differences.

The variability of $\omega$ on time scales from a month to several years is an important aspect that the MSEB model should capture. We therefore estimate the anomaly variability (mean seasonal cycle removed) of the observed $\omega$ and the MSEB model estimate over a 30yrs period. Figure 8 shows indices of the anomaly time series of the Walker and Hadley circulation. The index for Walker circulation is based on the difference between omega averaged over eastern equatorial and western equatorial Pacific. The index for northern Hadley (southern Hadley) circulation is based on the difference between northern Pacific (southern Pacific) and equatorial Pacific. The MSEB model captures the variability in the Walker and Hadley circulation indices fairly well, with correlations about 0.8 . There is also no indication of any significant biases in amplitude or time scale behavior (e.g. the match on shorter and longer time scales is equally good).

The match between the anomaly variability of $\omega$ and the MSEB model over a 30yrs period (360 monthly data points) for every grid point of the tropics is shown in terms of the mean correlation map for all 12 CMIP models and the observations in Fig. 9c. The MSEB model correlates fairly well over most ocean regions, but also over some land regions. In particular over the subtropical oceans the correlation values are higher.

We estimated similar correlation maps based on the comparison of $\omega$ versus the MSEB model estimate for the seasonal cycle in the CMIP simulations (Fig. 9b) and for the CMIP inter-model differences (Fig. 9d). For both, the correlation map values at each grid point are based on 12 data points (one for each model), and are therefore noisier than the ones for the anomaly variability (Fig. 9c). However, we can notice quite similar structures in the correlation pattern, with higher correlations in the subtropical oceans and lower correlations at the equatorial eastern Pacific and over some land regions. This shows that anomalies in these regions are not as well captured regardless of the timescale of variation, despite the very different physical origin of the variations. This is also highlighted in the Taylor diagrams for all three cases in Fig. 9a. The correlation scores are similar, with the seasonal cycle having the largest correlation values and the inter-model differences the lowest. We can also note that the seasonal cycle amplitude is slightly underestimated by the MSEB model.

Finally, we like to discuss the application of the MSEB model to the RCP8.5 scenarios, which presents an overall warmer tropical mean state. The warmer tropical mean state affects the tropopause height and therefore the baroclinic mode (Fig. 1). With the warmer tropical mean state, the convection tends to extend higher because of the uplifting tropopause height (Chou and Chen 2010; Chou et al. 2013), and therefore the baroclinic mode increases at higher levels and scales $\omega$ down by about $20 \%$. Subsequently $M$ (the denominator in Eq. [10]) magnitude increases, which scales $\omega$. The Taylor diagram for the climatological means for the period 2070-2099 in the RCP8.5 CMIP simulations illustrates that the MSEB model estimates of $\omega$ (red points in Fig. 6a) has similar correlation and scaling values as for the historical simulations. In particular, the scaling is scattering around 1.0, which indicates that on average the magnitudes of $\omega$ are estimate correctly and that the tropopause height changes are considered accurately. Thus, the MSEB model can be applied to different climate change scenarios without any systematic biases in $\omega$ due to the changes in the tropopause height. However, a more detailed analysis of the MSEB model's simulation on future warming climate will be addressed in future studies.

\section{c. Bias and limitations}

The above examples illustrated some limitations and biases of the MSEB model that we now like to discuss a bit more in detail. Figure 10 shows how well the MSEB model represents $\omega$ for different regions for the 12 CMIP simulations. First, we can note that the root mean squared error (RMSE) between the annual mean $\omega$ (at 500hP) with the corresponding MSEB model estimates is in general smallest near the equator for ocean point and tend to increase with latitude (Fig. 10a). Over land we find in general larger errors of smaller scales and somewhat linked to higher topography (e.g. The Andes in South America or the Himalaya in Asia). The seasonal cycle errors are similar in strength over land, but significantly weaker over oceans. The later indicates that the errors over oceans are a permanent offset. 
The analysis of the maps in Fig. 2 and S1 (see auxiliary material) already indicated that the MSEB model may have a bias towards upward motion at higher latitudes over oceans, which we can quantify by the mean difference (bias) between the annual mean MSEB model estimates and $\omega$ (at $500 \mathrm{hPa}$ ) for the 12 CMIP simulations (Fig. 10c). This mean bias shows overestimation of upward motion over ocean at high latitudes and large scales, while near the equator there is a smaller bias towards downward motions. The magnitude of the mean bias at higher latitudes is comparable with the overall RMSE, which indicates that the overall annual mean RMSE is mostly caused by the mean bias. The RMSE estimate with the mean bias removed from the MSEB estimates is substantially smaller and shows no more systematic dependency with latitudes (Fig. 10e). This suggests that the MSEB model can capture the variations in omega throughout the tropical ocean, but has a systematic offset at higher latitudes. The seasonal cycle mean bias is more complex and smaller over oceans (Fig. 10d). However, similar to the annual mean bias, removing the seasonal cycle mean bias reduces the RMSE in the seasonal cycle substantially, suggesting it contributes significantly to the overall errors.

The Taylor diagram estimates of the CMIP model with annual mean bias correction (CMIP historical ensemble annual mean bias removed) show very high correlation values and the amplitudes scatter close to 1.0, suggesting no more systematic scaling problems (Fig. 6a). While this may include some artificial skill (e.g. the ensemble mean is now by construction identical to the reference), we also subtracted the CMIP historical ensemble mean bias from the observed and the RCP8.5 ensemble to illustrate the bias with independent data (Fig. 6a). Both the observed and the RCP8.5 ensemble show clear improvements, illustrating that there is indeed a systematic bias in the data.

It is beyond this study to fully explore why the MSEB model is limited or biased towards the true vertical motion. However, we can give some indication of limiting factors. First of all, reduced skill over land and ocean points next to costal lines are strongly linked to smaller scale of the structures in the vertical motion at these locations. The MSEB model, over land in particular, is based on estimating gradients in temperatures and moisture (see Eq. [10]), which are more uncertain to estimate for smaller scale structures.

Secondly, at higher latitudes transient eddies contribute significantly to the advection of heat and moisture (Eq. [10]). This effect is not well captured when the estimation is based on monthly mean data. If the midlatitude transient eddy effect is excluded, excess upward motion tends to occur in the subtropics, often appearing as a broadening or extension of the ITCZs, due to the lack of dry static energy and moisture transports from the subtropics to midlatitudes (Neelin and Zeng 2000). We estimated this effect for the ERA-Interim dataset where daily data was available (not shown), and found that at higher latitudes the upward motion is indeed substantially reduced if daily data is considered. This would mostly explain the mean bias at the higher latitudes.

Further, the MSEB model is based on QE and the first baroclinic mode. The latter assumes weak temperature gradients in the free troposphere and only considers deep convection, neglecting shallow convections. The strong SST gradients between the equatorial cold tongue and the east Pacific ITCZ help drive "bottom-heavy" vertical motion profile in that region (Back and Bretherton 2009; Bui et al. 2016). We would therefore expect the model to be less accurate in regions of shallow convection or in general drier conditions. This may somewhat explain why the MSEB model has lower correlation values at the eastern equatorial Pacific region (see Fig. 9b-d) or some mismatches above and below 500hPa such as the south Pacific convergence zone (SPCZ) in Fig. 5. However, the MSEB model can still capture the eastern box of the Walker circulation index (shown in Fig. 8a) with a correlation 0.75 and also captures the ENSO variability, which is discussed in the following sections, fairly well.

420

\section{Diagnosis of tropical circulation variability with the MSEB Model}

In the following sections we will use the MSEB model to analyze what is driving changes or variability in the tropical circulation. The examples that we will discuss should give some indication of how the MSEB model could be used as a diagnostic tool for understanding the drivers of the tropical circulation. We will keep these discussions short to focus on the introduction of the MSEB model and will leave a more in-depth analysis for future studies.

We will start this discussion by illustrating how the sensitivity of the tropical circulation to the elements of the MSEB model can be calculated. We will base this discussion on the tropical mean circulation. We then will apply a similar discussion onto the seasonal cycle and ENSO. Both of these examples will be a discussion of anomalies of the tropical circulation. For this discussion of the drivers of anomalies we will introduce a second approach for defining sensitivities with the MSEB model.

\section{a. Sensitivity of the tropical circulation to the elements of the MSEB model}

Following Eq. [10] we present the tropical vertical motion, $\omega$, as a function of the difference between $F_{\text {top }}$ and $F_{s u r}$, the vertical integrals of $\nabla C_{p} T, \nabla L_{v} q, \mathbf{v}$ and $\Omega \partial_{\mathrm{p}} h$, and the baroclinic mode $\Omega$. The latter is only a function 
of $p$, but not a function of $x, y$. It therefore does not contribute to the spatial structure of $\omega$. It is instructive to analyze how the spatial structure in $\omega$ is related to the spatial structure forcing terms variables. This can be achieved by recomputing the MSEB model (Eq. [10]) with one of these variables replaced by its domain average, thus not considering the spatial structure of this variable. If the spatial structure of this variable is important, then the spatial structure of this recomputed $\omega$ should be significantly different from the original $\omega$ estimate. The differences between the original $\omega$ and the $\omega$ resulting from the sensitivity test can highlight what structures in $\omega$ are related to the evaluated variable. The results for each of these computations are shown in Fig. 11.

In the left column of Fig. 11 we can compare the sensitivity estimates of $\omega$ with the original MSEB estimate $\omega$ (Fig. 11a). The pattern correlation for each pair quantifies the similarity in the spatial structures of $\omega$. The higher the correlation, the less influence the variable under consideration has on the spatial structure of $\omega$. The right column of Fig. 11 shows the difference of each sensitivity estimates of $\omega$ with the original MSEB estimate $\omega$. It illustrates what spatial elements of $\omega$ are related to the spatial structure in the variable under consideration. Here we can note that all of the variables have some contribution to the spatial structure of $\omega$, but each has different structures.

Going through the variables one by one: $F_{\text {top }}$ mostly leads to more upward motion in the lower latitudes and in the warm pool regions. It overall has a moderate influence on the overall structure of $\omega . F_{\text {sur }}$ mostly influences oceanic regions. Here it has a fairly strong influence on the equatorial regions, leading to downward motions and a more moderate influence towards more upward motion in the western part of the subtropical oceans.

The horizontal winds, which influence the advection of moisture and heat, are the single most important elements of the MSEB model. They primarily lead to downward motion in the subtropical region, due to the advection of moisture. That is, they transport moisture away from these regions (negative advection; drying effect). The advection of heat plays a minor role, but is more important in the higher latitudes. The advection of moisture has a sensitivity to the spatial structure of $\omega$ that is similar to that of the horizontal wind fields. This suggests that the spatial structure in the advection of moisture is mostly controlled by the spatial structure in the wind field. Therefore, the spatial structure in the moisture distribution is of lesser importance (not shown). Finally, the $M$ has the smallest influence on the structure of $\omega$. It, however, contributes to the enhanced upward motions in the ITCZ and the warm pool regions.

\section{b. Forcing of Anomalies: The Seasonal Cycle}

In the previous section we discussed an example of how to evaluate the influence of the elements in the MSEB model onto the spatial structure of annual mean $\omega$. We now want to focus on the discussion of anomalies of the tropical circulation, and how they can be discussed in terms of sensitivities of the MSEB model. We will first show the forcing term of the MSEB model (Fig. 12) and then how these can be used to estimate sensitivities (Fig. 13).

Figure 7 show the seasonal cycle in $\omega$ (at $500 \mathrm{hPa}$ ) for the CMIP model ensemble mean and the observations. It shows the clear shift towards upward motion on the summer hemisphere for most regions. The MSEB model can capture these seasonal changes fairly well (see Taylor diagram Fig. 9a), although the complex behavior over land is not as well captured as the structures over ocean at large scales, and the ocean's seasonal cycle is slightly underestimated by the MSEB model (see standard deviation below 1.0 for most models in Fig. 9a).

The seasonal cycle of the climate variables that force the MSEB model are shown in Figure 12a-e. We can clearly see that $F_{\text {top }}$ is driving the shift towards upward motion on the summer hemisphere, as expected, since the seasonal cycle is forced by the seasonally changing incoming solar radiation $\left(S_{\text {top }}^{\downarrow}\right.$ in Eq. [4]). Interestingly, $F_{\text {sur }}$ is counteracting this shift over oceans, compensating for the $F_{t o p}$ tendencies almost completely. This reflects that the ocean's heat uptake keeps the SST relatively cold in the summer season and thereby counteracting the upward motion tendencies by the increased incoming solar radiation $\left(F_{\text {top }}\right)$ (Yu et al. 2006; Donohoe and Battisti 2013). In turn, this means that the relative warm SST in the winter season does lead towards upward motions. This appears to be the dominating element for the subtropical ocean basins (see positive (negative) values in the Northern (southern) hemisphere oceans in Fig. 7). The relative warm SSTs in the northern hemispheric offequatorial warm pools of the Indian, eastern Pacific and eastern Atlantic actually do force much of the summer upward motions (see Fig. 7 and 12b).

The advection terms (Fig. $12 \mathrm{c}$ and d) have fairly complex structures and are in general most dominant over land and higher latitudes. They mostly reflect the monsoon changes in the wind fields, with the most prominent example being the Indian monsoon system. Here we can clearly see how the advection of heat (Fig. 12c) lead to increased convection over India (Saini et al. 2011), and at the same time the advection of moisture away from the nearby ocean reduces the convection over theses oceanic regions (Pillai and Sahai 2014), but also further increases convection over India (Fig. 12d). In Fig. 12e, The seasonal cycle differences in the $M$ term $\left(-g<\Omega \partial_{\mathrm{p}} h>\right)$ are 
similar to those of $F_{t o p}$, with a destabilizing effect (green shaded) for the summer hemisphere. In addition, the $M$ term is more pronounced over land.

The sensitivity of seasonal cycle to the climate variables discussed above can be estimated more quantitatively, by recalculating the MSEB model for each calendar month by replacing one of the variables with an annual mean climatological value. The difference of the resulting seasonal cycle of the MSEB model in respect to the complete MSEB model gives us the sensitivity of this MSEB model to the seasonal cycle in this variable. Figure 13 shows the result of these sensitivity estimates for each of the variables discussed above and shown in Fig. 12.

The sensitivities in Fig. 13 are similar to the anomaly patterns in Fig. 12a-e. The main differences are related to the scaling factor of the annual mean $\boldsymbol{M}$ term (Fig. $4 \mathrm{~g}$ ), which enhances the effect of any forcing anomaly in the equatorial and warm pool regions. Subsequently, $\boldsymbol{F}_{\text {top }}$ and $\boldsymbol{F}_{\text {sur }}$ have stronger impacts in the subtropical western ocean basins (Moisan and Niiler 1998) and less impacts at higher latitudes than suggested by the anomalies pattern itself. The seasonal cycle in $\boldsymbol{M}$ has only a small effect on the MSEB model (Fig. 13f), despite its clear seasonal anomaly (Fig. 12e). This is due to the relatively small amplitude of the seasonal anomalies in $\boldsymbol{M}$, which are only about $20-30 \%$ of the annual mean values. The seasonal anomalies in the forcing terms (Fig. 12a-d) are mostly larger than their annual mean values (Fig. 4c-f) and are therefore more important.

\section{c. Forcing of anomalies: El Nino variability}

We now focus on the leading mode of interannual variability in the tropics: ENSO. It is marked by a strong interaction between the equatorial Pacific SST and the tropical atmosphere. A good indicator for the atmospheric variability associated with ENSO is the Southern Oscillation index based on sea level pressure shifts between the central equatorial Pacific and the western Pacific warm pool region. However, in the context of this study we are focused on $\omega$ (at $500 \mathrm{hPa}$ ) and therefore follow an index defined by Bayr et al. (2018) based on the central equatorial Pacific region (see Fig. 14). This is roughly the region with the strongest upward motion response to ENSO, see Fig. 15a.

Figure 14 shows the time series of $\omega$ (at $500 \mathrm{hPa}$ ) and the MSEB model estimate. The correlation between $\omega$ and the MSEB model estimate are generally high (correlation coefficient $\sim 0.8$ ), indicating that the MSEB model is capturing the $\omega$ variability fairly well. The strong cross correlation between the observed $\omega$ and SST time series (-0.8; Fig. 14a), clearly illustrates how the atmospheric variability is driven by the SST anomalies.

The mean composites for strong El Nino events (Nino3.4 SST anomaly > 1 standard deviation of the 30-year time series) of $\omega$ (at 500hPa) and the MSEB model estimates are shown in Fig. 15a and b. The MSEB model estimate correlates very well with the $\omega$ pattern, clearly highlighting the shift in upward motion from the warm pool regions towards the central equatorial Pacific. The mean composite values of the variables contributing to the MSEB model are shown in Fig. 15c-g, and the sensitivities of the MSEB model to each of these variables are shown in Fig. 16. The latter are computed with the same approach as done for the seasonal cycle.

We can clearly note here that the main driver of the $\omega$ anomalies for the El Nino composites is $\boldsymbol{F}_{\text {sur }}$ (Fig. 16b). This reflects that the warming SST is driving the changes in $\omega$. This is further amplified in the central equatorial Pacific by increases in $\boldsymbol{F}_{\text {top }}$ (Fig. 16a) due to increases high-level cloud cover (not shown), the advection of moisture (Fig. 16e) and by the decrease in stability in the $\boldsymbol{M}$ values (Fig. 16f). Further to the east on the equatorial Pacific the increased upward motion forced by $\boldsymbol{F}_{\text {sur }}$ is counteracted by the advection of dry air (Fig. 16e). Here it is further interesting to note how the $\boldsymbol{M}$ term is becoming more unstable throughout the whole tropics (Fig. 15g), reflecting the overall warming effect El Nino has on the tropics and thereby increasing the response of $\omega$ to the forcing terms of the MSEB model.

\section{Summary \& Discussion}

In this study we introduced the MSEB model as a diagnostic tool to conceptually understand the drivers of the large-scale tropical vertical motions. The model is based on previous studies of the MSE budget and combines them to a diagnostic model that estimates the large-scale vertical motions in the tropics as a function of the driving forces. The driving forces are the local air column heating balance and the advection of heat and moisture by the horizontal air flow. This is scaled by the first baroclinic mode and the gross moist stability $(M)$, which is also estimated by using the first baroclinic mode as a weighting function.

The MSEB model describes the large-scale features of the vertical motions for the climatological mean, seasonal cycle and interannual variability from observations and CMIP model simulations fairly well throughout most of the tropics $\left(30^{\circ} \mathrm{S}\right.$ to $\left.30^{\circ} \mathrm{N}\right)$, with significantly better skills over oceans than over land. The model can also successfully predict vertical motions in future warmer climates without systematic biases, as it considers changes in the tropopause height. Future studies will aim at a more detailed analysis of the tropical circulation change under global warming using the MSEB model diagnostics. 
The limitations of the model can result from a number of sources. First, the model assumptions of convective quasi-equilibrium and weak temperature gradients are not equally valid throughout the tropics. In particular over land, higher latitudes and over oceanic regions with relative cold SST and dominant shallow convection the model has stronger biases and somewhat lower correlation. Second, the model is based on a tropics-wide constant first baroclinic mode. While this study did not further evaluate regional differences in the baroclinic mode, it seems to be a likely candidate for further improvements in the model in regions with shallow convection. Some preliminary results indicated that biases at higher latitudes can be overcome with higher temporal resolution to better resolve transport of moisture and heat by transient eddies. A further uncertainty can result from estimating horizontal gradients on coarse resolutions grid, that are based on estimation that can go cross land-ocean boundaries. Overall, the MSEB model is a good starting point for the analysis of the large-scale vertical motion, but future developments could further improve this model by better considering the effect of transient eddies at higher latitudes and potentially by considering regional differences in the first baroclinic mode structure.

The MSEB model allows us to estimate the sensitivity of the large-scale vertical motion to the climate variables that drive the model. For the mean circulation the MSEB model illustrates how the pattern of large-scale vertical motion at 500hPa results from the interplay of heat terms, advection and overall stability. While it is expected that vertical motion results from the convergence of horizontal flow, the MSEB model illustrates that it is indeed a combination of forcing terms that lead to the large-scale pattern of vertical motion. The examples of the seasonal cycle and El Nino composites illustrated how the MSEB model can conceptually diagnose what is forcing variations in the large-scale vertical motion. This can also be quantified in terms of sensitivities of $\omega$ to each of the forcing terms by recomputing the MSEB model with one of the driving forces replaced by climatological values. This approach can be useful in discussions of what is driving future changes in the tropical circulations or why do models have tropical mean circulation different from the observed.

Based on the MSEB model, tropical circulation or changes thereof can be diagnosed on the basis of the largescale climate variables. This can provide a basis for further development to estimate circulation changes in simplified energy balance models, such as the globally resolved energy balance (GREB) model (Dommenget and Floter 2011; Stassen et al. 2019). Models like the GREB model can simulate changes in the energy balance and precipitation as they would result from changes in the $\mathrm{CO}_{2}$ concentrations, but the model is limited by assuming a fixed background circulation. This could provide a starting point to estimate tropical circulation changes in the GREB model framework or in other simplified atmospheric energy balance models to have further studies about feedbacks between tropical circulation and the other climate variables.

To sum up, the take-home message is that MSEB model can capture the large-scale circulation pattern quite well especially over oceanic region in tropics. This simple diagnostic model has considered the dynamic and thermodynamic perspectives for simulating vertical motion. It can be used for many different studies in the future.

\section{Acknowledgements}

This study was supported by the Australian Research Council (ARC), with additional support coming via the ARC Centre of Excellence for Climate Extremes (CLEX). The research was undertaken with the assistance of resources and services from the National Computational Infrastructure (NCI), which is supported by the Australian Government. We thank Robert Wills, Xavier Levine, Jia-Yuh Yu, Martin Singh, Chao-An Chen, and Zhiang Xie for useful discussion during the development of this study.

\section{Funding}

This study was supported by the Australian Research Council (ARC), ARC Centre of Excellence for Climate Extremes (grant numbers: CE170100023).

\section{Conflicts of interest}

The authors have no conflicts of interest to declare that are relevant to the content of this article.

\section{Availability of data and material}

The datasets generated and analysed during the current study are available from the corresponding author on reasonable request. 


\section{References}

Adam, O., Schneider, T., Brient, F., \& Bischoff, T. (2016). Relation of the double-ITCZ bias to the atmospheric energy budget in climate models. Geophysical Research Letters, 43(14), 7670-7677.

Back, L. E., \& Bretherton, C. S. (2006). Geographic variability in the export of moist static energy and vertical motion profiles in the tropical Pacific. Geophysical research letters, 33(17). , \& ___ (2009). A simple model of climatological rainfall and vertical motion patterns over the tropical oceans. Journal of Climate, 22(23), 6477-6497.

Bayr, T., Dommenget, D., Martin, T., \& Power, S. B. (2014). The eastward shift of the Walker Circulation in response to global warming and its relationship to ENSO variability. Climate dynamics, 43(9-10), 27472763. , Latif, M., Dommenget, D., Wengel, C., Harlaß, J., \& Park, W. (2018). Mean-state dependence of ENSO atmospheric feedbacks in climate models. Climate Dynamics, 50(9-10), 3171-3194.

Wengel, C., Latif, M., Dommenget, D., Lübbecke, J., \& Park, W. (2019). Error compensation of ENSO atmospheric feedbacks in climate models and its influence on simulated ENSO dynamics. Climate dynamics, 53(1-2), 155-172.

Bellenger, H., Guilyardi, E., Leloup, J., Lengaigne, J. \& Vialard, J. ENSO representation in climate models: from CMIP3 to CMIP5. Climate Dyn. 42, 1999-2018 (2014).

Berrisford, P., Dee, D., Poli, P., Brugge, R., Fielding, K., Fuentes, M., ... \& Simmons, A. (2011). The era-interim archive version 2.0, era report series 1, ecmwf, shinfield park. Reading, UK, 13177, 480.

Bischoff, T., \& Schneider, T. (2014). Energetic constraints on the position of the intertropical convergence zone. Journal of Climate, 27(13), 4937-4951.

Bretherton, C. S., \& Sobel, A. H. (2002). A simple model of a convectively coupled Walker circulation using the weak temperature gradient approximation. Journal of climate, 15(20), 2907-2920.

Bui, H. X., Yu, J. Y., \& Chou, C. (2016). Impacts of vertical structure of large-scale vertical motion in tropical climate: Moist static energy framework. Journal of the Atmospheric Sciences, 73(11), 4427-4437.

Chadwick, R., Boutle, I., \& Martin, G. (2013). Spatial patterns of precipitation change in CMIP5: Why the rich do not get richer in the tropics. Journal of climate, 26(11), 3803-3822.

Chemke, R., \& Polvani, L. M. (2019). Opposite tropical circulation trends in climate models and in reanalyses. Nature Geoscience, 12(7), 528-532.

Chou, C., \& Chen, C. A. (2010). Depth of convection and the weakening of tropical circulation in global warming. Journal of Climate, 23(11), 3019-3030.

\& Neelin, J. D. (2004). Mechanisms of global warming impacts on regional tropical precipitation. Journal of climate, 17(13), 2688-2701.

Chen, C. A., \& Tu, J. Y. (2009). Evaluating the "rich-get-richer" mechanism in tropical precipitation change under global warming. Journal of Climate, 22(8), 1982-2005.

, Wu, T. C., \& Tan, P. H. (2013). Changes in gross moist stability in the tropics under global warming. Climate dynamics, 41(9-10), 2481-2496.

Cook, K. H. (2004). Hadley circulation dynamics. In The Hadley circulation: present, past and future (pp. 61-83). Springer, Dordrecht.

Davis, N., \& Birner, T. (2017). On the discrepancies in tropical belt expansion between reanalyses and climate models and among tropical belt width metrics. Journal of Climate, 30(4), 1211-1231.

Davis, S. M., \& Rosenlof, K. H. (2012). A multidiagnostic intercomparison of tropical-width time series using reanalyses and satellite observations. Journal of Climate, 25(4), 1061-1078.

Dima, I. M., \& Wallace, J. M. (2003). On the seasonality of the Hadley cell. Journal of the atmospheric sciences, 60(12), 1522-1527.

Dommenget, D., \& Flöter, J. (2011). Conceptual understanding of climate change with a globally resolved energy balance model. Climate dynamics, 37(11-12), 2143-2165.

Donohoe, A., \& Battisti, D. S. (2013). The seasonal cycle of atmospheric heating and temperature. Journal of climate, 26(14), 4962-4980.

Emanuel, K. (2007). Quasi-equilibrium dynamics of the tropical atmosphere. The Global Circulation of the Atmosphere, 186-218.

, David Neelin, J., \& Bretherton, C. S. (1994). On large-scale circulations in convecting atmospheres. Quarterly Journal of the Royal Meteorological Society, 120(519), 1111-1143.

England, M. H., McGregor, S., Spence, P., Meehl, G. A., Timmermann, A., Cai, W., ... \& Santoso, A. (2014). Recent intensification of wind-driven circulation in the Pacific and the ongoing warming hiatus. Nature climate change, 4(3), 222-227.

Fiedler, S., Crueger, T., D’Agostino, R., Peters, K., Becker, T., Leutwyler, D., ... \& Dauhut, T. (2020). Simulated tropical precipitation assessed across three major phases of the Coupled Model Intercomparison Project (CMIP). Monthly Weather Review, 148(9), 3653-3680. 
Held, I. M. (2001). The partitioning of the poleward energy transport between the tropical ocean and atmosphere. Journal of the Atmospheric Sciences, 58(8), 943-948. , \& Soden, B. J. (2006). Robust responses of the hydrological cycle to global warming. Journal of climate, $19(21), 5686-5699$.

Hersbach, H., Bell, B., Berrisford, P., Hirahara, S., Horányi, A., Muñoz-Sabater, J., ... \& Thépaut, J. N. (2020). The ERA5 global reanalysis. Quarterly Journal of the Royal Meteorological Society, 146(730), 1999-2049.

Hu, Y., Huang, H., \& Zhou, C. (2018). Widening and weakening of the Hadley circulation under global warming. Science Bulletin, 63(10), 640-644.

Kjellsson, J. (2015). Weakening of the global atmospheric circulation with global warming. Climate Dynamics, 45(3-4), 975-988.

Lau, K. M., \& Yang, S. (2003). Walker circulation. Encyclopedia of atmospheric sciences, 2505-2510.

Lian, T., Chen, D., Ying, J., Huang, P., \& Tang, Y. (2018). Tropical Pacific trends under global warming: El Niño-like or La Niña-like?. National Science Review, 5(6), 810-812.

Li, G., \& Xie, S. P. (2012). Origins of tropical-wide SST biases in CMIP multi-model ensembles. Geophysical research letters, 39(22).

Lu, J., Vecchi, G. A., \& Reichler, T. (2007). Expansion of the Hadley cell under global warming. Geophysical Research Letters, 34(6).

Luo, J. J., Wang, G., \& Dommenget, D. (2018). May common model biases reduce CMIP5's ability to simulate the recent Pacific La Niña-like cooling?. Climate dynamics, 50(3-4), 1335-1351.

Levine, X. J., \& Boos, W. R. (2016). A mechanism for the response of the zonally asymmetric subtropical hydrologic cycle to global warming. Journal of Climate, 29(21), 7851-7867.

Ma, J., Chadwick, R., Seo, K.-H., Dong, C., Huang, G., Foltz, G. R., \& Jiang, J. H. (2018). Responses of the Tropical Atmospheric Circulation to Climate Change and Connection to the Hydrological Cycle. Annual Review of Earth and Planetary Sciences, 46(1), 549-580.

Mitas, C. M., \& Clement, A. (2006). Recent behavior of the Hadley cell and tropical thermodynamics in climate models and reanalyses. Geophysical Research Letters, 33(1).

Moisan, J. R., \& Niiler, P. P. (1998). The seasonal heat budget of the North Pacific: Net heat flux and heat storage rates (1950-1990). Journal of Physical Oceanography, 28(3), 401-421.

Neelin, J. D., \& Held, I. M. (1987). Modeling tropical convergence based on the moist static energy budget. Monthly Weather Review, 115(1), 3-12.

\& Yu, J. Y. (1994). Modes of tropical variability under convective adjustment and the Madden-Julian oscillation. Part I: Analytical theory. Journal of the atmospheric sciences, 51(13), 1876-1894.

, \& Zeng, N. (2000). A quasi-equilibrium tropical circulation model-Formulation. Journal of the atmospheric sciences, 57(11), 1741-1766.

Nguyen, H., Evans, A., Lucas, C., Smith, I., \& Timbal, B. (2013). The Hadley circulation in reanalyses: Climatology, variability, and change. Journal of Climate, 26(10), 3357-3376.

Peters, M. E., \& Bretherton, C. S. (2005). A simplified model of the Walker circulation with an interactive ocean mixed layer and cloud-radiative feedbacks. Journal of Climate, 18(20), 4216-4234.

Pillai, P. A., \& Sahai, A. K. (2014). Moist dynamics of active/break cycle of Indian summer monsoon rainfall from NCEPR2 and MERRA reanalysis. International Journal of Climatology, 34(5), 1429-1444.

Plesca, E., Grützun, V., \& Buehler, S. A. (2018). How robust is the weakening of the Pacific Walker circulation in CMIP5 idealized transient climate simulations? Journal of Climate, 31(1), 81-97.

Power, S. B., \& Kociuba, G. (2011). The impact of global warming on the Southern Oscillation Index. Climate dynamics, 37(9-10), 1745-1754.

RAND Corporation, 1980: Rand's Global Elevation and Depth Data. Research Data Archive at the National Center for Atmospheric Research, Computational and Information Systems Laboratory, Boulder, CO. [Available online at https://rda.ucar.edu/datasets/ds750.1/.]

Raymond, D. J., Sessions, S. L., Sobel, A. H., \& Fuchs, Ž. (2009). The mechanics of gross moist stability. Journal of Advances in Modeling Earth Systems, 1(3).

Saini, R., Barlow, M., \& Hoell, A. (2011). Dynamics and thermodynamics of the regional response to the Indian monsoon onset. Journal of climate, 24(22), 5879-5886.

Samanta, D., Karnauskas, K. B., \& Goodkin, N. F. (2019). Tropical Pacific SST and ITCZ biases in climate models: Double trouble for future rainfall projections?. Geophysical Research Letters, 46(4), 2242-2252.

Satoh, M. (2013). Atmospheric circulation dynamics and general circulation models. Springer Science \& Business Media.

Stassen, C., Dommenget, D., \& Loveday, N. (2019). A hydrological cycle model for the Globally Resolved Energy Balance (GREB) model v1. 0. Geoscientific Model Development, 12(1), 425-440.

Staten, P. W., Lu, J., Grise, K. M., Davis, S. M., \& Birner, T. (2018). Re-examining tropical expansion. Nature Climate Change, 8(9), 768-775. 
Taylor, K. E., Stouffer, R. J., \& Meehl, G. A. (2012). An overview of CMIP5 and the experiment design. Bulletin of the American Meteorological Society, 93(4), 485-498.

Tokinaga, H., Xie, S. P., Deser, C., Kosaka, Y., \& Okumura, Y. M. (2012). Slowdown of the Walker circulation driven by tropical Indo-Pacific warming. Nature, 491(7424), 439-443.

Uppala, S. M., Kållberg, P. W., Simmons, A. J., Andrae, U., Bechtold, V. D. C., Fiorino, M., ... \& Li, X. (2005). The ERA-40 re-analysis. Quarterly Journal of the Royal Meteorological Society: A journal of the atmospheric sciences, applied meteorology and physical oceanography, 131(612), 2961-3012.

Vallis, G. K. (2017). Atmospheric and oceanic fluid dynamics. Cambridge University Press.

Vecchi, G. A., \& Soden, B. J. (2007). Global warming and the weakening of the tropical circulation. Journal of Climate, 20(17), 4316-4340.

Wittenberg, A. T., Held, I. M., Leetmaa, A., \& Harrison, M. J. (2006). Weakening of tropical Pacific atmospheric circulation due to anthropogenic forcing. Nature, 441(7089), 73.

Vijayeta, A., \& Dommenget, D. (2018). An evaluation of ENSO dynamics in CMIP simulations in the framework of the recharge oscillator model. Climate Dynamics, 51(5-6), 1753-1771.

Wills, R. C., Byrne, M. P., \& Schneider, T. (2016). Thermodynamic and dynamic controls on changes in the zonally anomalous hydrological cycle. Geophysical Research Letters, 43(9), 4640-4649.

, Levine, X. J., \& Schneider, T. (2017). Local energetic constraints on Walker circulation strength. Journal of the Atmospheric Sciences, 74(6), 1907-1922.

World Meteorological Organization (1992). International meteorological vocabulary (2nd ed.). WMO, Geneva.

Yu, J. Y., Chou, C., \& Neelin, J. D. (1998). Estimating the gross moist stability of the tropical atmosphere. Journal of the atmospheric sciences, 55(8), 1354-1372. , \& Neelin, J. D. (1997). Analytic approximations for moist convectively adjusted regions. Journal of the atmospheric sciences, 54(8), 1054-1063.

Yu, L., Jin, X., \& Weller, R. A. (2006). Role of net surface heat flux in seasonal variations of sea surface temperature in the tropical Atlantic Ocean. Journal of climate, 19(23), 6153-6169.

\section{List of Tables}

Table. 1 List of CMIP5 models.

Table. 2

Variables of the MSEB model.

\section{List of Figures}

Fig. 1

(a) Vertical profile of tropical-mean MSE (h) as function of the mean tropical surface temperature in the RCP8.5 scenario of bcc-csm1-1 simulations. Tropopause height $\left(P_{\mathrm{T}}\right)$ estimates are shown with blue dots. (b) Partial enlargement of (a) from $200 \mathrm{hPa}$ to $50 \mathrm{hPa}$. (c) Baroclinic mode profile in relation to different tropical-mean surface temperature color coded from coldest (blue) to warmest (red). Profiles computed based on bcc-csm1-1 RCP8.5 scenario from 2009 to 2099 , each curve represent yearly baroclinic mode and the time interval between each curve is 10 -year.

Fig. 3

Mean $\omega$ at $500 \mathrm{hPa}$ in historical period (upper panels) vs. the MSEB model estimates (lower panels) for ERA5 reanalysis (left) and the ensemble mean of 12 CMIP5 models (right). The pattern correlation values between $\omega$ and the MSEB model estimates for land (first value) and oceans are shown in the heading of (b) and (d).

Sketch illustrating the MSEB model. Upper panels illustrate the vertical motion (gray arrow) for three different forcings (red arrows), but with the same background stability profile $\left(\Omega \partial_{\mathrm{p}} h\right)$. Lower panels illustrate the vertical motion for identical forcing terms, but different background stability profiles (left: less stable; right: more stable).

(a) Mean $\omega$ at 500hpa from ERA5 reanalysis. (b) Corresponding MSEB model estimate. (c)-(g) RHS term of Eq. [10]: (c) $F_{t o p}$, (d) $-F_{\text {sur }}$, (e) $-<\mathbf{v} \cdot \nabla\left(L_{v} T\right)>$, (f) $-<\mathbf{v} \cdot \nabla\left(L_{v} q\right)>$ and (g) 
$-\mathrm{g}\left\langle\Omega \partial_{p} h\right\rangle$. The pattern correlation values between $\omega$ and the MSEB model estimates for land (first value) and oceans are shown in the heading of (b).

$780 \quad$ Fig. 5

781

782

783

784

785

786

787

788

Mean $\omega$ (left) vs. MSEB model estimates (right) at different pressure levels for ERA5 reanalysis. The pattern correlation values between $\omega$ and the MSEB model estimates for land (first value) and oceans are shown in the heading for each MSEB model estimate panel.

Fig. 6

Fig. 7

Fig. 8

Fig. 9

Fig. 10

Fig. 11

Fig. 12

Fig. 13

Fig. 14

Taylor diagrams of different MSEB model estimates vs. the reference $\omega$ : Left: at $500 \mathrm{hPa}$ for different regions (see legend) and for bias corrected oceans in historical (skyblue) and oceans in the RCP8.5 (orange). Right: for ocean points at different pressure levels. Symbols are: ERA5 reanalysis (triangle), individual CMIP models (numbers; see Table 1) and CMIP ensemble mean (circles).

Seasonal cycle $\omega$ at $500 \mathrm{hPa}$ in historical period (upper panels) vs. the MSEB model estimates (lower panels) for ERA5 reanalysis (left) and the ensemble mean of 12 CMIP5 models (right). The pattern correlation values between $\omega$ and the MSEB model estimates for land (first value) and oceans are shown in the heading of (b) and (d).

Circulation index between $\omega$ at 500hPa and MSEB estimates for ERA5. (a) Walker circulation index for eastern equatorial Pacific $\left(3.75^{\circ} \mathrm{N}-3.75^{\circ} \mathrm{S}, 120^{\circ} \mathrm{E}-160^{\circ} \mathrm{E}\right)$ minus western equatorial Pacific $\left(3.75^{\circ} \mathrm{N}-3.75^{\circ} \mathrm{S}, 200^{\circ} \mathrm{E}-240^{\circ} \mathrm{E}\right)$. (b) Northern Hadley circulation index for northern Pacific $\left(22.5^{\circ} \mathrm{N}-30.0^{\circ} \mathrm{N}, 150^{\circ} \mathrm{E}-251.25^{\circ} \mathrm{E}\right)$ minus equatorial Pacific $\left(3.75^{\circ} \mathrm{N}-3.75^{\circ} \mathrm{S}, 150^{\circ} \mathrm{E}-\right.$ $\left.251.25^{\circ} \mathrm{E}\right)$. (c) Southern Hadley circulation index for southern Pacific $\left(22.5^{\circ} \mathrm{S}-30.0^{\circ} \mathrm{S}, 150^{\circ} \mathrm{E}-\right.$ $\left.251.25^{\circ} \mathrm{E}\right)$ minus equatorial Pacific $\left(3.75^{\circ} \mathrm{N}-3.75^{\circ} \mathrm{S}, 150^{\circ} \mathrm{E}-251.25^{\circ} \mathrm{E}\right)$. The upper right value for each panel is correlation between $\omega$ and MSEB estimates.

(a) Taylor diagrams of MSEB model estimates vs. the reference $\omega$ at $500 \mathrm{hPa}$ for the seasonal cycle (blue), anomalous monthly mean variability (red) and for CMIP inter-model differences relative to the ensemble mean (black). Maps of local correlation values for: (b) the seasonal cycle, (c) anomalous monthly mean variability (red) and (d) for CMIP inter-model differences relative to the ensemble mean based on $12 \mathrm{CMIP}$ model simulations. Blue and red ensembles in (a), maps in (b) and (c) include ERA5 estimates too.

(a) RMSE of the annual mean MSEB model estimates relative to $\omega$ at $500 \mathrm{hPa}$ for the CMIP5 ensemble mean. (b) the same for the seasonal cycle (0.5*(JJA-DJF)). (c) Annual mean MSEB model estimates minus the $\omega$ at $500 \mathrm{hPa}$. (d) the same for the seasonal cycle difference. (e) RMSE of the annual mean as in (a), but with the mean bias of (c) removed. (f) RMSE of the seasonal cycle as in (b), but with the mean bias of (d) removed. The numbers in the headings are the mean absolute values for land (first value) and ocean points.

Sensitivity estimates for the MSEB model based on the mean ERA5. (a) $\omega$ at 500hPa MSEB estimate. The domain mean RMS for land (first value) and ocean points are shown in the heading. Left column: MSEB estimates with a specific term fixed (see heading of each panel). The spatial correlation values of each panel with panel (a) for land (first value) and ocean points are shown in the heading of each panel. Right column: differences of panel (a) minus the left panel in each row. The domain mean RMSE between (a) and each plot in the left column for land (first value) and ocean points are shown in the heading.

Mean seasonal cycle $\left(0.5^{*}(\mathrm{JJA}-\mathrm{DJF})\right)$ of MSEB model estimate from ERA5 reanalysis. (a)-(e) RHS term of Eq. [10]: (a) $F_{\text {top }}$, (b) $-F_{\text {sur }}$, (c) $\left.-<\mathbf{v} \cdot \nabla\left(L_{v} T\right)\right\rangle$, (d) $\left.-<\mathbf{v} \cdot \nabla\left(L_{v} q\right)\right\rangle$ and (e) $-\mathrm{g}\left\langle\Omega \partial_{p} h>\right.$.

Sensitivities of the mean seasonal cycle in of $\omega$ at $500 \mathrm{hPa}$ of the MSEB model to different forcing terms (see heading in panels (a) to (f)). (g) Sum of (a) to (f). (a). (a)-(f) are obtained by following the same procedures as the right column in Fig. 11. The RMSE for each panel for land (first value) and ocean points are shown in the heading of each panel (a) to (f). See text for details on the estimation of sensitivities.

(a) Monthly mean time series of Nino3.4 $\left(3.75^{\circ} \mathrm{N}-3.75^{\circ} \mathrm{S}, 170^{\circ} \mathrm{W}-120^{\circ} \mathrm{W}\right) \mathrm{SST}$. (b) Monthly mean time series of $\omega$ at $500 \mathrm{hpa}$ in the central equatorial Pacific region $\left(3.75^{\circ} \mathrm{N}-3.75^{\circ} \mathrm{S}, 150^{\circ} \mathrm{E}-\right.$ $150^{\circ} \mathrm{W}$ ) and the corresponding MSEB model estimate. The correlation between $\omega$ at 500hpa and the MSEB estimate for ERA5 period is shown in the heading of (b). 
$830 \quad$ Fig. 15

831

832

833

834

835

836

837

838

839

(a) El Nino composites of $\omega$ at 500hPa from ERA5 reanalysis. (b) Corresponding MSEB model estimate. (c)-(g) RHS term of Eq. [10]: (c) $F_{t o p}$, (d) $-F_{\text {sur }}$, (e) $-<\mathbf{v} \cdot \nabla\left(L_{v} T\right)>$, (f) $-<\mathbf{v}$. $\nabla\left(L_{v} q\right)>$ and $(\mathrm{g})-\mathrm{g}<\Omega \partial_{p} h>$. The black box in (a) outlining the omega index mentioned in Fig. 14(b). The pattern correlation values between $\omega$ and the MSEB model estimates for land (first value) and oceans are shown in the heading of (b).

Fig. 16 Sensitivities of the El Nino composites of $\omega$ at 500hpa of the MSEB model to different forcing terms (see heading in panels (a) to (f)). (g) Sum of (a) to (f). (a)-(f) are obtained by following the same procedures as the right column in Fig.11. The RMSE for each panel for land (first value) and ocean points are shown in the heading of each panel (a) to (f). See text for details on the estimation of sensitivities.

Table. 1 List of CMIP5 models.

\begin{tabular}{ll}
\hline No. & Models \\
\hline 1 & GFDL-ESM2G \\
2 & MIROC5
\end{tabular}


Table. 2 Variables of the MSEB model

\begin{tabular}{|llll|}
\hline Variable & Unit & Dimension & Description \\
\hline$\omega$ & $\mathrm{Pa} \mathrm{s}^{-1}$ & $\mathrm{x}, \mathrm{y}, \mathrm{p}, \mathrm{t}$ & Pressure velocity \\
$T$ & $\mathrm{~K}$ & $\mathrm{x}, \mathrm{y}, \mathrm{p}, \mathrm{t}$ & Air temperature \\
$q$ & 1 & $\mathrm{x}, \mathrm{y}, \mathrm{p}, \mathrm{t}$ & Specific humidity \\
$Z$ & $\mathrm{~m}$ & $\mathrm{x}, \mathrm{y}, \mathrm{p}, \mathrm{t}$ & Geopotential height \\
$\mathbf{v}$ & $\mathrm{m} \mathrm{s}^{-1}$ & $\mathrm{x}, \mathrm{y}, \mathrm{p}, \mathrm{t}$ & Horizontal velocity \\
$h$ & $\mathrm{~J} \mathrm{Kg}^{-1}$ & $\mathrm{x}, \mathrm{y}, \mathrm{p}, \mathrm{t}$ & Moist static energy \\
$S_{\text {top }}^{\downarrow}$ & $\mathrm{W} \mathrm{m}^{-2}$ & $\mathrm{x}, \mathrm{y}, \mathrm{t}$ & TOA incident shortwave radiation
\end{tabular}




\begin{tabular}{|c|c|c|c|}
\hline$S_{\text {top }}^{\uparrow}$ & $\mathrm{W} \mathrm{m} \mathrm{m}^{-2}$ & $\mathrm{x}, \mathrm{y}, \mathrm{t}$ & TOA outgoing shortwave radiation \\
\hline$R_{\text {top }}^{\uparrow}$ & $\mathrm{W} \mathrm{m}^{-2}$ & $\mathrm{x}, \mathrm{y}, \mathrm{t}$ & TOA outgoing longwave radiation \\
\hline$S_{\text {sur }}^{\downarrow}$ & $\mathrm{W} \mathrm{m} \mathrm{m}^{-2}$ & $\mathrm{x}, \mathrm{y}, \mathrm{t}$ & Surface downwelling shortwave radiation \\
\hline$S_{\text {sur }}^{\uparrow}$ & $\mathrm{W} \mathrm{m} \mathrm{m}^{-2}$ & $\mathrm{x}, \mathrm{y}, \mathrm{t}$ & Surface upwelling shortwave radiation \\
\hline$R_{\text {sur }}^{\downarrow}$ & $\mathrm{W} \mathrm{m} \mathrm{m}^{-2}$ & $\mathrm{x}, \mathrm{y}, \mathrm{t}$ & Surface downwelling longwave radiation \\
\hline$R_{\text {sur }}^{\uparrow}$ & $\mathrm{W} \mathrm{m} \mathrm{m}^{-2}$ & $\mathrm{x}, \mathrm{y}, \mathrm{t}$ & Surface upwelling longwave radiation \\
\hline$E$ & $\mathrm{~W} \mathrm{~m} \mathrm{~m}^{-2}$ & $\mathrm{x}, \mathrm{y}, \mathrm{t}$ & Surface upward latent heat flux \\
\hline$H$ & $\mathrm{~W} \mathrm{~m} \mathrm{~m}^{-2}$ & $\mathrm{x}, \mathrm{y}, \mathrm{t}$ & Surface upward sensible heat flux \\
\hline$F_{t o p}$ & $\mathrm{~W} \mathrm{~m} \mathrm{~m}^{-2}$ & $\mathrm{x}, \mathrm{y}, \mathrm{t}$ & Net energy flux at the TOA \\
\hline$F_{\text {sur }}$ & $\mathrm{W} \mathrm{m} \mathrm{m}^{-2}$ & $\mathrm{x}, \mathrm{y}, \mathrm{t}$ & Net energy flux at the surface \\
\hline$F_{\text {net }}$ & $\mathrm{W} \mathrm{m}^{-2}$ & $\mathrm{x}, \mathrm{y}, \mathrm{t}$ & Net energy flux into atmospheric column \\
\hline $\mathbf{v}_{1}$ & $\mathrm{~m} \mathrm{~s}^{-1}$ & $\mathrm{x}, \mathrm{y}, \mathrm{t}$ & The first baroclinic mode winds \\
\hline$M$ & $\mathrm{~J} \mathrm{Kg}^{-1}$ & $\mathrm{x}, \mathrm{y}, \mathrm{t}$ & Gross moist stability \\
\hline$\Omega$ & 1 & $\mathrm{p}, \mathrm{t}$ & The first baroclinic mode \\
\hline$P_{\mathrm{T}}$ & $\mathrm{Pa}$ & $\mathrm{t}$ & Tropopause height \\
\hline$\delta p$ & $\mathrm{~Pa}$ & $\mathrm{t}$ & Tropospheric depth $\left(P_{\mathrm{S}}-P_{\mathrm{T}}\right)$ \\
\hline$C_{p}$ & $\mathrm{~J} \mathrm{Kg}^{-1} \mathrm{~K}^{-1}$ & constant & Specific heat at constant pressure \\
\hline$L_{v}$ & $\mathrm{~J} \mathrm{Kg}^{-1}$ & constant & Latent heat of vaporization \\
\hline$g$ & $\mathrm{~m} \mathrm{~s}^{-2}$ & constant & Gravitational acceleration \\
\hline$P_{\mathrm{S}}$ & $\mathrm{Pa}$ & constant & Reference surface pressure at $1000 \mathrm{hPa}$ \\
\hline
\end{tabular}



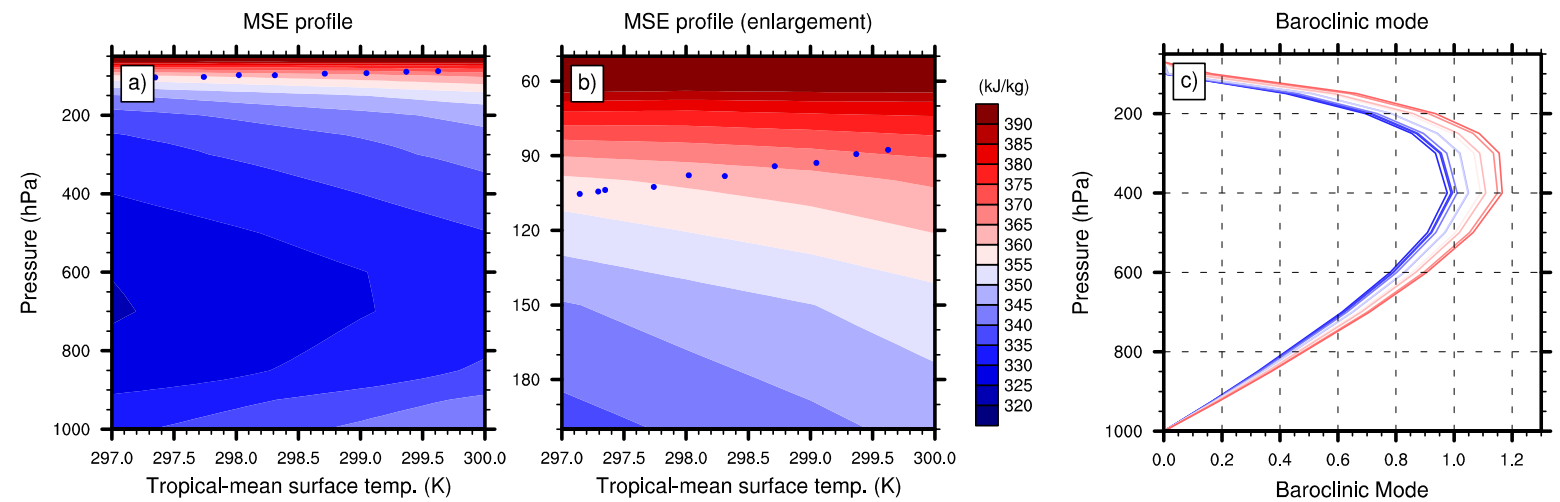

Fig. 1 (a) Vertical profile of tropical-mean MSE $(h)$ as function of the mean tropical surface temperature in the RCP8.5 scenario of bcc-csm1-1 simulations. Tropopause height $\left(P_{\mathrm{T}}\right)$ estimates are shown with blue dots. (b) Partial enlargement of (a) from $200 \mathrm{hPa}$ to $50 \mathrm{hPa}$. (c) Baroclinic mode profile in relation to different tropical-mean surface temperature color coded from coldest (blue) to warmest (red). Profiles are computed based on bcc-csm11 RCP8.5 scenario from 2009 to 2099 , each curve represent yearly baroclinic mode and the time interval between each curve is 10-year. 


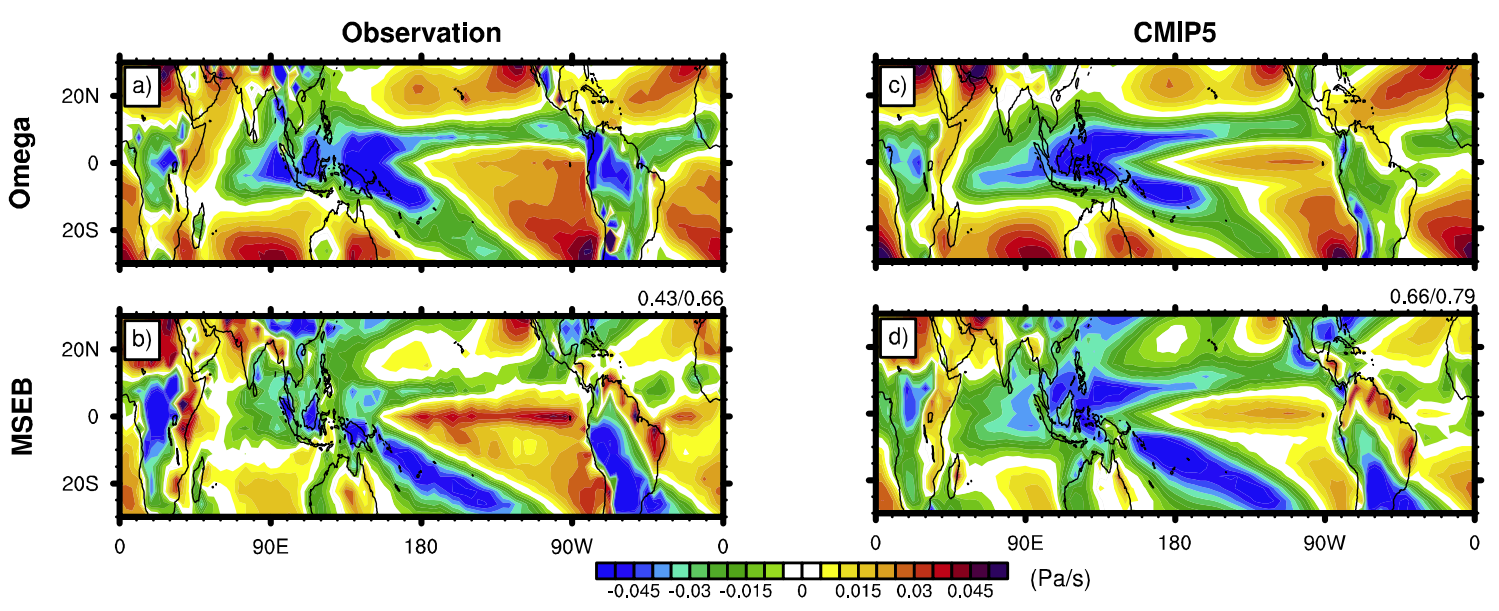

Fig. 2 Mean $\omega$ at $500 \mathrm{hPa}$ in historical period (upper panels) vs. the MSEB model estimates (lower panels) for ERA5 reanalysis (left) and the ensemble mean of 12 CMIP5 models (right). The pattern correlation values between $\omega$ and the MSEB model estimates for land (first value) and oceans are shown in the heading of (b) and (d). 

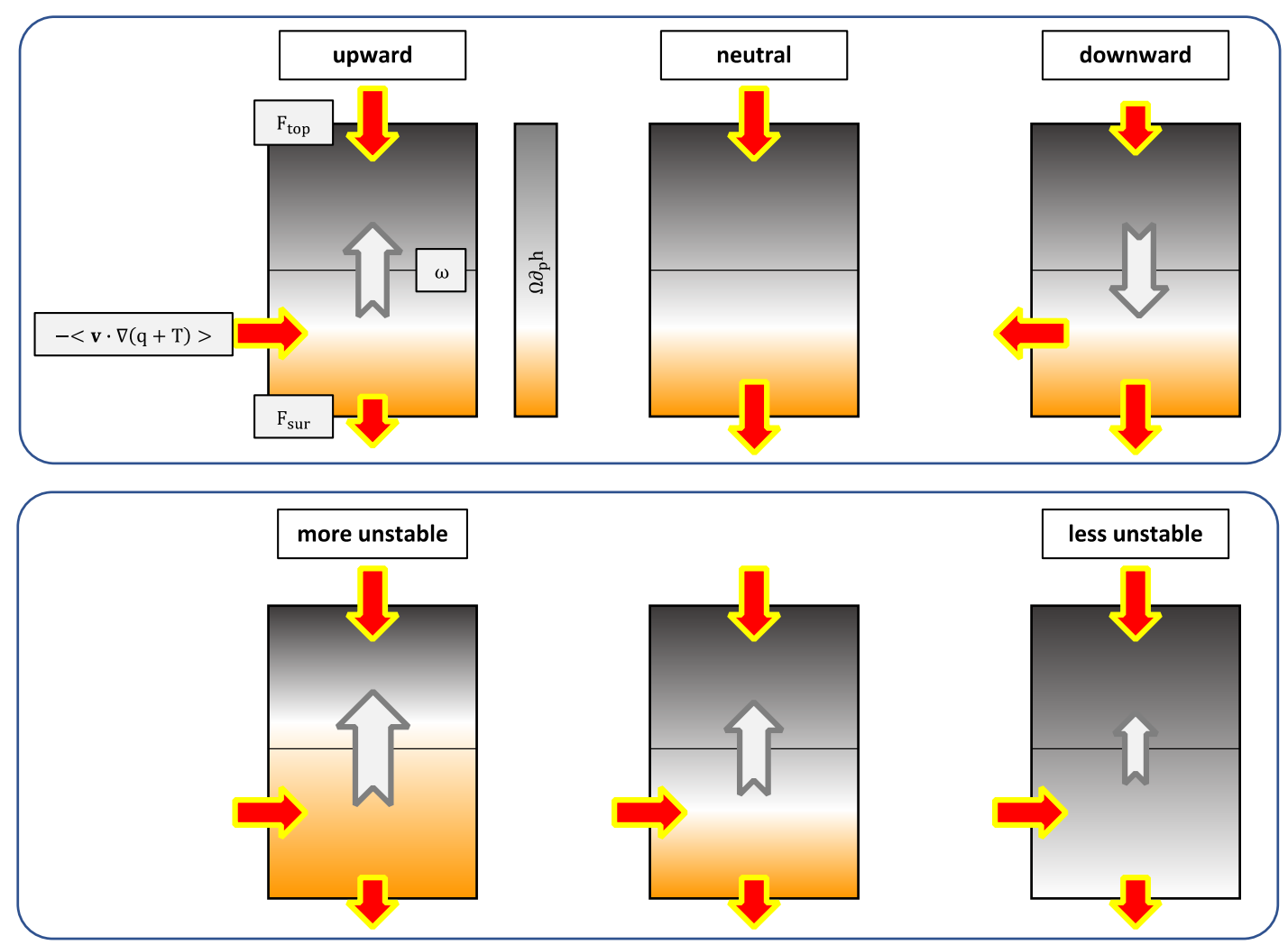

Fig. 3 Sketch illustrating the MSEB model. Upper panels illustrate the vertical motion (gray arrow) for three different forcings (red arrows), but with the same background stability profile $\left(\Omega \partial_{\mathrm{p}} h\right)$. Lower panels illustrate the vertical motion for identical forcing terms, but different background stability profiles (left: less stable; right: more stable). 

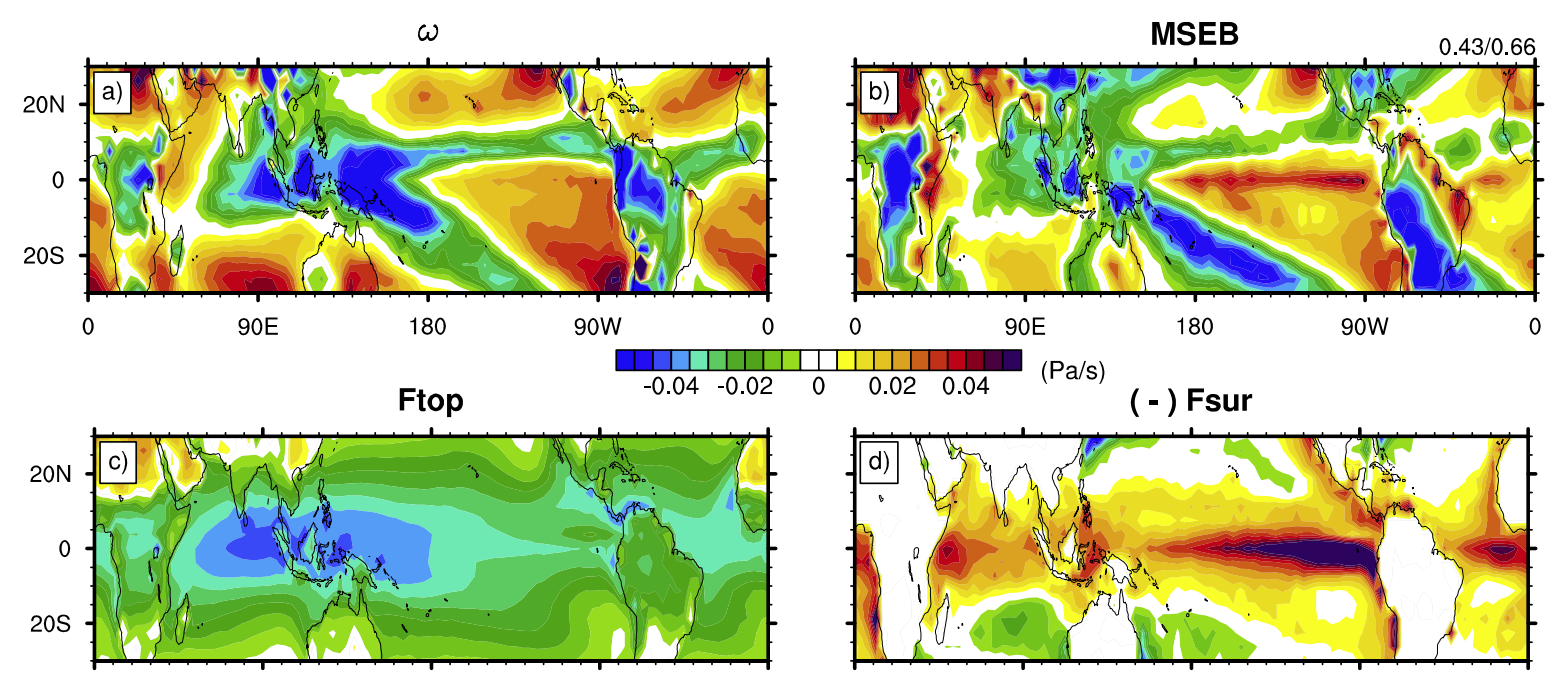

AdvT
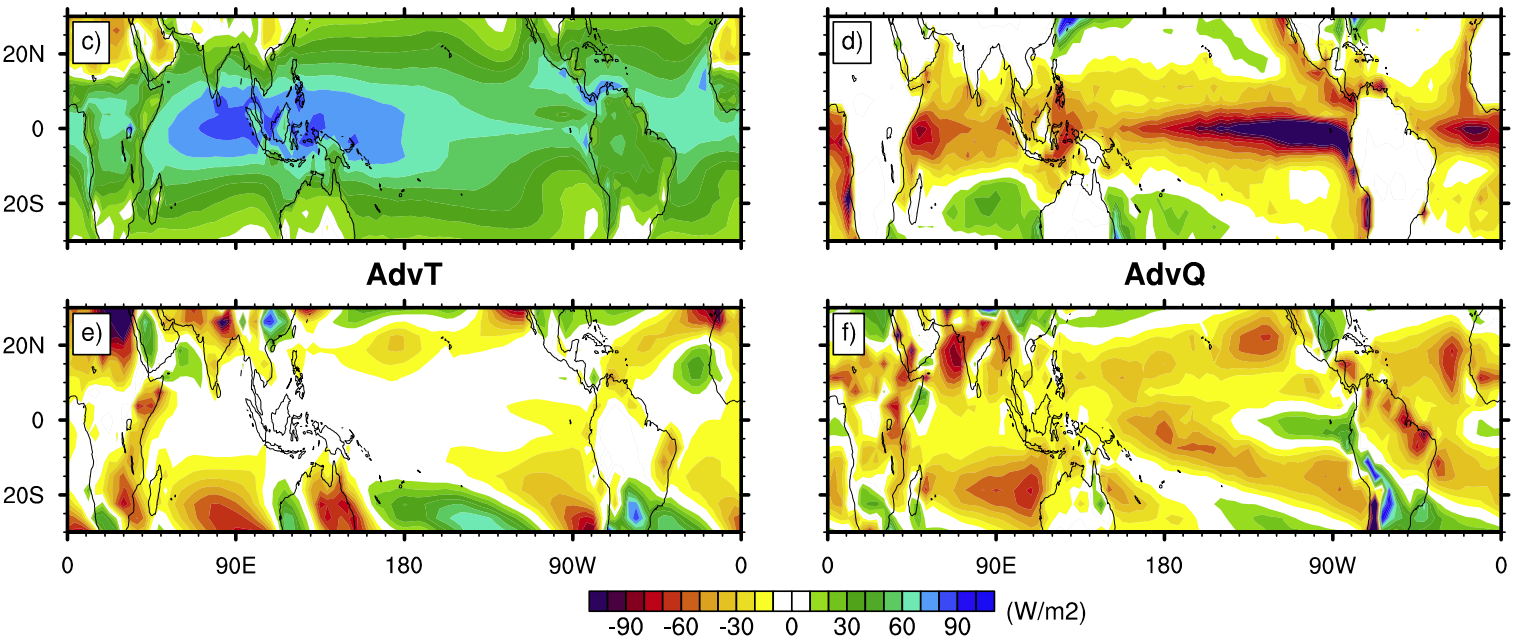

M

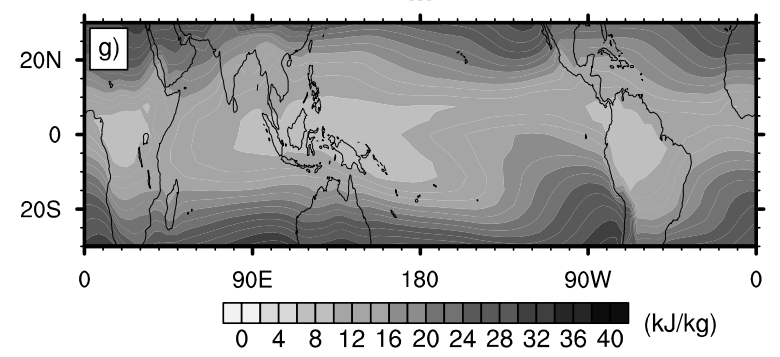

Fig. 4 (a) Mean $\omega$ at 500hpa from ERA5 reanalysis. (b) Corresponding MSEB model estimate. (c)-(g) RHS term of Eq. [10]: (c) $F_{\text {top }}$, (d) $-F_{\text {sur }}$, (e) $-<\mathbf{v} \cdot \nabla\left(L_{v} T\right)>$, (f) $-<\mathbf{v} \cdot \nabla\left(L_{v} q\right)>$ and $(\mathrm{g})-\mathrm{g}<\Omega \partial_{p} h>$. The pattern correlation values between $\omega$ and the MSEB model estimates for land (first value) and oceans are shown in the heading of (b). 

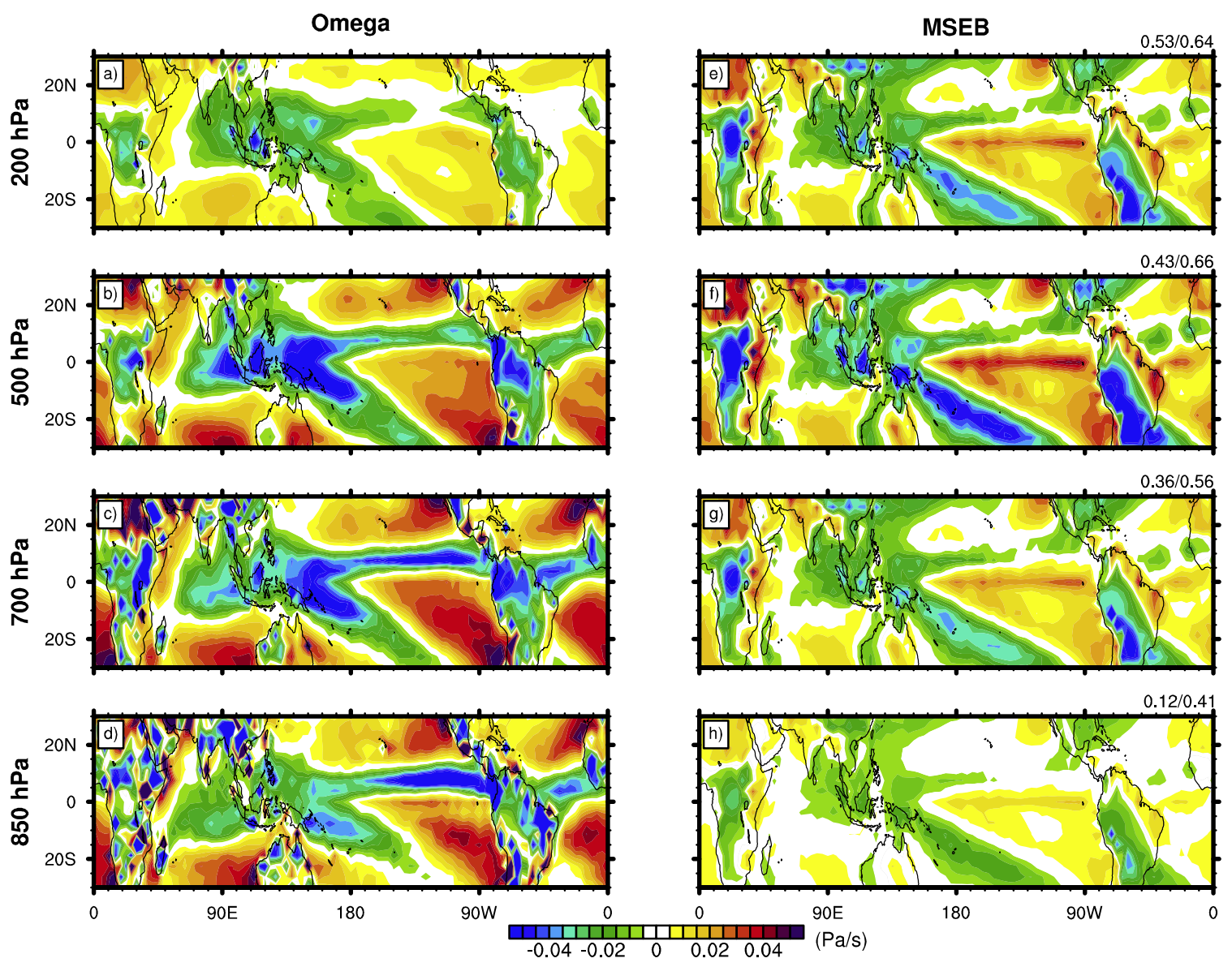

Fig. 5 Mean $\omega$ (left) vs. MSEB model estimates (right) at different pressure levels for ERA5 reanalysis. The pattern correlation values between $\omega$ and the MSEB model estimates for land (first value) and oceans are shown in the heading for each MSEB model estimate panel. 
$\omega$ at $500 \mathrm{hPa}$

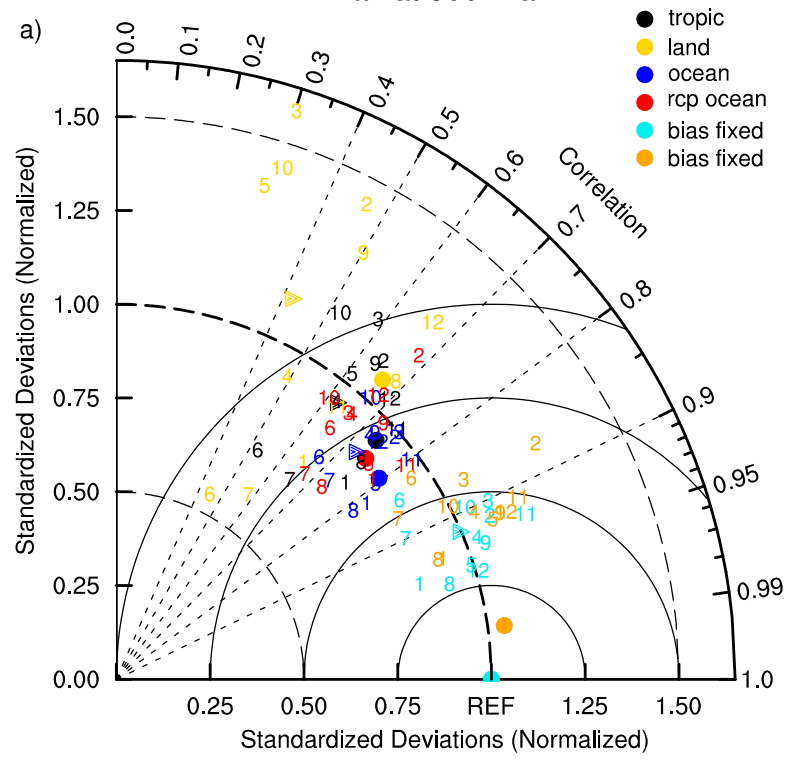

$\omega$ at different vertical levels

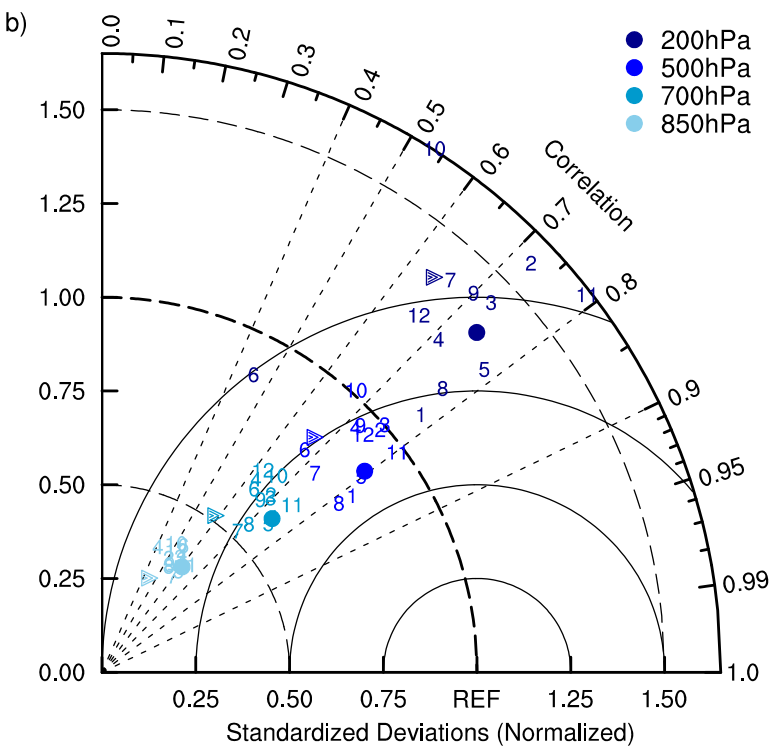

Fig. 6 Taylor diagrams of different MSEB model estimates vs. the reference $\omega$ : Left: at $500 \mathrm{hPa}$ for different regions (see legend) and for bias corrected oceans in historical (skyblue) and oceans in the RCP8.5 (orange). Right: for ocean points at different pressure levels. Symbols are: ERA5 reanalysis (triangle), individual CMIP models (numbers; see Table 1) and CMIP ensemble mean (circles). 

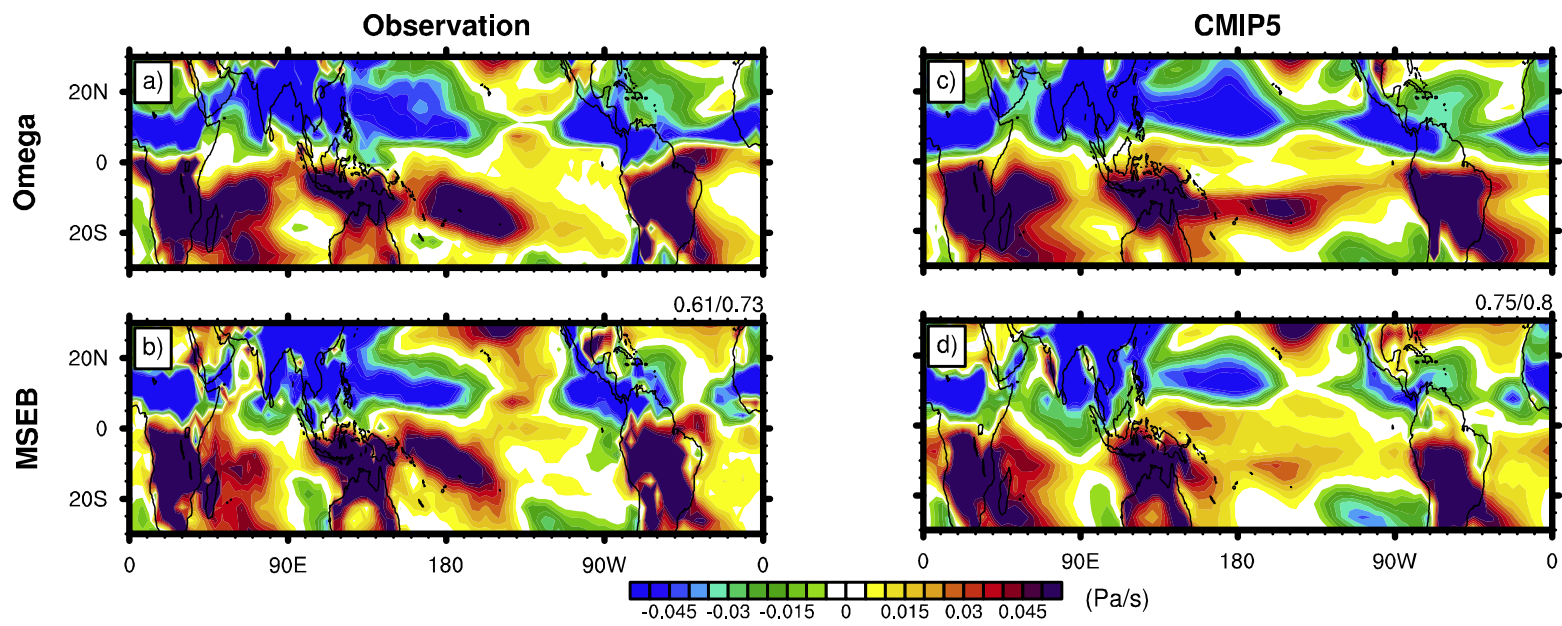

Fig. 7 Seasonal cycle $\omega$ at 500hPa in historical period (upper panels) vs. the MSEB model estimates (lower panels) for ERA5 reanalysis (left) and the ensemble mean of 12 CMIP5 models (right). The pattern correlation values between $\omega$ and the MSEB model estimates for land (first value) and oceans are shown in the heading of (b) and (d). 

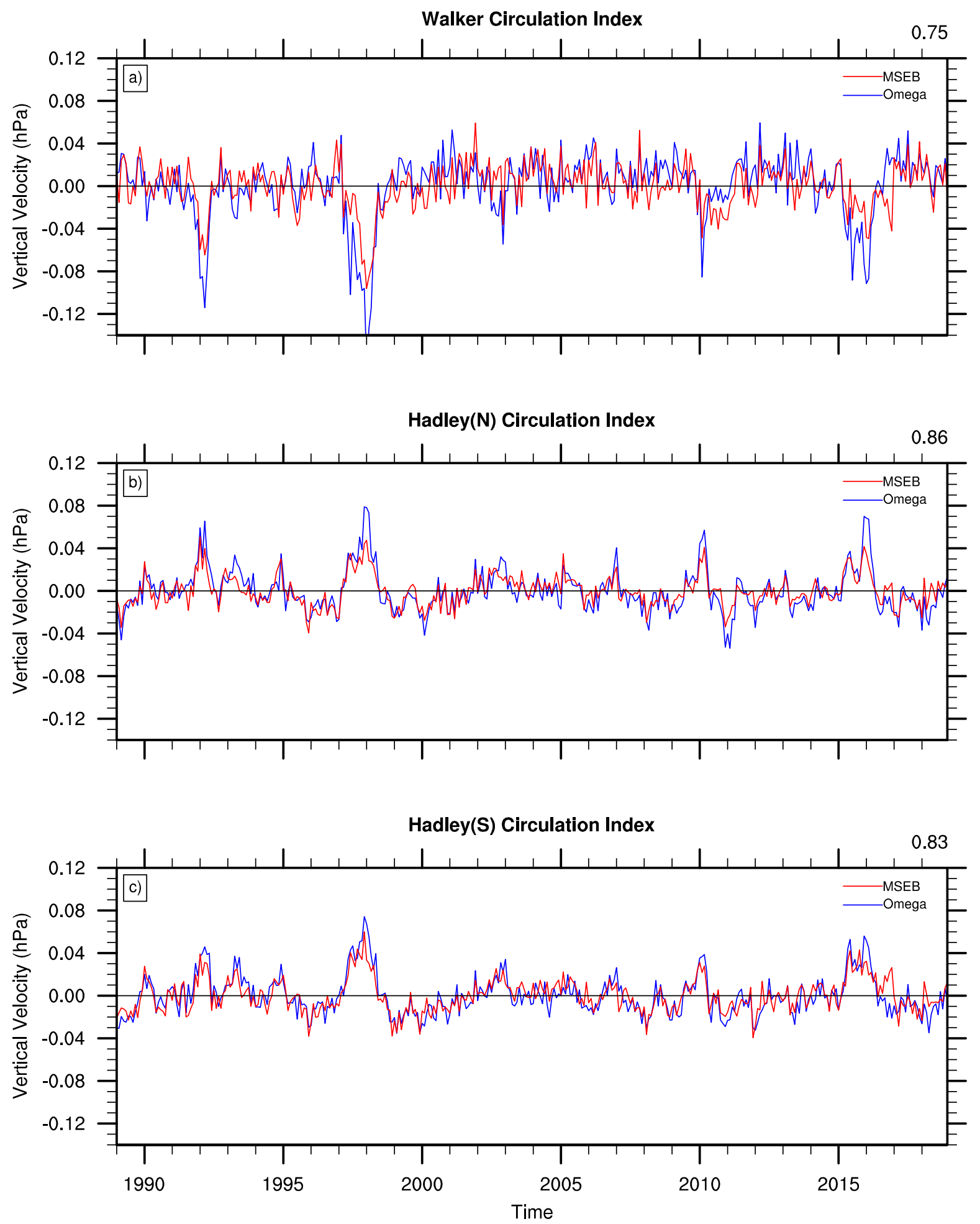

Fig. 8 Circulation index between $\omega$ at 500hPa and MSEB estimates for ERA5. (a) Walker circulation index for eastern equatorial Pacific $\left(3.75^{\circ} \mathrm{N}-3.75^{\circ} \mathrm{S}, 120^{\circ} \mathrm{E}-160^{\circ} \mathrm{E}\right)$ minus western equatorial Pacific $\left(3.75^{\circ} \mathrm{N}-3.75^{\circ} \mathrm{S}\right.$, $\left.200^{\circ} \mathrm{E}-240^{\circ} \mathrm{E}\right)$. (b) Northern Hadley circulation index for northern Pacific $\left(22.5^{\circ} \mathrm{N}-30.0^{\circ} \mathrm{N}, 150^{\circ} \mathrm{E}-251.25^{\circ} \mathrm{E}\right)$ minus equatorial Pacific $\left(3.75^{\circ} \mathrm{N}-3.75^{\circ} \mathrm{S}, 150^{\circ} \mathrm{E}-251.25^{\circ} \mathrm{E}\right)$. (c) Southern Hadley circulation index for southern Pacific $\left(22.5^{\circ} \mathrm{S}-30.0^{\circ} \mathrm{S}, 150^{\circ} \mathrm{E}-251.25^{\circ} \mathrm{E}\right)$ minus equatorial Pacific $\left(3.75^{\circ} \mathrm{N}-3.75^{\circ} \mathrm{S}, 150^{\circ} \mathrm{E}-251.25^{\circ} \mathrm{E}\right)$. The upper right value for each panel is correlation between $\omega$ and MSEB estimates. 

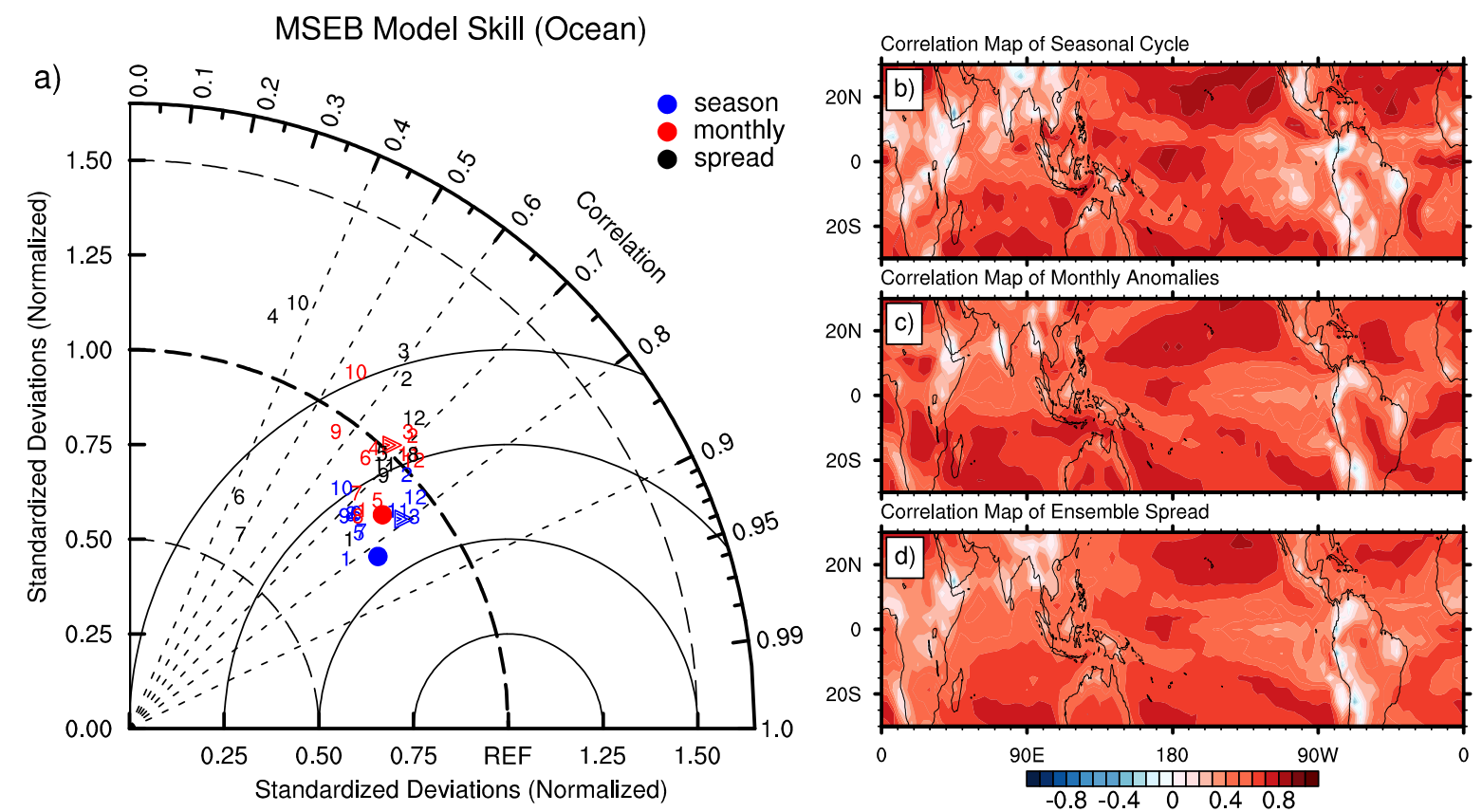

Fig. 9 (a) Taylor diagrams of MSEB model estimates vs. the reference $\omega$ at $500 \mathrm{hPa}$ for the seasonal cycle (blue), anomalous monthly mean variability (red) and for CMIP inter-model differences relative to the ensemble mean (black). Maps of local correlation values for: (b) the seasonal cycle, (c) anomalous monthly mean variability (red) and (d) for CMIP inter-model differences relative to the ensemble mean based on 12 CMIP model simulations. Blue and red ensembles in (a), maps in (b) and (c) include ERA5 estimates too. 

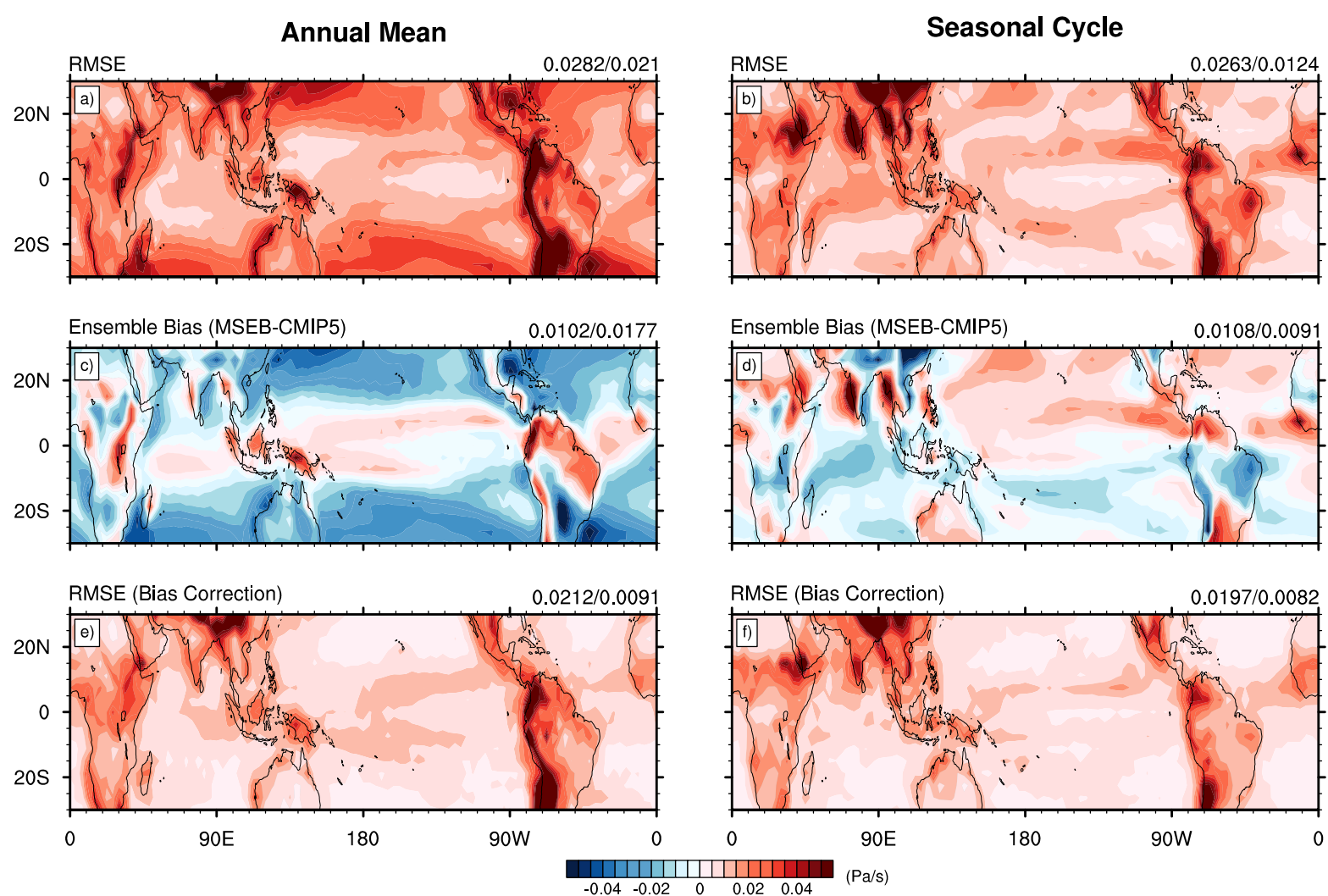

Fig. 10 (a) RMSE of the annual mean MSEB model estimates relative to $\omega$ at 500hPa for the CMIP5 ensemble mean. (b) the same for the seasonal cycle $\left(0.5^{*}(\mathrm{JJ}\right.$ A-DJF)). (c) Annual mean MSEB model estimates minus the $\omega$ at $500 \mathrm{hPa}$. (d) the same for the seasonal cycle difference. (e) RMSE of the annual mean as in (a), but with the mean bias of (c) removed. (f) RMSE of the seasonal cycle as in (b), but with the mean bias of (d) removed. The numbers in the headings are the mean absolute values for land (first value) and ocean points. 

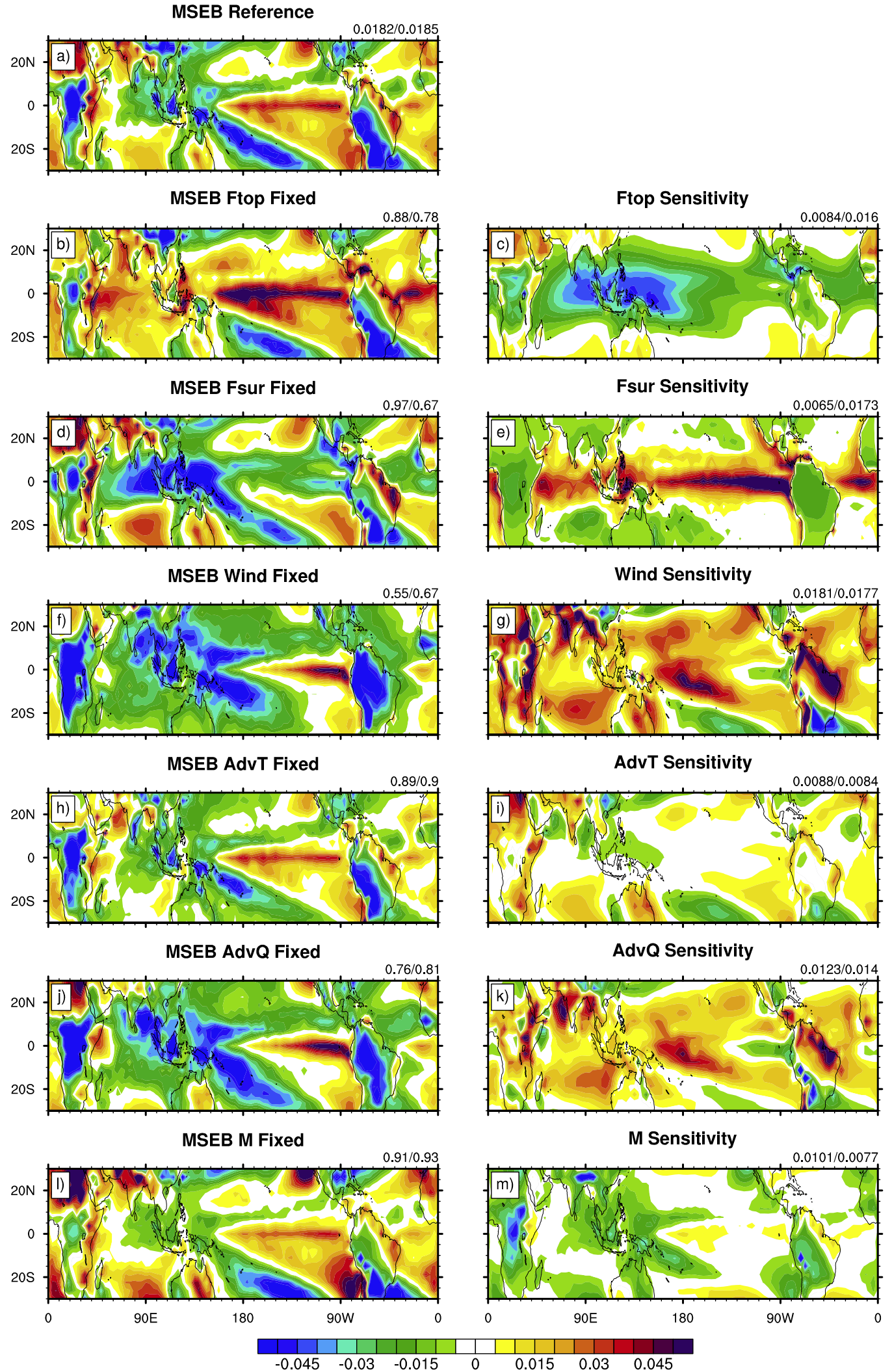

Fig. 11 Sensitivity estimates for the MSEB model based on the mean ERA5. (a) $\omega$ at 500hPa MSEB estimate. The domain mean RMS for land (first value) and ocean points are shown in the heading. Left column: MSEB estimates with a specific term fixed (see heading of each panel). The spatial correlation values of each panel with panel (a) for land (first value) and ocean points are shown in the heading of each panel. Right column: differences 
of panel (a) minus the left panel in each row. The domain mean RMSE between (a) and each plot in the left column for land (first value) and ocean points are shown in the heading.

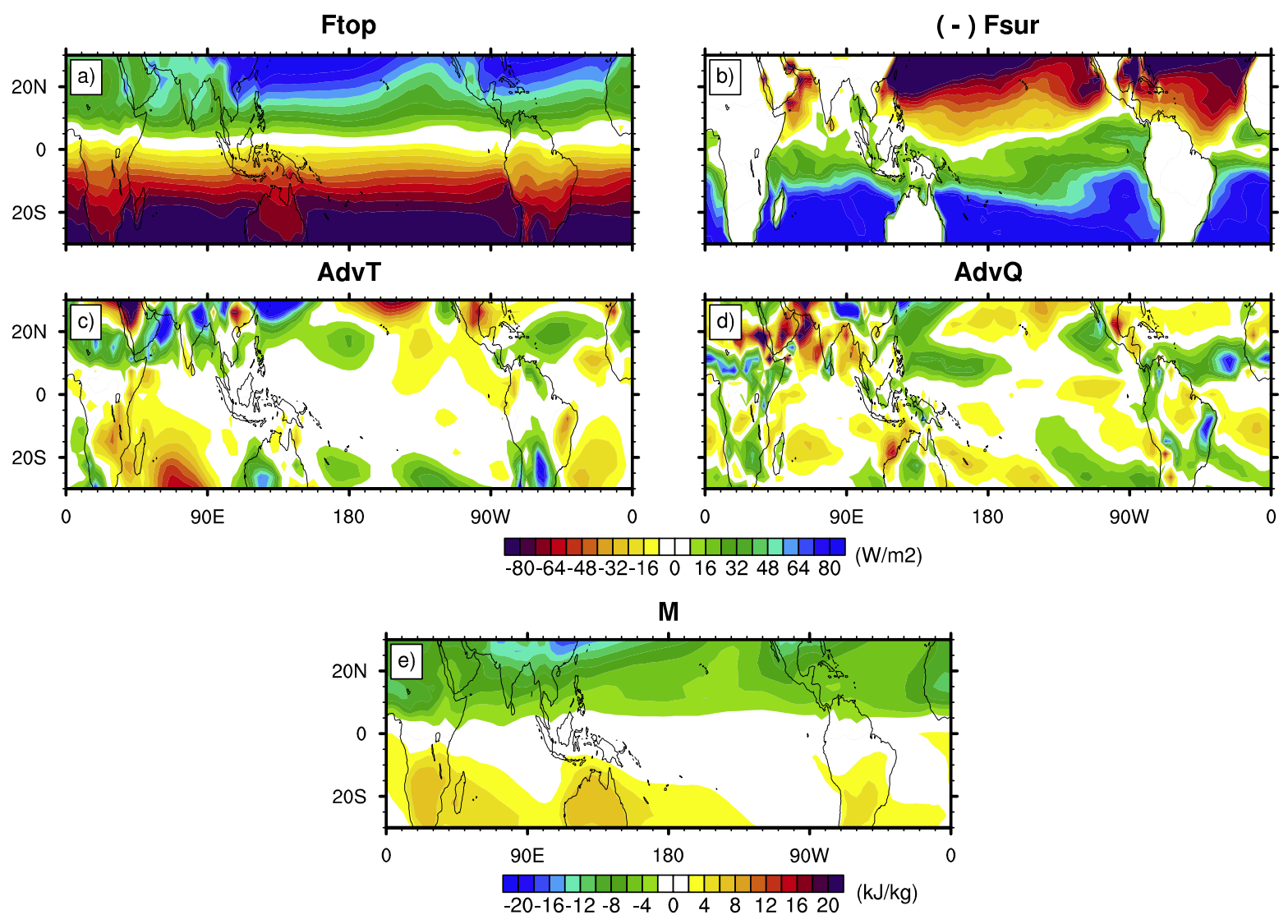

Fig. 12 Mean seasonal cycle $(0.5 *(J J A-D J F))$ of MSEB model estimate from ERA5 reanalysis. (a)-(e) RHS term of Eq. [10]: (a) $F_{\text {top }}$, (b) $-F_{\text {sur }}$, (c) $-<\mathbf{v} \cdot \nabla\left(L_{v} T\right)>$, (d) $-<\mathbf{v} \cdot \nabla\left(L_{v} q\right)>$ and (e) $-\mathrm{g}<\Omega \partial_{p} h>$. 


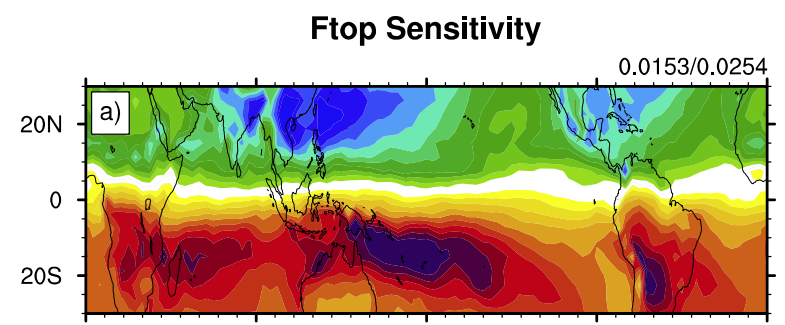

Wind Sensitivity

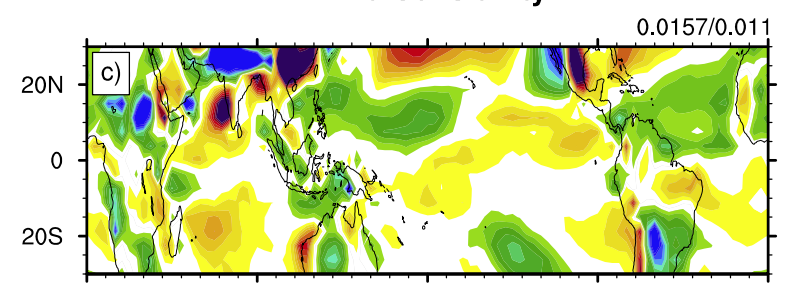

AdvQ Sensitivity

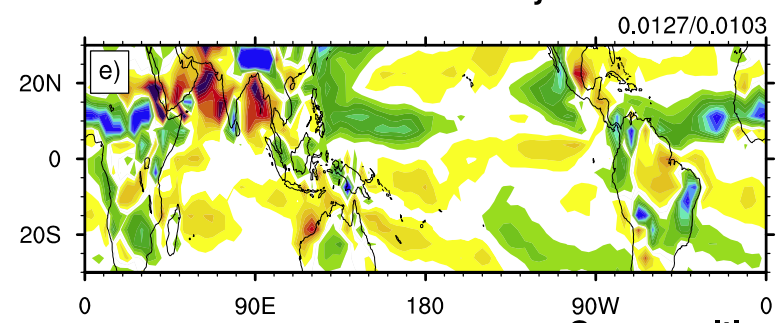

Superposition: $a)+(b)+c)+d)+e)+f$ )
Fsur Sensitivity

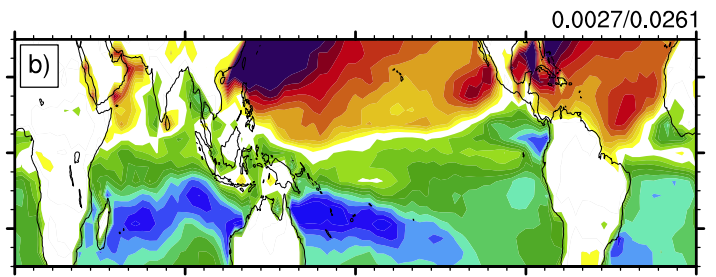

AdvT Sensitivity

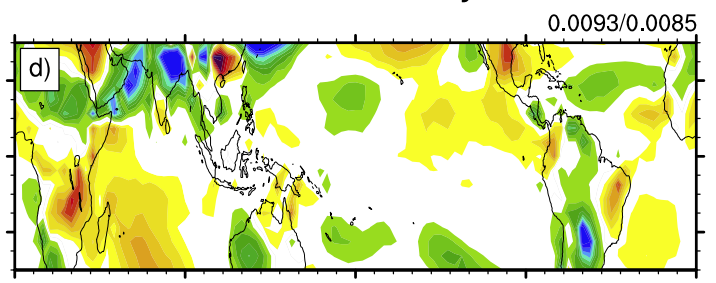

M Sensitivity

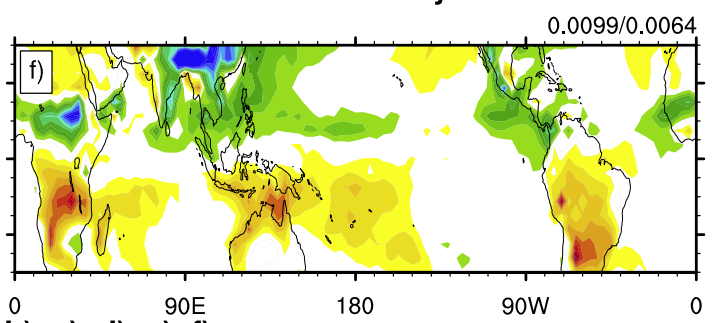

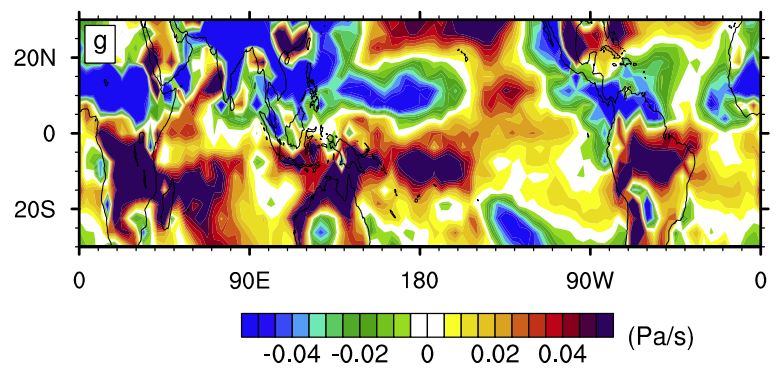

Fig. 13 Sensitivities of the mean seasonal cycle in of $\omega$ at 500hPa of the MSEB model to different forcing terms (see heading in panels (a) to (f)). (g) Sum of (a) to (f). (a). (a)-(f) are obtained by following the same procedures as the right column in Fig. 11. The RMSE for each panel for land (first value) and ocean points are shown in the heading of each panel (a) to (f). See text for details on the estimation of sensitivities. 

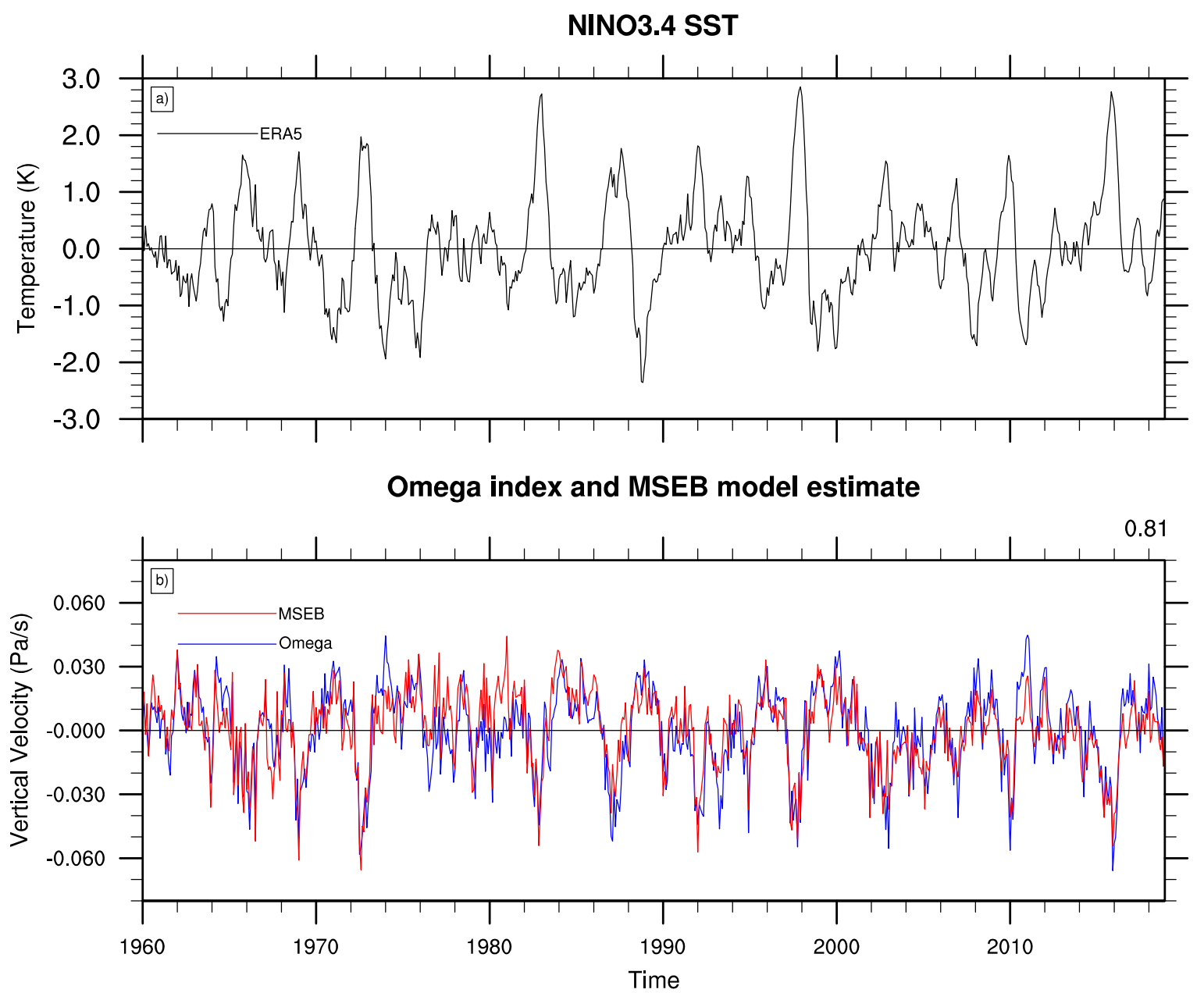

Fig. 14 (a) Monthly mean time series of Nino3.4 $\left(3.75^{\circ} \mathrm{N}-3.75^{\circ} \mathrm{S}, 170^{\circ} \mathrm{W}-120^{\circ} \mathrm{W}\right) \mathrm{SST}$. (b) Monthly mean time series of $\omega$ at $500 \mathrm{hpa}$ in the central equatorial Pacific region $\left(3.75^{\circ} \mathrm{N}-3.75^{\circ} \mathrm{S}, 150^{\circ} \mathrm{E}-150^{\circ} \mathrm{W}\right)$ and the corresponding MSEB model estimate. The correlation between $\omega$ at $500 \mathrm{hPa}$ and the MSEB estimate for ERA5 period is shown in the heading of (b). 

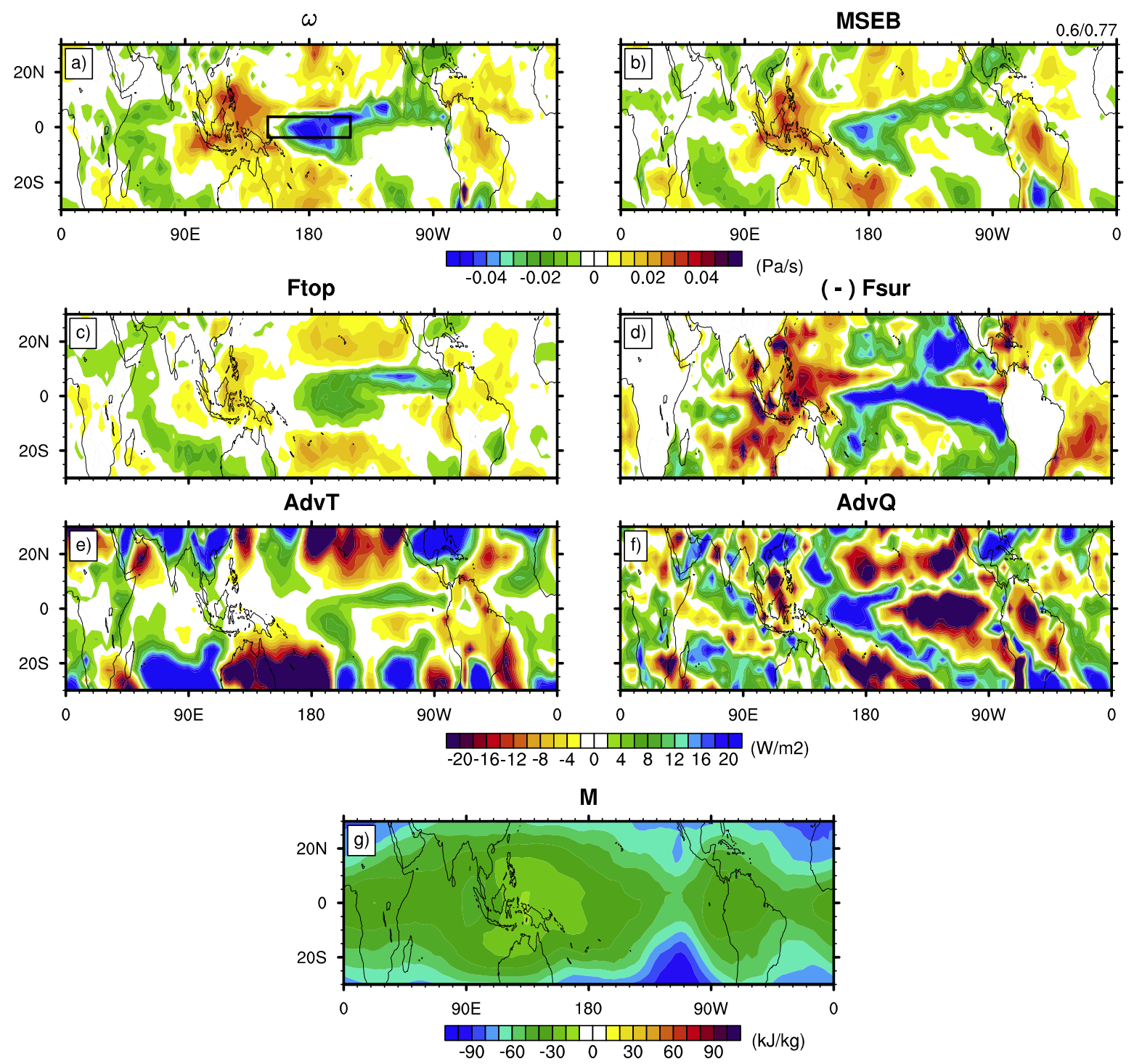

Fig. 15 (a) El Nino composites of $\omega$ at 500hPa from ERA5 reanalysis. (b) Corresponding MSEB model estimate. (c)-(g) RHS term of Eq. [10]: (c) $F_{\text {top }}$, (d) $-F_{\text {sur }}$, (e) $-<\mathbf{v} \cdot \nabla\left(L_{v} T\right)>$, (f) $-<\mathbf{v} \cdot \nabla\left(L_{v} q\right)>$ and (g) $-\mathrm{g}<$ $\Omega \partial_{p} h>$. The black box in (a) outlining the omega index mentioned in Fig. 14(b). The pattern correlation values between $\omega$ and the MSEB model estimates for land (first value) and oceans are shown in the heading of (b). 

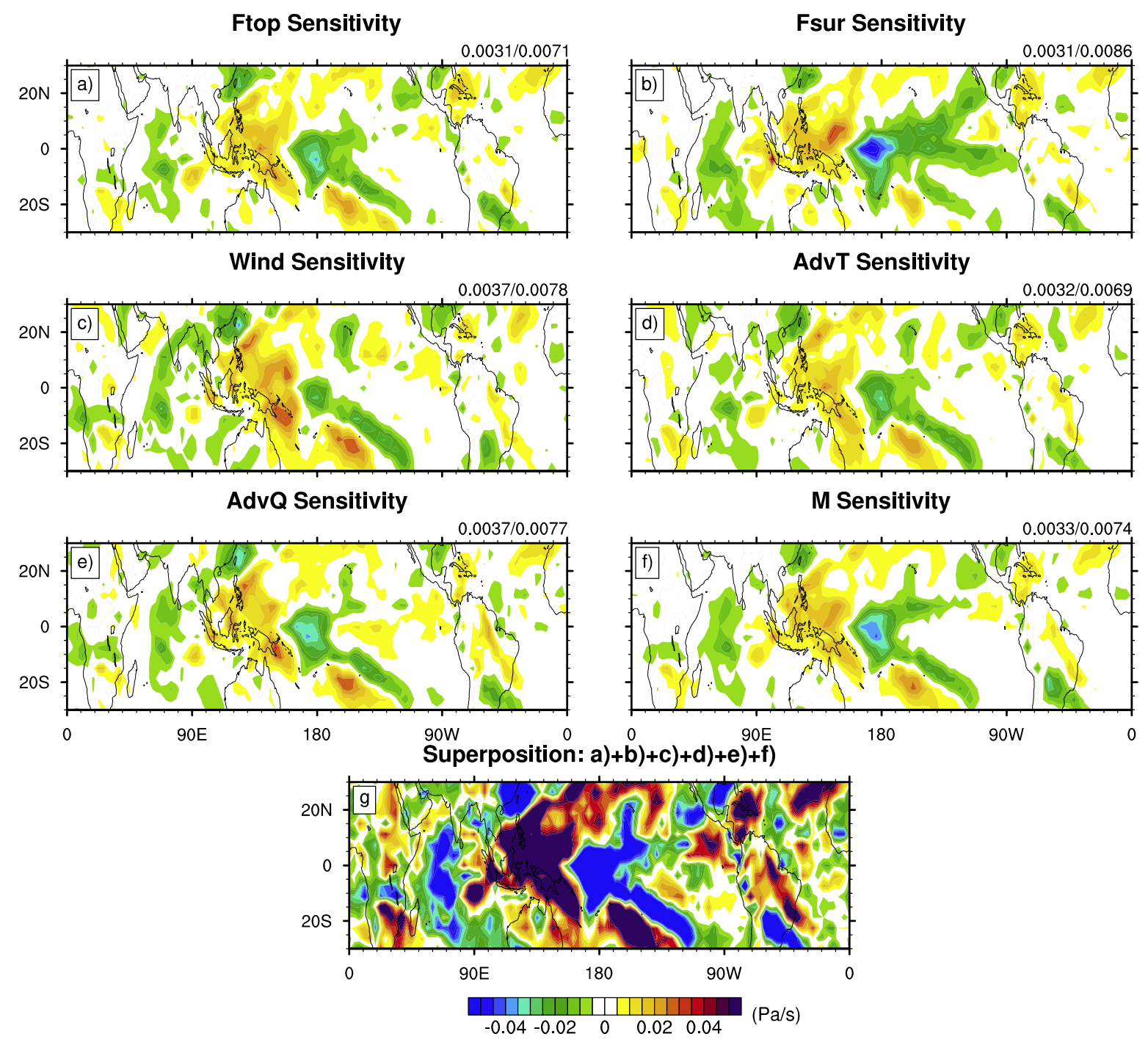

Fig. 16 Sensitivities of the El Nino composites of $\omega$ at 500hpa of the MSEB model to different forcing terms (see heading in panels (a) to (f)). (g) Sum of (a) to (f). (a)-(f) are obtained by following the same procedures as the right column in Fig.11. The RMSE for each panel for land (first value) and ocean points are shown in the heading of each panel (a) to (f). See text for details on the estimation of sensitivities. 


\section{Figures}
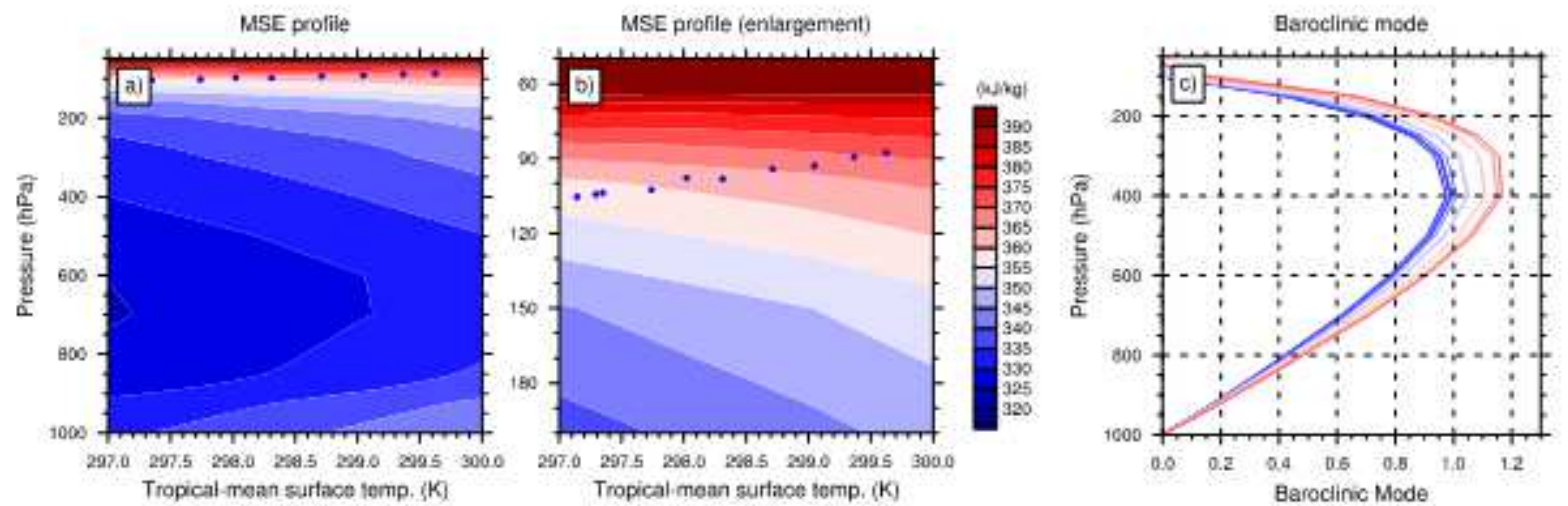

\section{Figure 1}

(a) Vertical profile of tropical-mean MSE (h) as function of the mean tropical surface temperature in the RCP8.5 scenario of bcc-csm1-1 simulations. Tropopause height ( $\left.P_{-} T\right)$ estimates are shown with blue dots. (b) Partial enlargement of (a) from $200 \mathrm{hPa}$ to $50 \mathrm{hPa}$. (c) Baroclinic mode profile in relation to different tropical-mean surface temperature color coded from coldest (blue) to warmest (red). Profiles are computed based on bcc-csm1-1 RCP8.5 scenario from 2009 to 2099, each curve represent yearly baroclinic mode and the time interval between each curve is 10 -year.

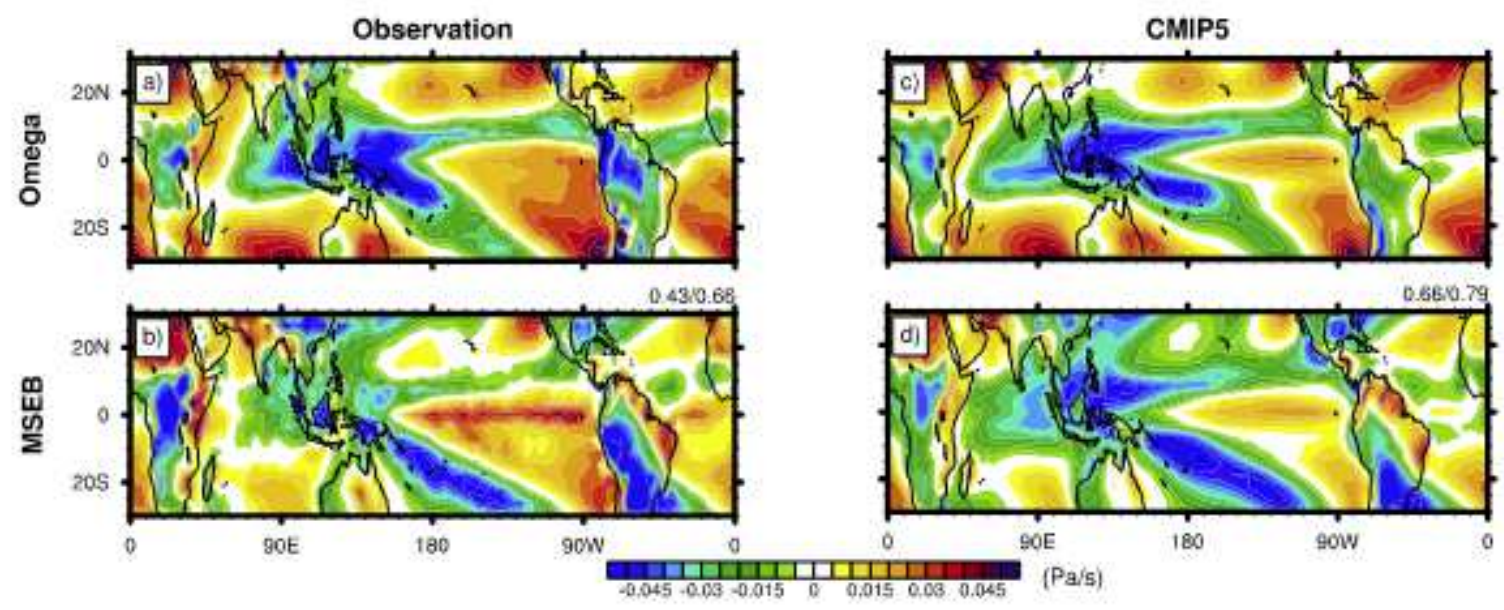

Figure 2

Mean $\omega$ at $500 \mathrm{hPa}$ in historical period (upper panels) vs. the MSEB model estimates (lower panels) for ERA5 reanalysis (left) and the ensemble mean of 12 CMIP5 models (right). The pattern correlation values between $\omega$ and the MSEB model estimates for land (first value) and oceans are shown in the heading of (b) and (d). Note: The designations employed and the presentation of the material on this map do not imply the expression of any opinion whatsoever on the part of Research Square concerning the legal status of any country, territory, city or area or of its authorities, or concerning the delimitation of its frontiers or boundaries. This map has been provided by the authors. 

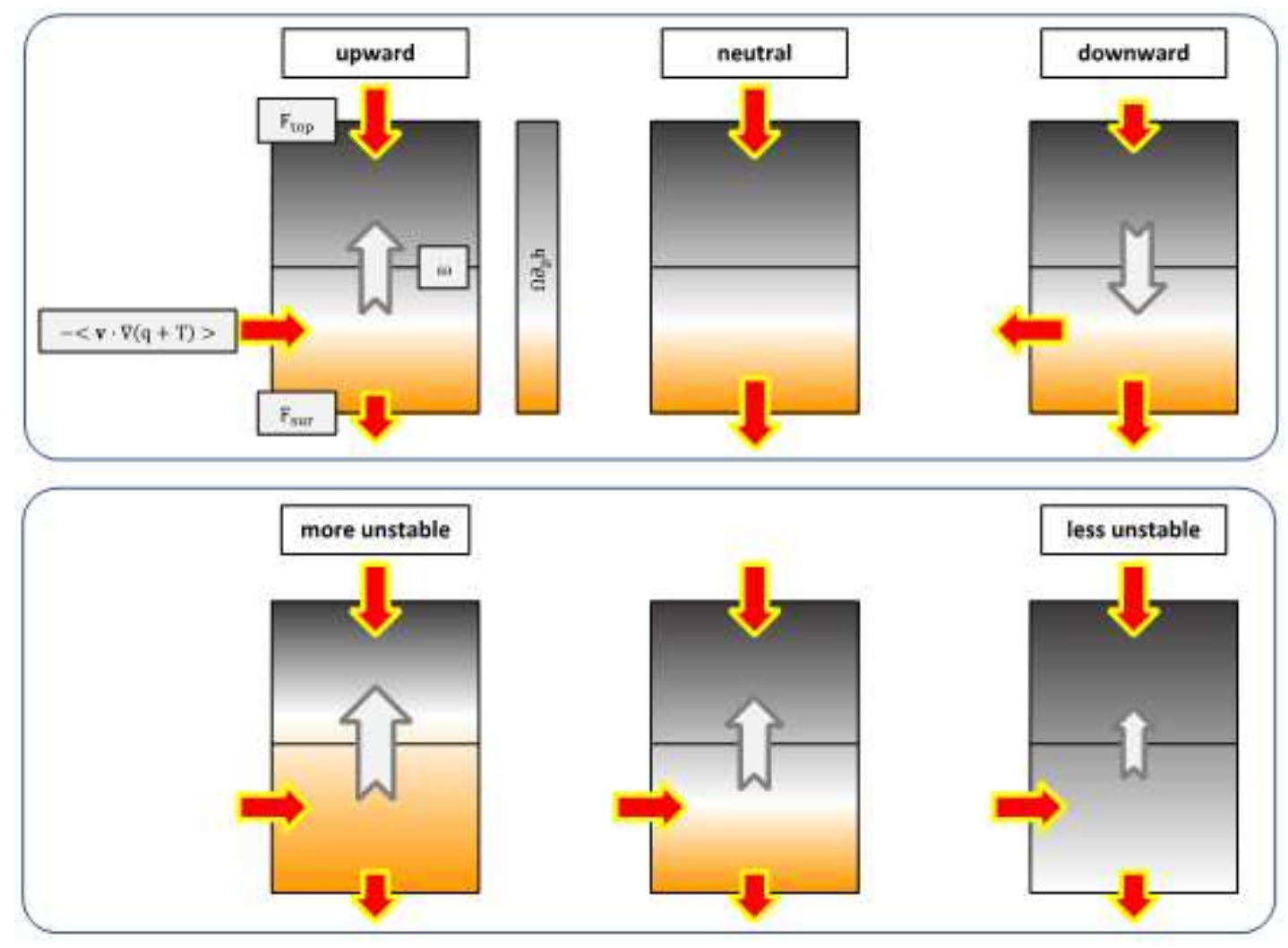

Figure 3

Sketch illustrating the MSEB model. Upper panels illustrate the vertical motion (gray arrow) for three different forcings (red arrows), but with the same background stability profile ( $\Omega \partial_{-} p \mathrm{~h}$ ). Lower panels illustrate the vertical motion for identical forcing terms, but different background stability profiles (left: less stable; right: more stable). 

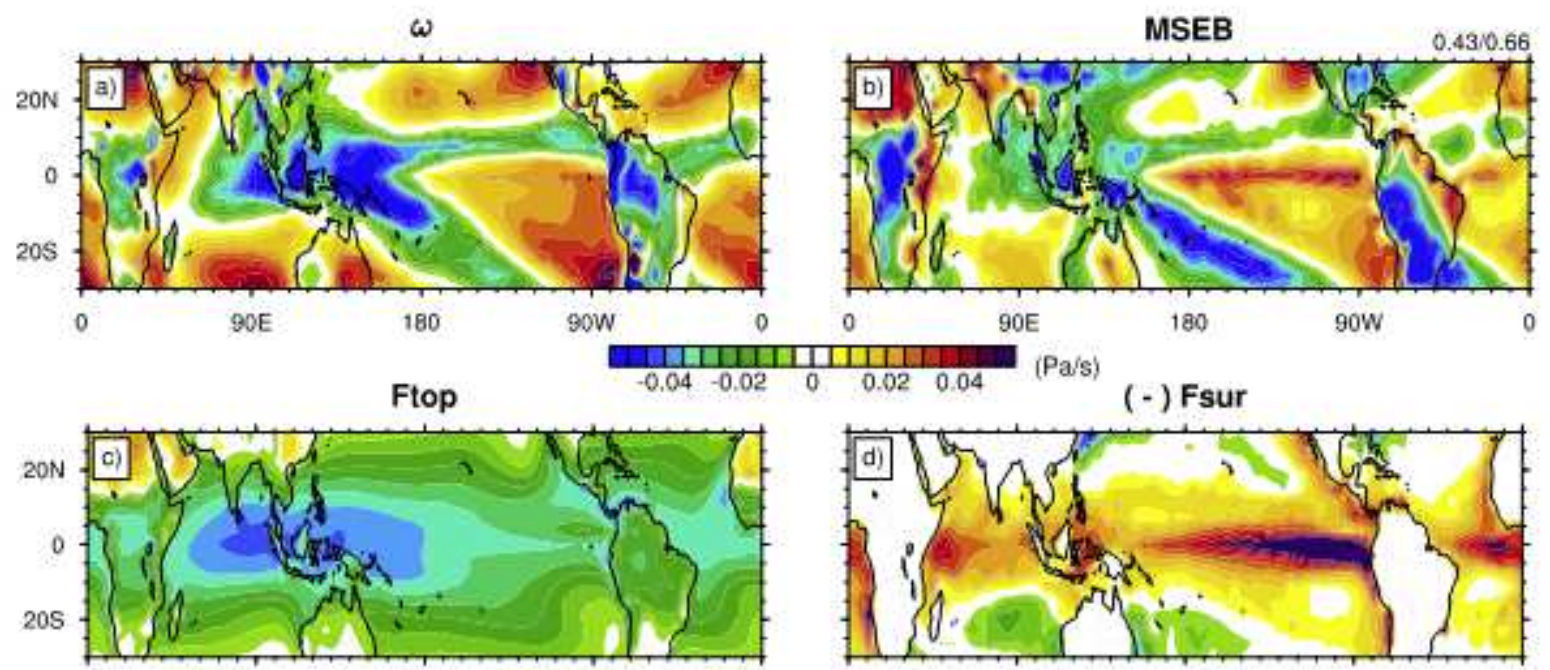

AdvT

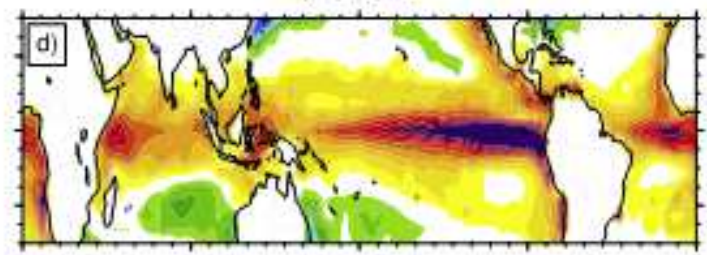

Advo

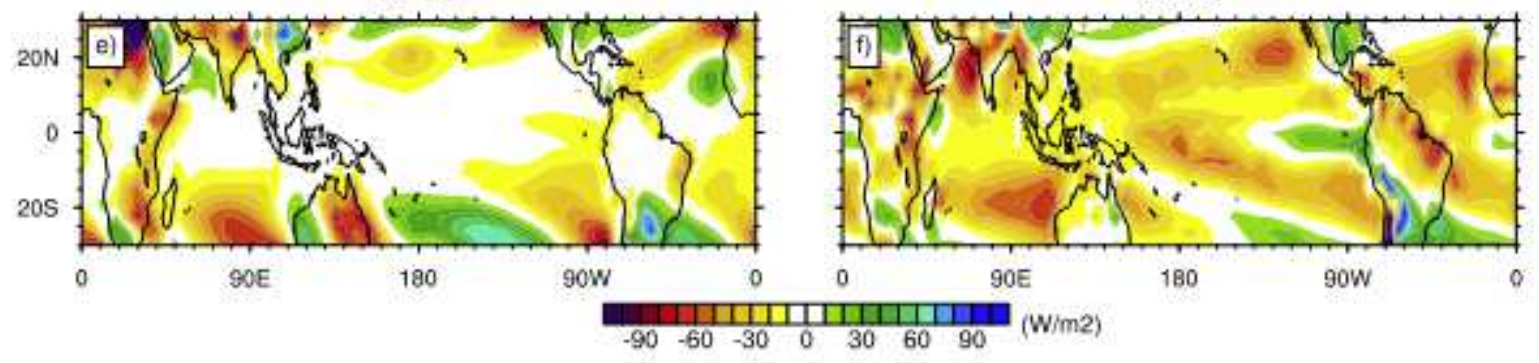

M

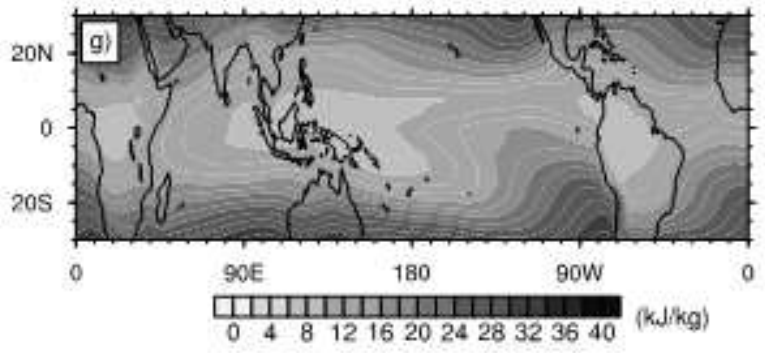

Figure 4

Please see the Manuscript PDF file for the complete figure caption. Note: The designations employed and the presentation of the material on this map do not imply the expression of any opinion whatsoever on the part of Research Square concerning the legal status of any country, territory, city or area or of its authorities, or concerning the delimitation of its frontiers or boundaries. This map has been provided by the authors. 

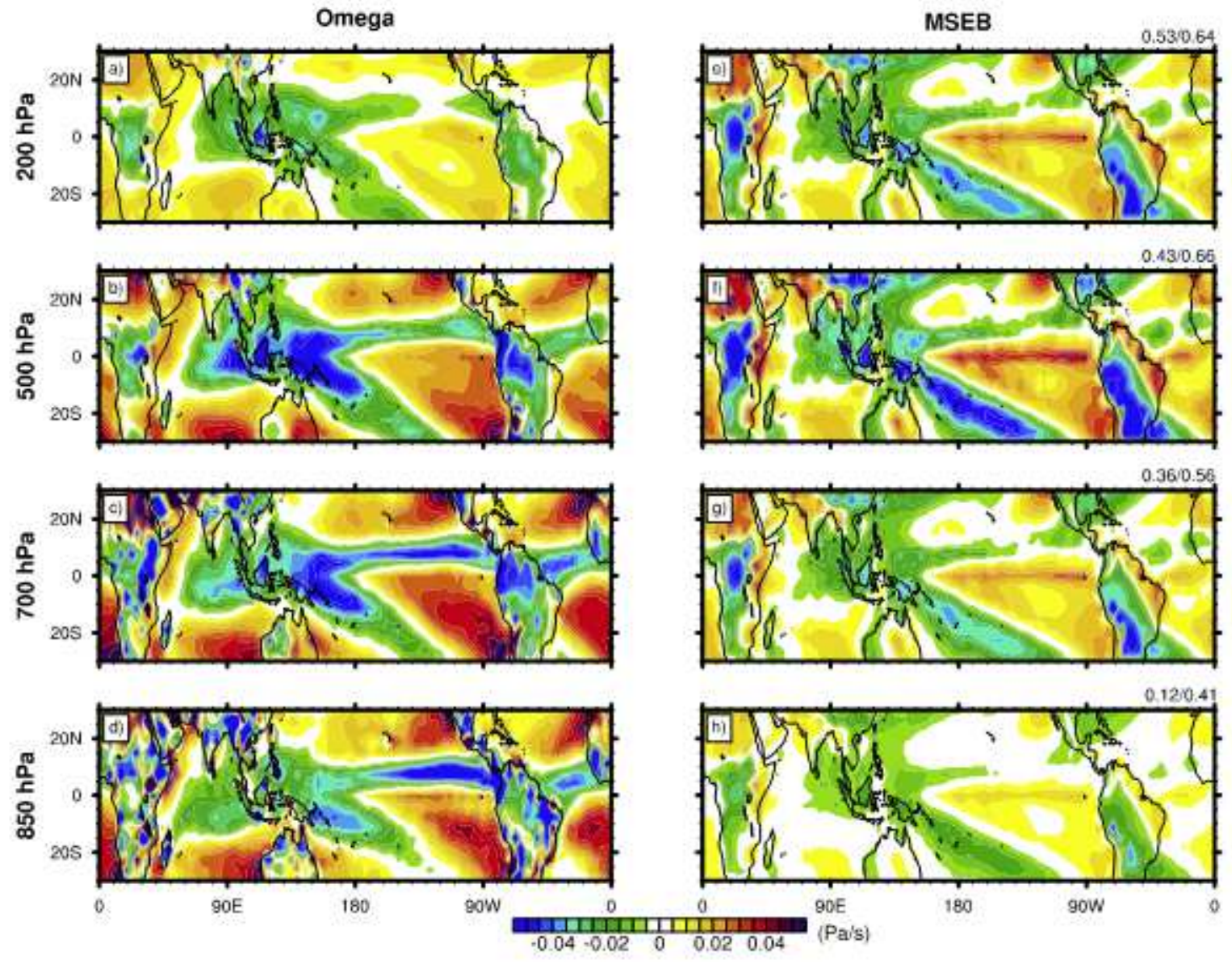

Figure 5

Mean $\omega$ (left) vs. MSEB model estimates (right) at different pressure levels for ERA5 reanalysis. The pattern correlation values between $\omega$ and the MSEB model estimates for land (first value) and oceans are shown in the heading for each MSEB model estimate panel. Note: The designations employed and the presentation of the material on this map do not imply the expression of any opinion whatsoever on the part of Research Square concerning the legal status of any country, territory, city or area or of its authorities, or concerning the delimitation of its frontiers or boundaries. This map has been provided by the authors. 

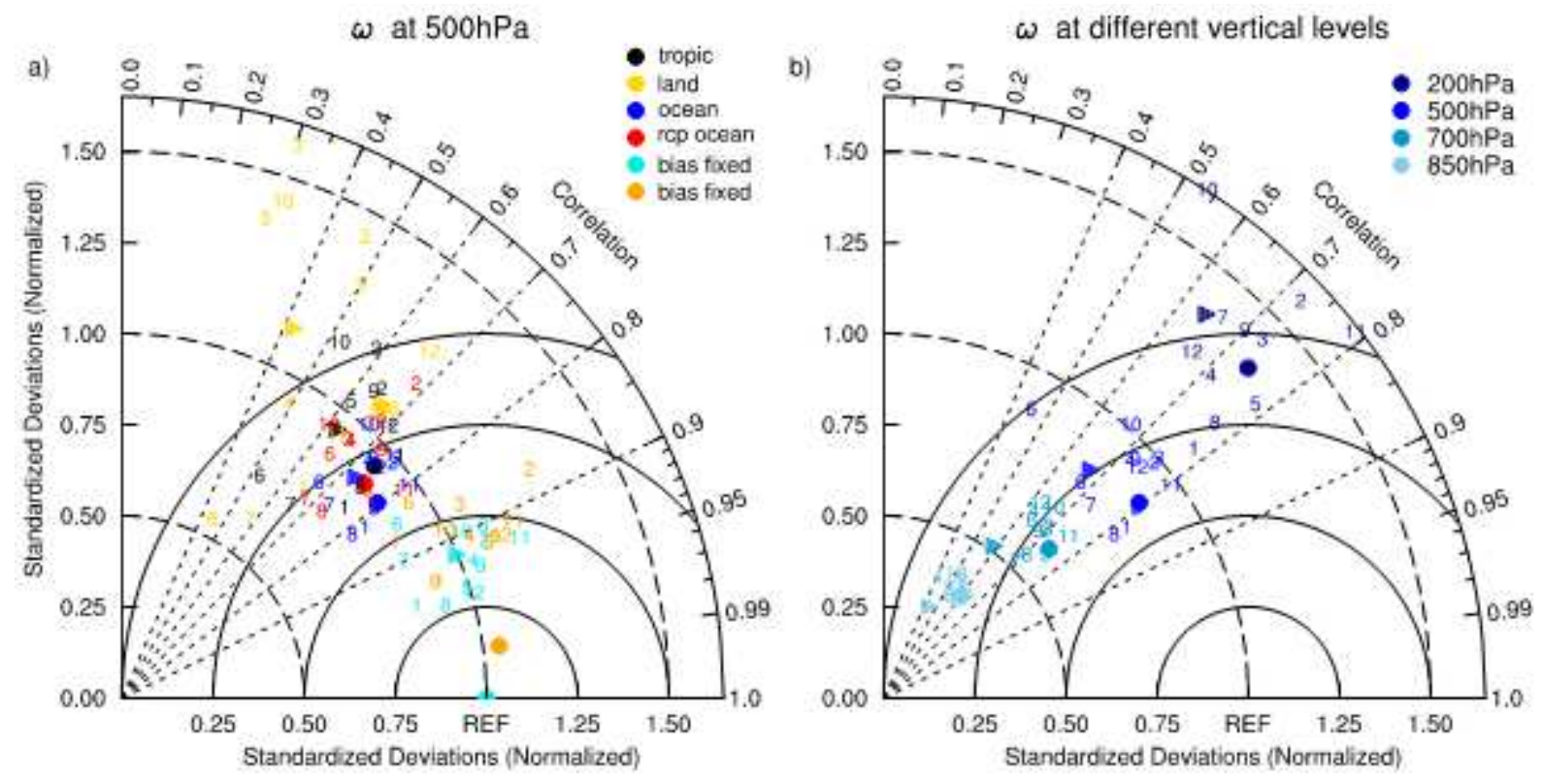

Figure 6

Taylor diagrams of different MSEB model estimates vs. the reference $\omega$ : Left: at $500 \mathrm{hPa}$ for different regions (see legend) and for bias corrected oceans in historical (skyblue) and oceans in the RCP8.5 (orange). Right: for ocean points at different pressure levels. Symbols are: ERA5 reanalysis (triangle), individual CMIP models (numbers; see Table 1) and CMIP ensemble mean (circles).



Figure 7

Seasonal cycle $\omega$ at $500 \mathrm{hPa}$ in historical period (upper panels) vs. the MSEB model estimates (lower panels) for ERA5 reanalysis (left) and the ensemble mean of 12 CMIP5 models (right). The pattern correlation values between $\omega$ and the MSEB model estimates for land (first value) and oceans are shown in the heading of (b) and (d). Note: The designations employed and the presentation of the material on this map do not imply the expression of any opinion whatsoever on the part of Research Square concerning the legal status of any country, territory, city or area or of its authorities, or concerning the delimitation of its frontiers or boundaries. This map has been provided by the authors. 

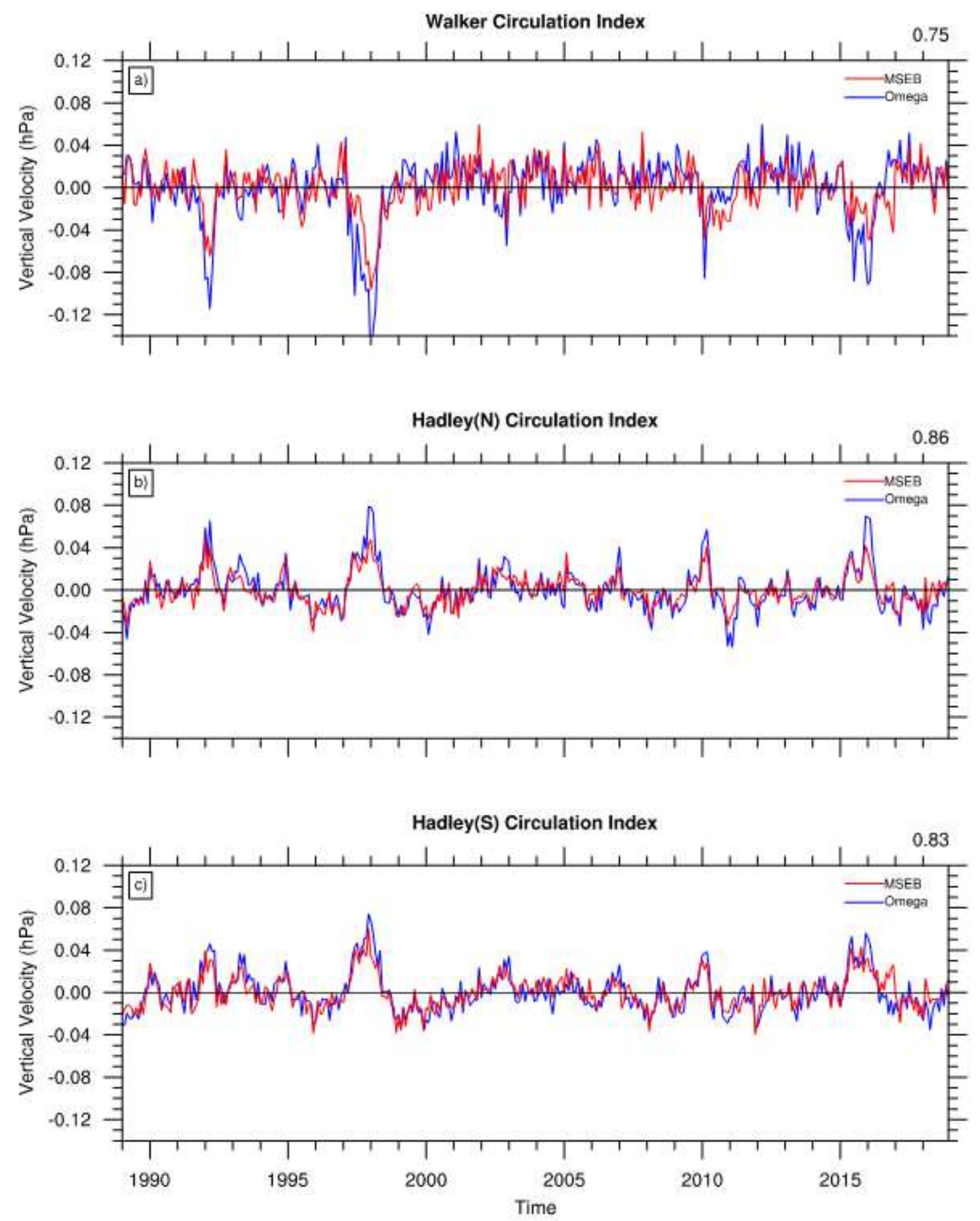

Figure 8

Circulation index between $\omega$ at 500hPa and MSEB estimates for ERA5. (a) Walker circulation index for eastern equatorial Pacific $\left(3.75^{\circ} \mathrm{N}-3.75^{\circ} \mathrm{S}, 120^{\circ} \mathrm{E}-160^{\circ} \mathrm{E}\right)$ minus western equatorial Pacific $\left(3.75^{\circ} \mathrm{N}-3.75^{\circ} \mathrm{S}\right.$, $\left.200^{\circ} \mathrm{E}-240^{\circ} \mathrm{E}\right)$. (b) Northern Hadley circulation index for northern Pacific $\left(22.5^{\circ} \mathrm{N}-30.0^{\circ} \mathrm{N}, 150^{\circ} \mathrm{E}-251.25^{\circ} \mathrm{E}\right)$ minus equatorial Pacific $\left(3.75^{\circ} \mathrm{N}-3.75^{\circ} \mathrm{S}, 150^{\circ} \mathrm{E}-251.25^{\circ} \mathrm{E}\right)$. (c) Southern Hadley circulation index for 
southern Pacific $\left(22.5^{\circ} \mathrm{S}-30.0^{\circ} \mathrm{S}, 150^{\circ} \mathrm{E}-251.25^{\circ} \mathrm{E}\right)$ minus equatorial Pacific $\left(3.75^{\circ} \mathrm{N}-3.75^{\circ} \mathrm{S}, 150^{\circ} \mathrm{E}-\right.$ $\left.251.25^{\circ} \mathrm{E}\right)$. The upper right value for each panel is correlation between $\omega$ and MSEB estimates.
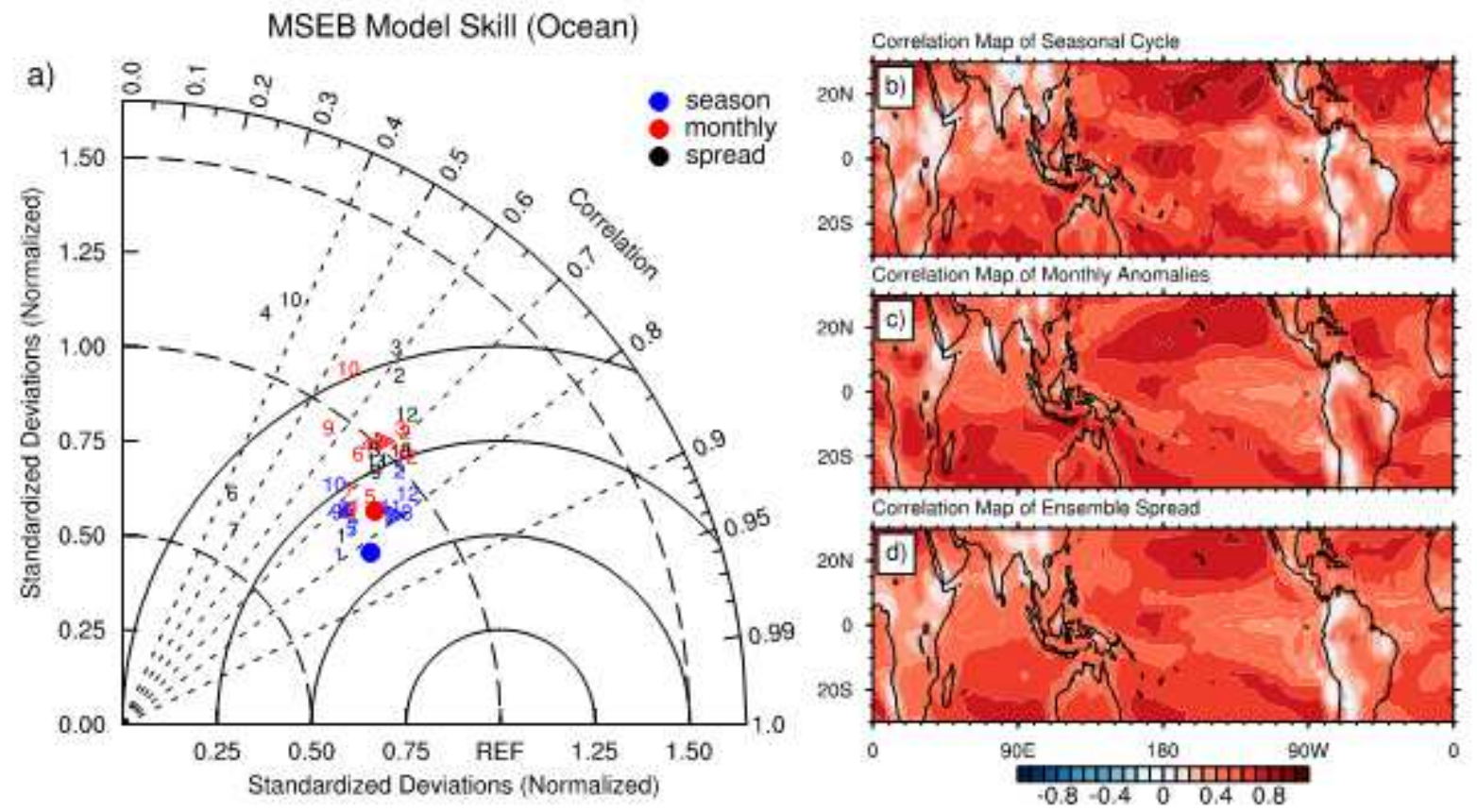

Figure 9

(a) Taylor diagrams of MSEB model estimates vs. the reference $\omega$ at $500 \mathrm{hPa}$ for the seasonal cycle (blue), anomalous monthly mean variability (red) and for CMIP inter-model differences relative to the ensemble mean (black). Maps of local correlation values for: (b) the seasonal cycle, (c) anomalous monthly mean variability (red) and (d) for CMIP inter-model differences relative to the ensemble mean based on 12 CMIP model simulations. Blue and red ensembles in (a), maps in (b) and (c) include ERA5 estimates too. Note: The designations employed and the presentation of the material on this map do not imply the expression of any opinion whatsoever on the part of Research Square concerning the legal status of any country, territory, city or area or of its authorities, or concerning the delimitation of its frontiers or boundaries. This map has been provided by the authors. 

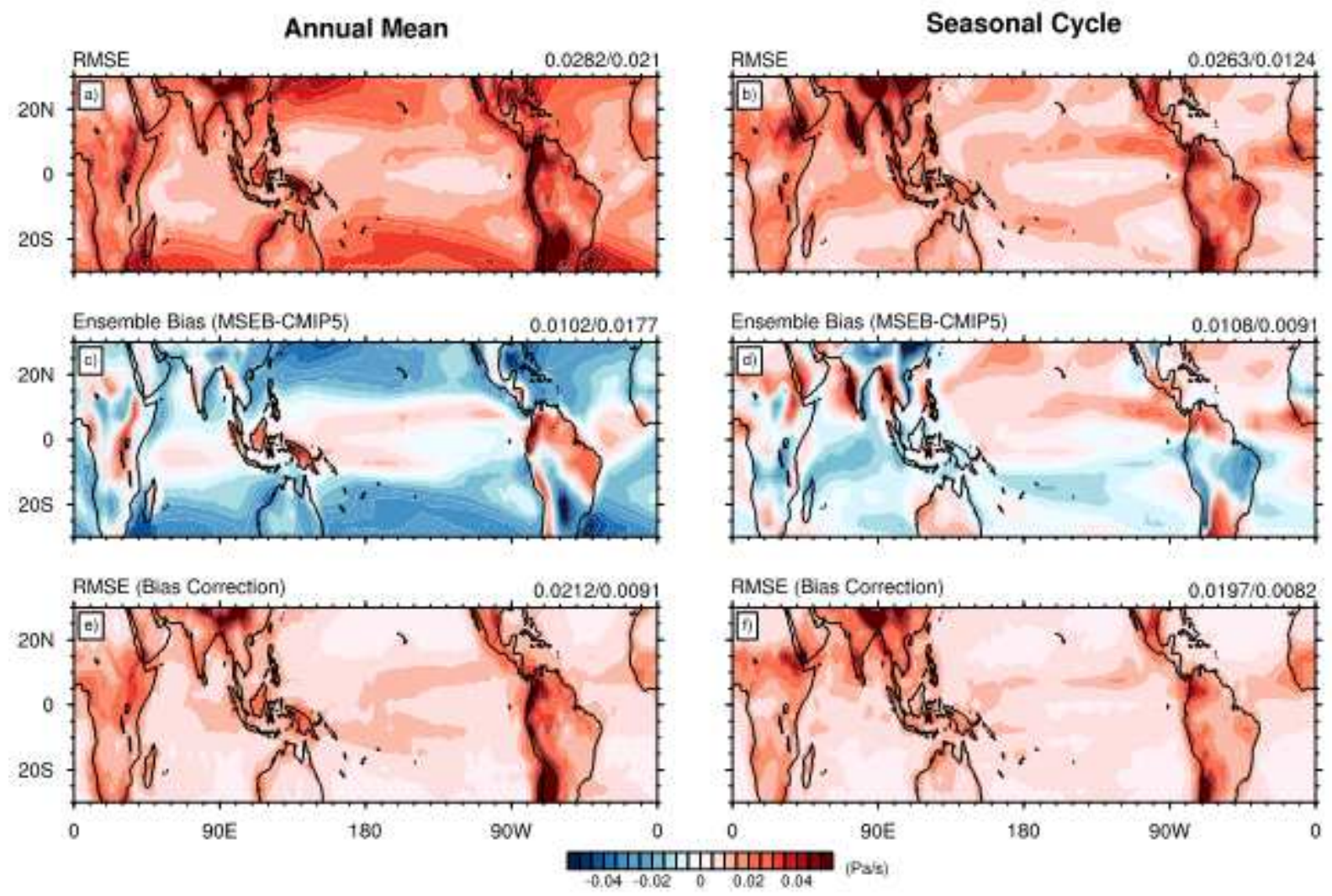

Figure 10

(a) RMSE of the annual mean MSEB model estimates relative to $\omega$ at $500 \mathrm{hPa}$ for the CMIP5 ensemble mean. (b) the same for the seasonal cycle (0.5*(JJA-DJF)). (c) Annual mean MSEB model estimates minus the $\omega$ at $500 \mathrm{hPa}$. (d) the same for the seasonal cycle difference. (e) RMSE of the annual mean as in (a), but with the mean bias of (c) removed. (f) RMSE of the seasonal cycle as in (b), but with the mean bias of (d) removed. The numbers in the headings are the mean absolute values for land (first value) and ocean points. Note: The designations employed and the presentation of the material on this map do not imply the expression of any opinion whatsoever on the part of Research Square concerning the legal status of any country, territory, city or area or of its authorities, or concerning the delimitation of its frontiers or boundaries. This map has been provided by the authors. 

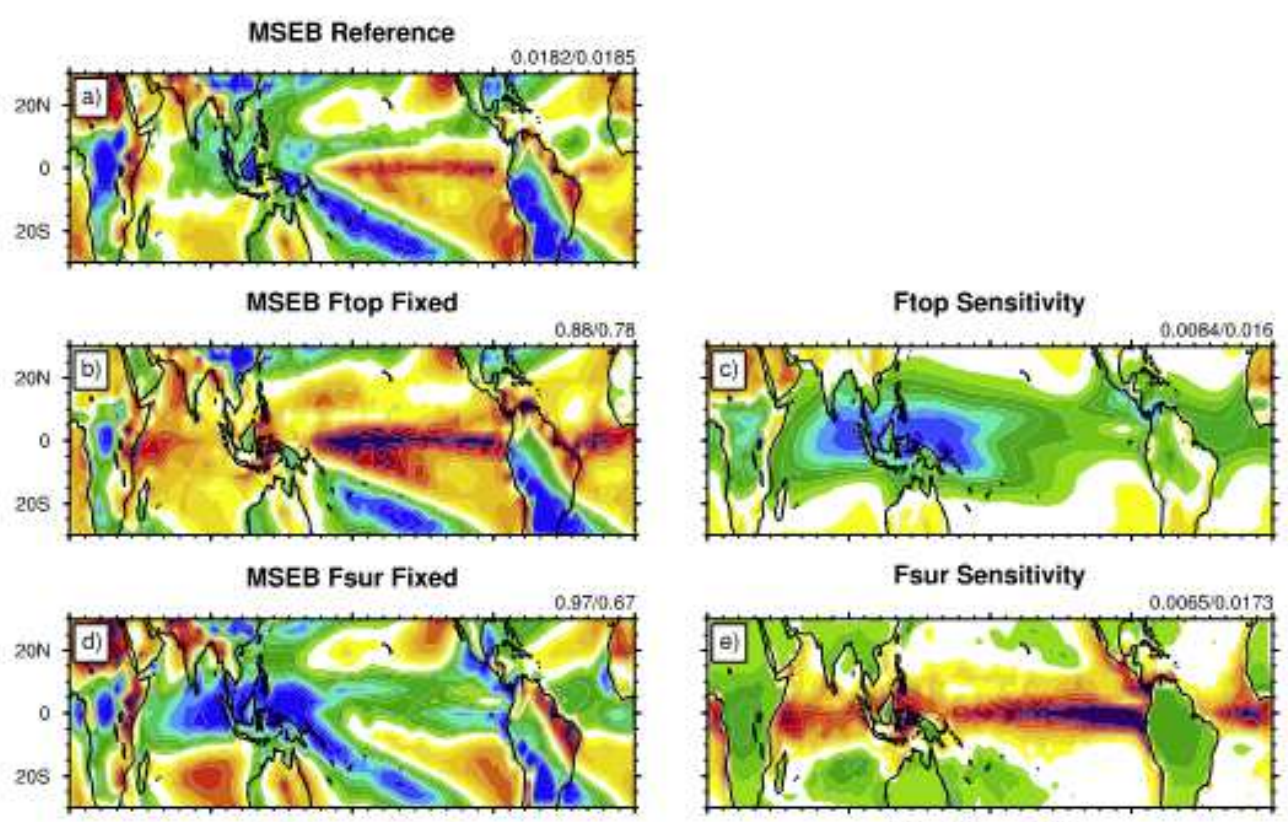

Fsur Sensitivity

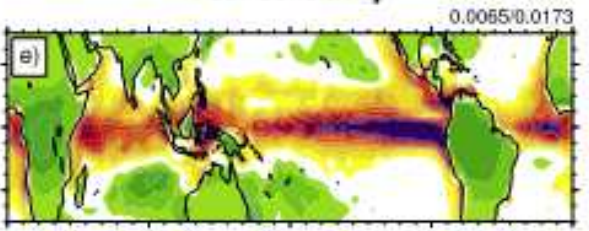

MSEB Wind Fixed

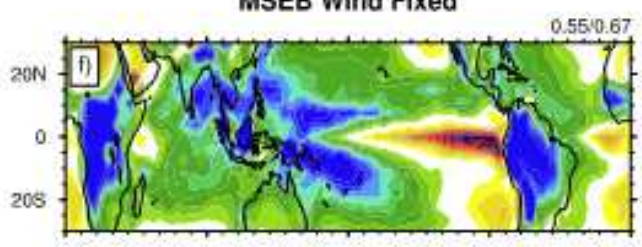

Wind Sensitivity

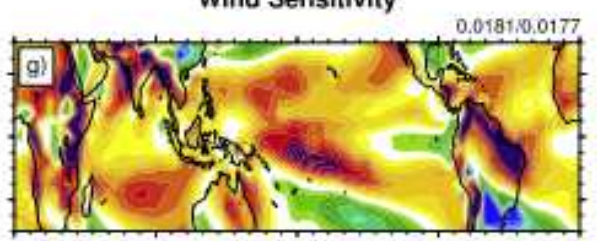

AdvT Sensitivity
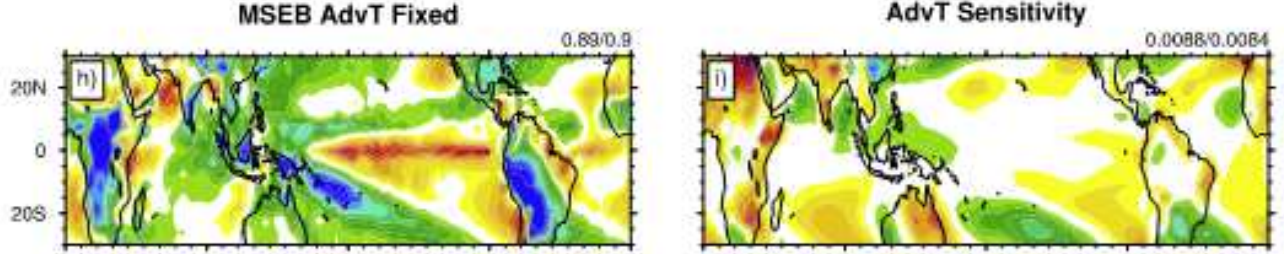

MSEB AdvQ Fixed

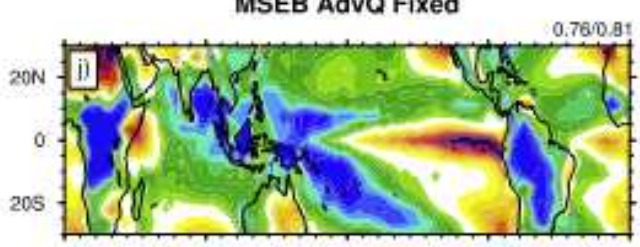

Adva Sensitivity

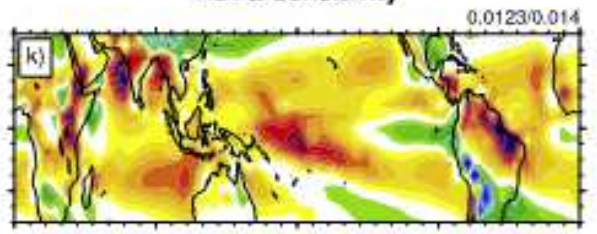

M Sensitivity
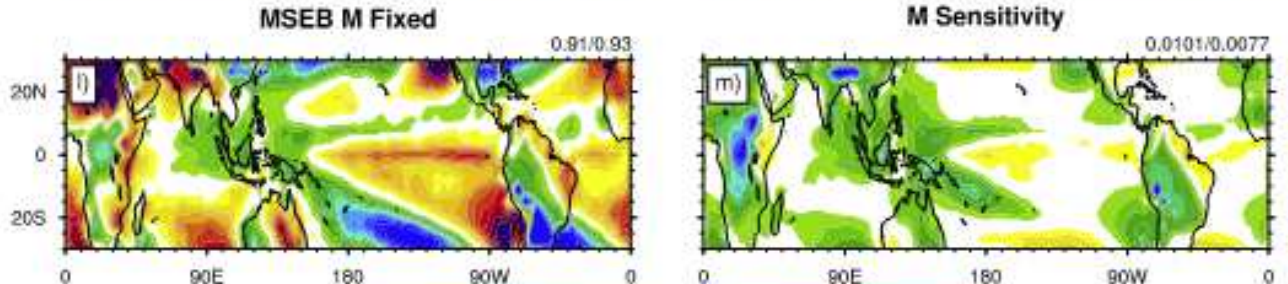

180

sow

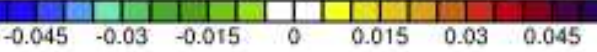

Figure 11

Sensitivity estimates for the MSEB model based on the mean ERA5. (a) $\omega$ at 500hPa MSEB estimate. The domain mean RMS for land (first value) and ocean points are shown in the heading. Left column: MSEB estimates with a specific term fixed (see heading of each panel). The spatial correlation values of each panel with panel (a) for land (first value) and ocean points are shown in the heading of each panel. Right column: differences of panel (a) minus the left panel in each row. The domain mean RMSE between (a) 
and each plot in the left column for land (first value) and ocean points are shown in the heading. Note: The designations employed and the presentation of the material on this map do not imply the expression of any opinion whatsoever on the part of Research Square concerning the legal status of any country, territory, city or area or of its authorities, or concerning the delimitation of its frontiers or boundaries. This map has been provided by the authors.

Ftop

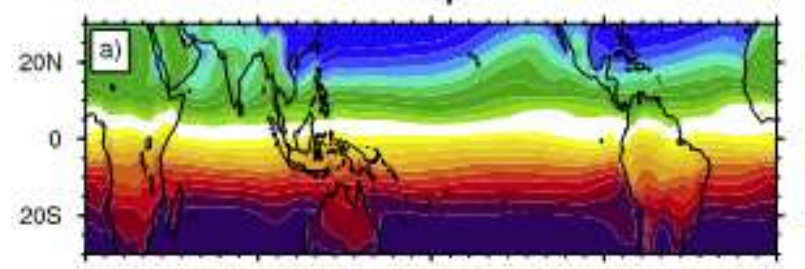

AdvT

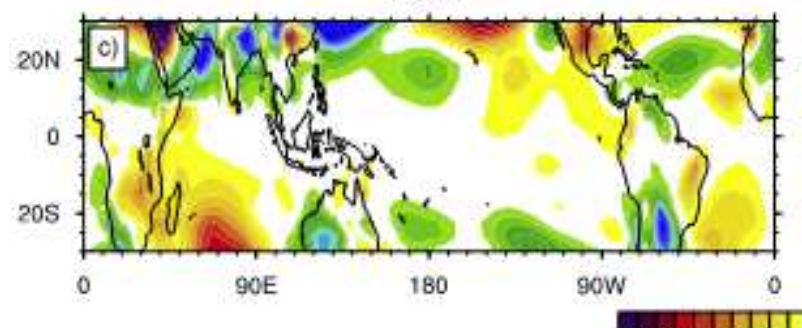

(-) Fsur

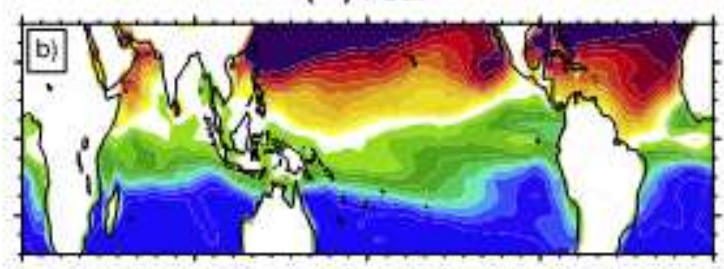

AdvQ

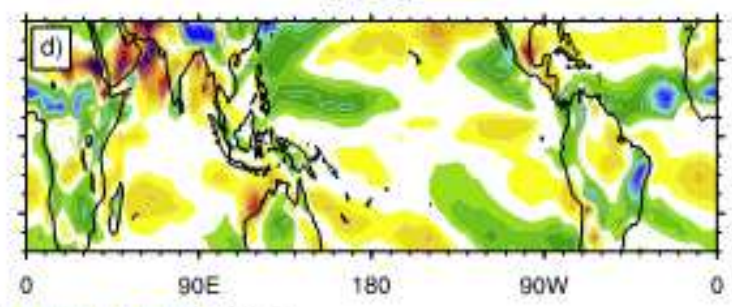

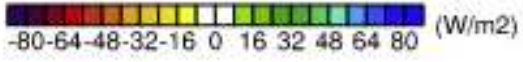

M

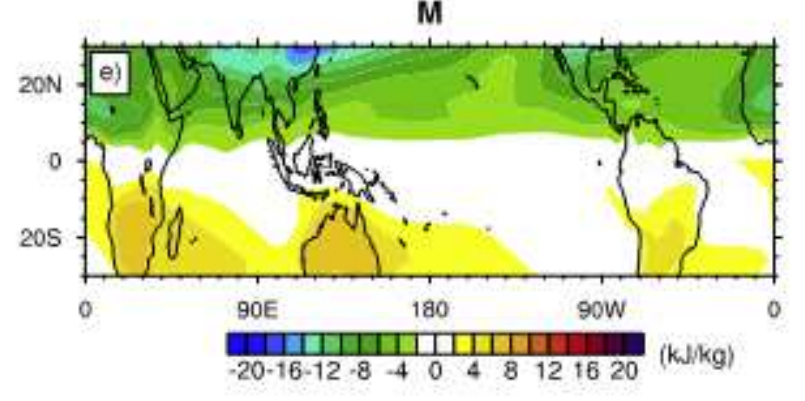

\section{Figure 12}

Please see the Manuscript PDF file for the complete figure caption. Note: The designations employed and the presentation of the material on this map do not imply the expression of any opinion whatsoever on the part of Research Square concerning the legal status of any country, territory, city or area or of its authorities, or concerning the delimitation of its frontiers or boundaries. This map has been provided by the authors. 
Ftop Sensitivity

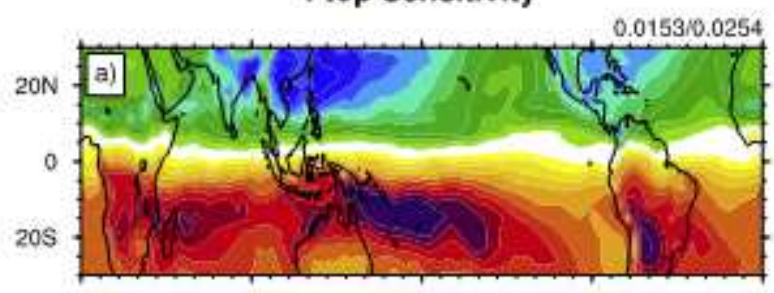

Wind Sensitivity

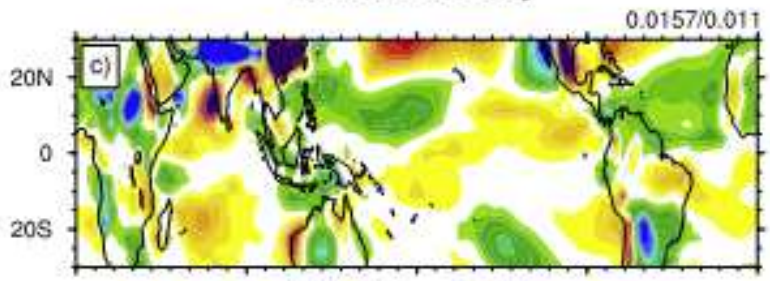

AdvQ Sensitivity

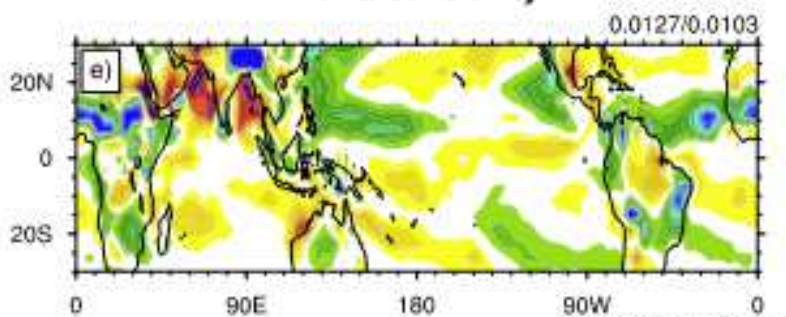

Fsur Sensitivity

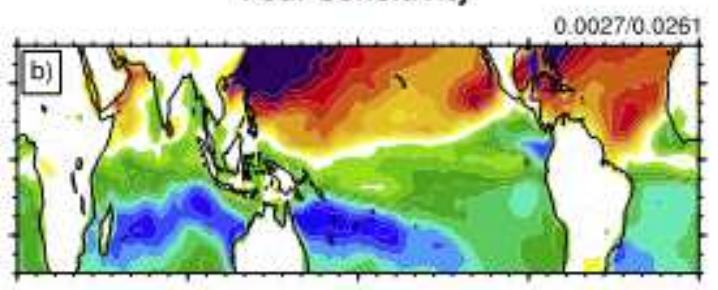

AdvT Sensitivity

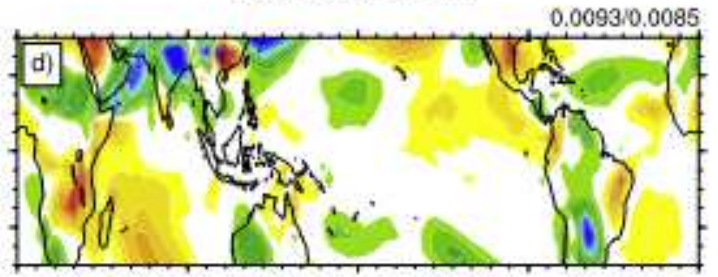

M Sensitivity

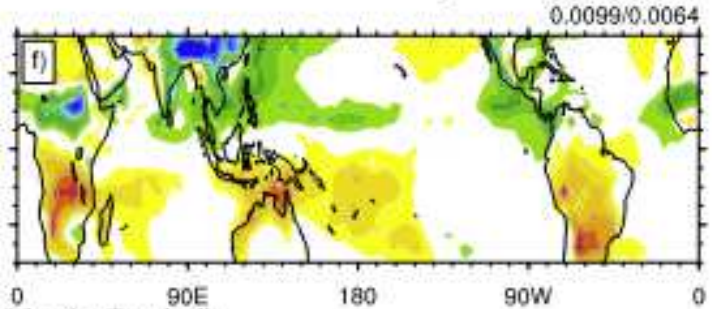

$\left.\left.\left(b^{0}\right)+(c)+d\right)+()^{90 E}+f\right)$

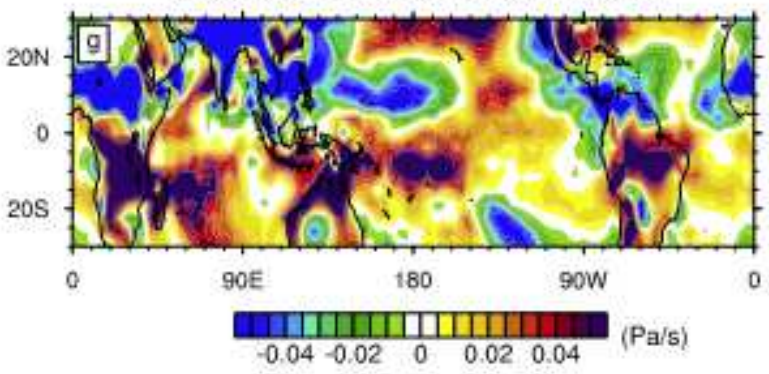

\section{Figure 13}

Sensitivities of the mean seasonal cycle in of $\omega$ at $500 \mathrm{hPa}$ of the MSEB model to different forcing terms (see heading in panels (a) to (f)). (g) Sum of (a) to (f). (a). (a)-(f) are obtained by following the same procedures as the right column in Fig. 11. The RMSE for each panel for land (first value) and ocean points are shown in the heading of each panel (a) to (f). See text for details on the estimation of sensitivities. Note: The designations employed and the presentation of the material on this map do not imply the expression of any opinion whatsoever on the part of Research Square concerning the legal status of any country, territory, city or area or of its authorities, or concerning the delimitation of its frontiers or boundaries. This map has been provided by the authors. 
NINO3.4 SST

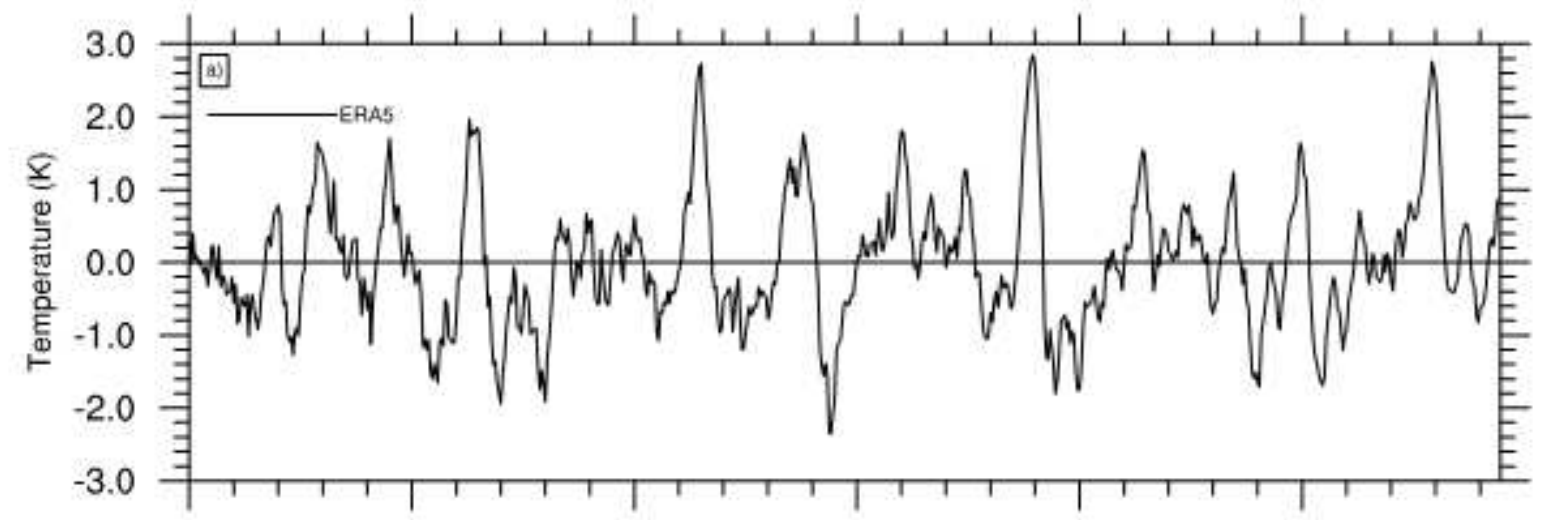

Omega index and MSEB model estimate



Figure 14

(a) Monthly mean time series of Nino3.4 $\left(3.75^{\circ} \mathrm{N}-3.75^{\circ} \mathrm{S}, 170^{\circ} \mathrm{W}-120^{\circ} \mathrm{W}\right) \mathrm{SST}$. (b) Monthly mean time series of $\omega$ at $500 \mathrm{hpa}$ in the central equatorial Pacific region $\left(3.75^{\circ} \mathrm{N}-3.75^{\circ} \mathrm{S}, 150^{\circ} \mathrm{E}-150^{\circ} \mathrm{W}\right)$ and the corresponding MSEB model estimate. The correlation between $\omega$ at $500 \mathrm{hPa}$ and the MSEB estimate for ERA5 period is shown in the heading of (b). 

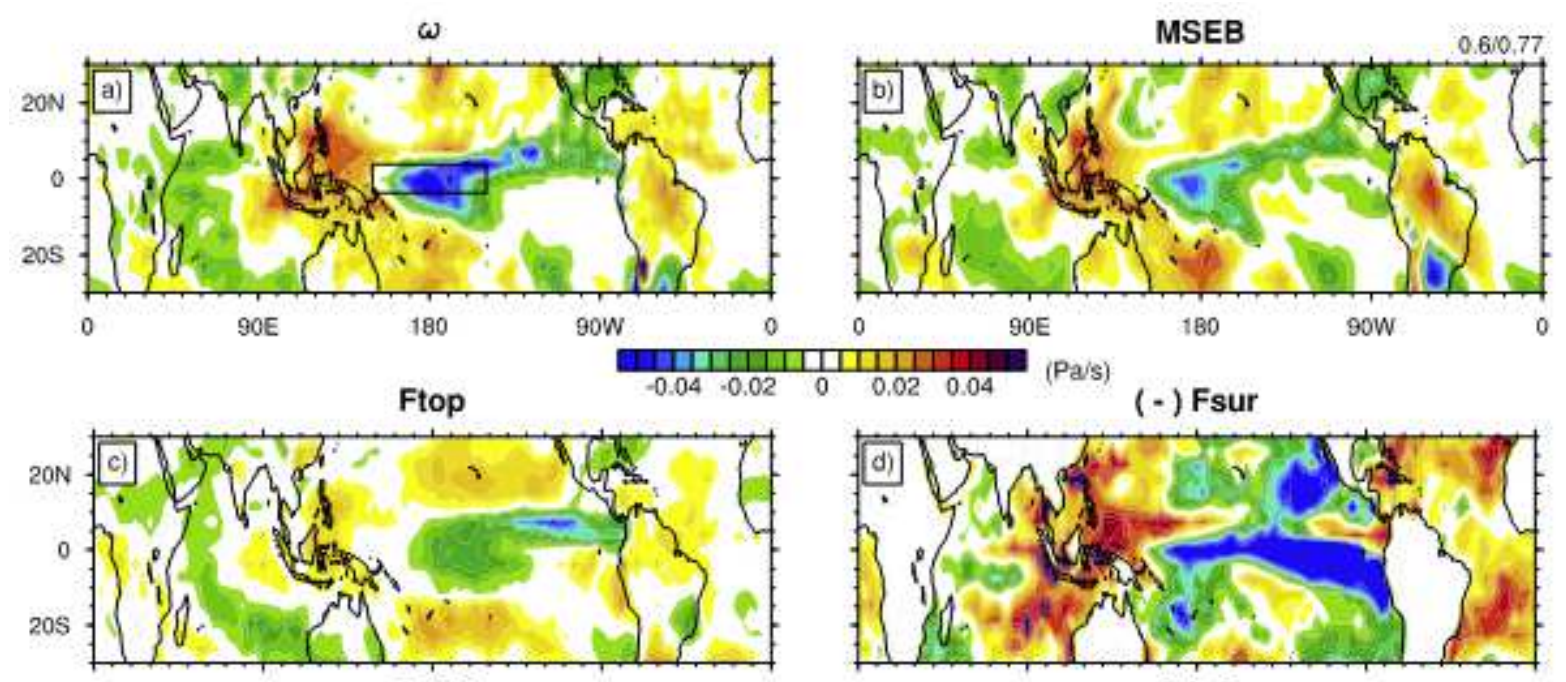

AdvT

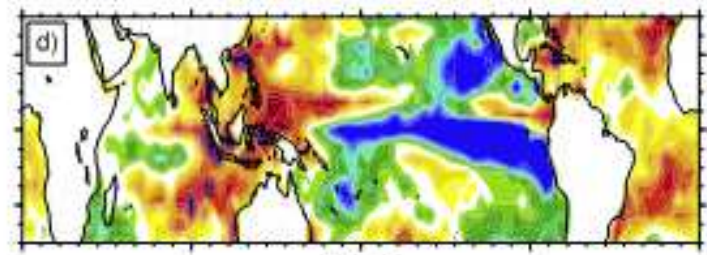

AdvQ

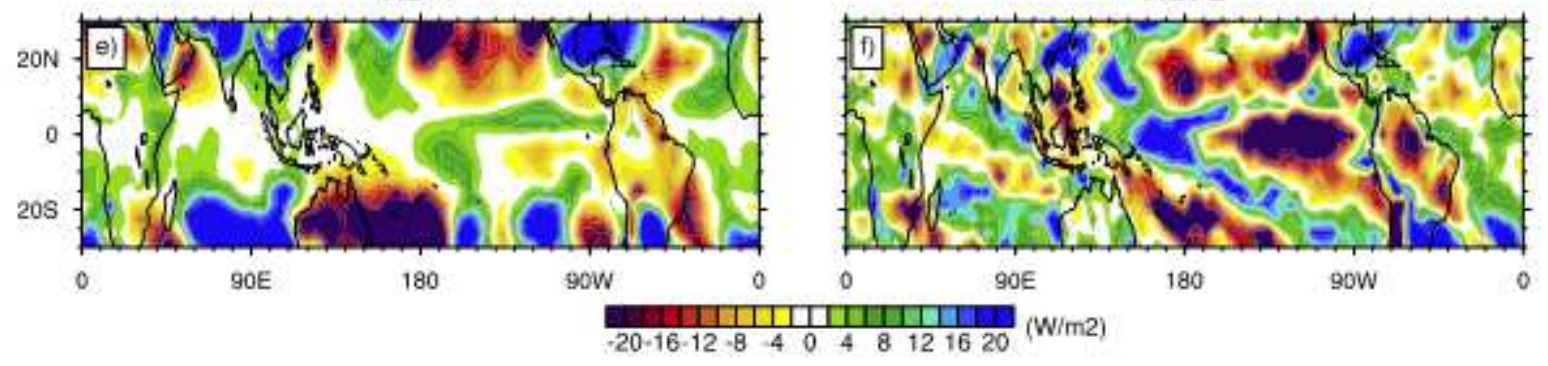

M

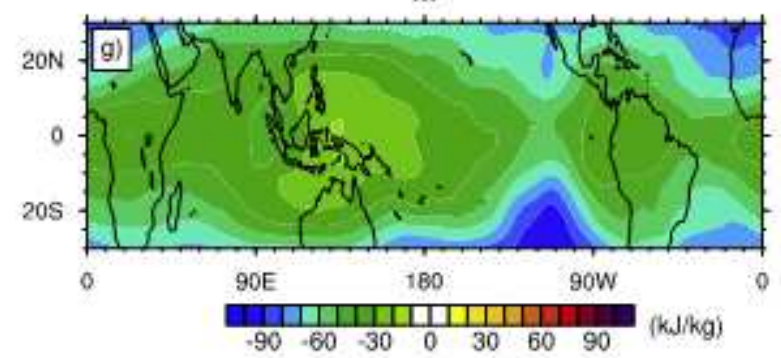

Figure 15

Please see the Manuscript PDF file for the complete figure caption. Note: The designations employed and the presentation of the material on this map do not imply the expression of any opinion whatsoever on the part of Research Square concerning the legal status of any country, territory, city or area or of its authorities, or concerning the delimitation of its frontiers or boundaries. This map has been provided by the authors. 
Ftop Sensitivity

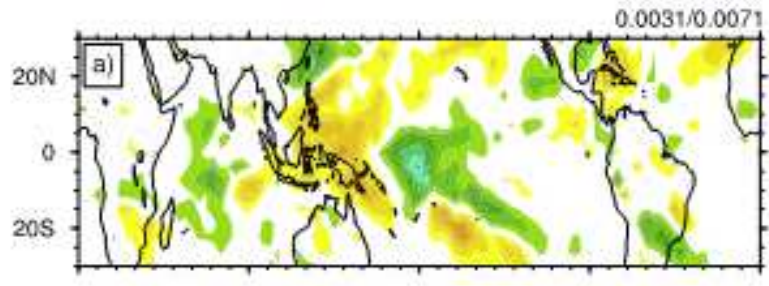

Wind Sensitivity

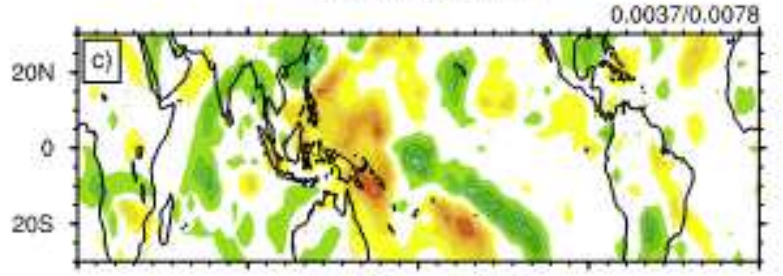

AdvQ Sensitivity

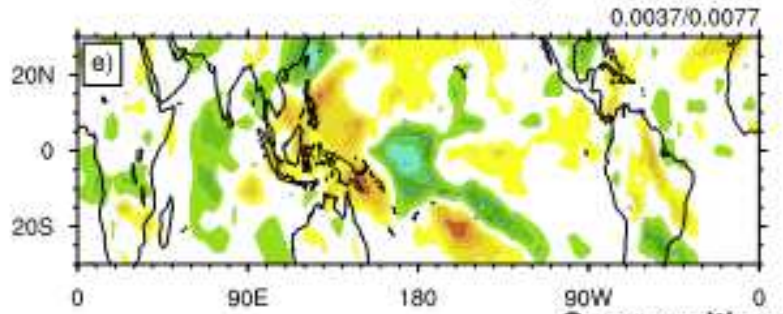

Superposition: $a)+(b)+c)+d)+e)+f$ )

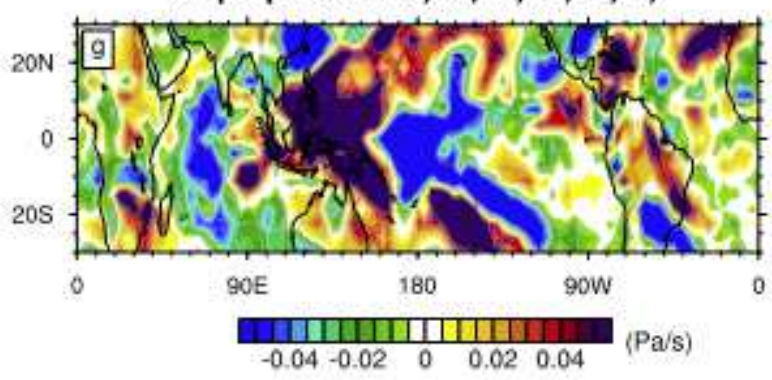

Fsur Sensitivity

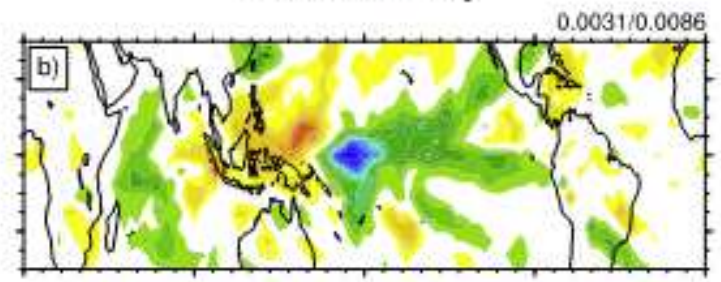

AdvT Sensitivity

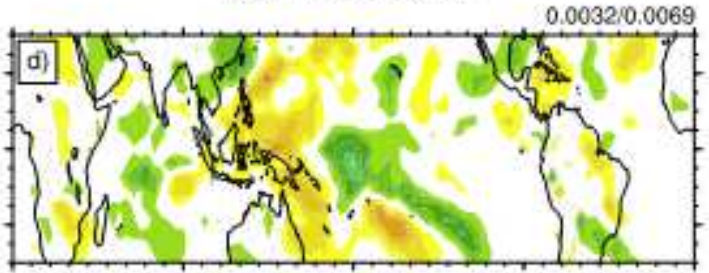

M Sensitivity

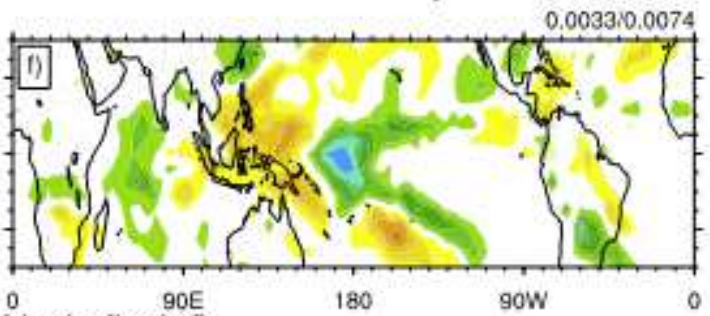

180

\section{Figure 16}

Sensitivities of the El Nino composites of $\omega$ at 500hpa of the MSEB model to different forcing terms (see heading in panels (a) to (f)). (g) Sum of (a) to (f). (a)-(f) are obtained by following the same procedures as the right column in Fig.11. The RMSE for each panel for land (first value) and ocean points are shown in the heading of each panel (a) to (f). See text for details on the estimation of sensitivities. Note: The designations employed and the presentation of the material on this map do not imply the expression of any opinion whatsoever on the part of Research Square concerning the legal status of any country, territory, city or area or of its authorities, or concerning the delimitation of its frontiers or boundaries. This map has been provided by the authors. 